University of Louisville

ThinkIR: The University of Louisville's Institutional Repository

$5-2013$

\title{
Translingualism in post-secondary writing and language instruction : negotiating language ideologies in policies and pedagogical practices.
}

Nancy Bou Ayash

University of Louisville

Follow this and additional works at: https://ir.library.louisville.edu/etd

Part of the Education Commons, English Language and Literature Commons, and the Rhetoric and Composition Commons

\section{Recommended Citation}

Ayash, Nancy Bou, "Translingualism in post-secondary writing and language instruction : negotiating language ideologies in policies and pedagogical practices." (2013). Electronic Theses and Dissertations. Paper 2481.

https://doi.org/10.18297/etd/2481

This Doctoral Dissertation is brought to you for free and open access by ThinkIR: The University of Louisville's Institutional Repository. It has been accepted for inclusion in Electronic Theses and Dissertations by an authorized administrator of ThinkIR: The University of Louisville's Institutional Repository. This title appears here courtesy of the author, who has retained all other copyrights. For more information, please contact thinkir@louisville.edu. 


\title{
TRANSLINGUALISM IN POST-SECONDARY WRITING AND LANGUAGE INSTRUCTION: NEGOTIATING LANGUAGE IDEOLOGIES IN POLICIES AND PEDAGOGICAL PRACTICES
}

\author{
By \\ Nancy Bou Ayash \\ B.A. American University of Beirut, 2003 \\ M.A. in English Language, American University of Beirut, 2006
}

\begin{abstract}
A Dissertation
Submitted to the Faculty of

the College of Arts and Sciences of the University of Louisville in Partial Fulfillment of the requirements

for the Degree of
\end{abstract}

\author{
Doctor of Philosophy \\ Department of English \\ University of Louisville
}

May 2013 
TRANSLINGUALISM IN POST-SECONDARY WRITING AND LANGUAGE INSTRUCTION: NEGOTIATING LANGUAGE IDEOLOGIES IN POLICIES AND PEDAGOGICAL PRACTICES

\section{By}

Nancy Bou Ayash

B.A., American University of Beirut, 2003

M.A. American University of Beirut, 2006

A Dissertation Approved on

April 17, 2013

By the following Dissertation Committee:

\begin{tabular}{c}
\hline Bruce Horner \\
\hline Min-Zhan Lu \\
\hline Bronwyn Williams \\
\hline Tatjana Soldat-Jaffe \\
\hline Suresh Canagarajah
\end{tabular}




\section{DEDICATION}

This dissertation is dedicated to the mentorship and memory of Dr.Boulos Sarru' for his

unwavering support and encouragement over the years. He has helped me keep an eye on the big picture and was the reason I decided to pursue my doctoral degree in the first place. He has been an invisible presence during the composition of these pages. 


\section{ACKNOWLEDGMENTS}

This dissertation would not have been possible without the guidance and the help of several individuals who in one way or another contributed and extended their valuable assistance in the preparation and completion of this study.

First and foremost, I offer my sincerest gratitude to my mentor Prof. Bruce Horner for persevering with me as my advisor throughout various stages of completing this research and writing this dissertation. His continuous support, patience, attention to detail, hard work, and thought-provoking scholarship have set an example I hope to match some day. Through the process of coursework, exams, dissertation, and the job search, Prof. Horner has provided me with an exceptional degree of support and guidance in my scholarship and professionalization efforts. The inspiration for doing this research came directly from the career-changing seminar he offered on language politics scholarship outside composition "proper" at the University of Louisville.

My special thanks and appreciation to Prof. Min-Zhan Lu whose sincerity and encouragement I will never forget. She has been my inspiration as I hurdle all the obstacles in the completion of this research and my degree. I owe my gratitude to both Prof. Lu and Horner who have made this dissertation and other achievements in my academic career possible and because of whom my graduate experience has been one that I will cherish forever. I am very thankful to them for their insightful comments and constructive criticism on countless revisions of this manuscript. 
I am also indebted to Prof. Bronwyn Williams, who has been a gracious mentor, an amazing director at the writing center, and a dear friend. He has always been there to listen and give heartfelt advice and encouraging words that have made this long journey unforgettable and rewarding. I am deeply grateful to him for the long discussions and thoughtful comments that helped me sort out the details of my work.

I would like to also thank my dissertation committee members, Min-Zhan Lu, Brownyn Williams, Tatjana Soldat-Jaffe, and Suresh Canagarajah, who have generously given their time and expertise to better my work. I thank them for their contribution and their support.

I have to give a special mention for the support given by Dr. Kassem Shaaban and Dr. Lina Choueiri who have always offered their unflagging guidance, mentorship, and wise advice.

I must acknowledge as well the many friends, colleagues, students, and teachers at the American University of Beirut who assisted and supported my research and writing efforts. Especially, I need to express my gratitude and deep appreciation to Ms. Rula Baalbaki whose dear friendship, hospitality, knowledge, expertise, and passion for translation have heavily inspired this project. I also thank Lisa Arnold for handling and following up on IRB matters.

As part of the AUB community, I am mostly indebted to Dr. Joseph Nassif for all the peace of mind, good health, and happiness that his medical skill, expertise, and utmost care have granted me.

Most importantly, none of this would have been possible without the love and patience of my family. My parents, Amin and Sawsan Bou Ayash, who have been a 
constant source of love, concern, moral and material support, and strength during the long years of my education. Thank you for instilling in me the confidence and drive for pursuing my Ph.D. and for always coming to my defense.

To my invaluable network of supportive, generous, and loving friends without whom I could not have survived the process: Carrie Kilfoil, Jennifer Marciniak, Mike Sobiech, Tika Lamsal, Shyam Sharma, Hem Paudel, Caroline Wilkinson, Amy Leuck, Meghan Bardolph, Adam Robinson, Robin Blackett, Jeremy Williamson, and Ricardo Gongora. I greatly value their friendship that has helped me adjust to and fall in love with a new country that I now consider my home.

Last but not the least, to Riad Bou Sleiman, my dearest friend, voice of reason, and my treasure, for giving me the strength to persevere. I am grateful to him for his continued love, care, patience, steadfast encouragement, and emotional support throughout this challenging endeavor. He has often had to bear the brunt of my frustration and rages against the endless demands of graduate school life. He has consistently helped me keep perspective on what is most important in life and shown me how to best deal with stress and hardship. 


\begin{abstract}
TRANSLINGUALISM IN POST-SECONDARY WRITING AND LANGUAGE

INSTRUCTION

Nancy Bou Ayash

April 17, 2013

Drawing on text-oriented data from the American University of Beirut, Lebanon, this study examines how writing teachers and students constantly negotiate tensions between translingual sociolinguistic realities on one hand and monolingualist assumptions about language and language relations on another that dominate curricular and pedagogical designs in first year writing courses. The study involves a multiplicity of data sources, such as official institutional documents, individual instructional materials, classroom observations, structured interviews, and a method of "talk around texts." Writing teachers in this study sensitively grappled with tensions between the constant political pressures of generating the status quo and their ideological orientations towards keeping up with rapid sociolinguistic changes on the ground. As multilingual student participants in this study continued to grow more worldly with English, this study demonstrates the relevance of a translingual approach to their specific personal, social, linguistic, and cultural affiliations in addition to their academic and professional aspirations. By taking a translingual approach to writing instruction, this study puts forward strategies of ideological and pedagogical change aligned with translingualism that pays special attention to the diversity and complexity of linguistic and discursive resources already flowing into the writing program and classroom.
\end{abstract}


TABLE OF CONTENTS

\begin{tabular}{|c|c|c|}
\hline & & \\
\hline $\mathrm{ACK}$ & NOWLEDGMENTS.. & iv \\
\hline ABST & RACT.... & vii \\
\hline LIST & 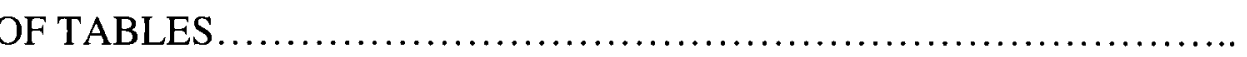 & ix \\
\hline I. & INTRODUCTION........... & 1 \\
\hline II. & LITERATURE REVIEW .......................... & 28 \\
\hline III. & 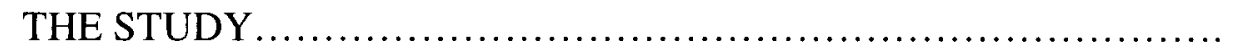 & 65 \\
\hline & 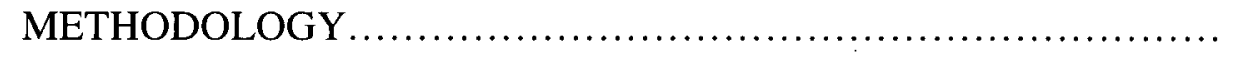 & 75 \\
\hline IV. & 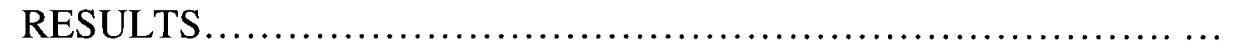 & 95 \\
\hline & MULTILINGUAL STUDENTS' LANGUAGE PERCEPTIONS........ & 98 \\
\hline & WRITING TEACHERS' PERCEPTIONS .......................... & 117 \\
\hline & TRANSLINGUAL PRACTICE.... & 133 \\
\hline & TRANSLINGUAL MEANING MAKING AND TRANSLATION...... & 153 \\
\hline & CONCLUSION.. & 168 \\
\hline REFE & RENCES......... & 185 \\
\hline APPE & NDICES.. & 203 \\
\hline CURF & ULUM VITAE. & 211 \\
\hline
\end{tabular}




\section{LIST OF TABLES}

Table

1. Description of Teacher Participants..................... 203

2. Description of Student participants.................... 204

3. Student Participant Distribution by Academic Discipline.... 208

4. Student Participant Distribution by Specific Major......... 208

5. Student Participant Distribution by Gender.............. 209

6. Student Participant Distribution by Current Course.......... 209

7. Student Participant Distribution by Language Background.... 209

8. Student Participant Distribution by Educational Background... 210 


\title{
CHAPTER ONE
}

\section{RETHINKING MONOLINGUALISM IN COMPOSITION PEDAGOGY: EMERGENCE OF A TRANSLINGUAL PARADIGM}

\author{
"Without English you can't do anything," said the farmer sagely. \\ Mann wondered what possible use English could be to the farmer. \\ "What use is English?" said Mann. \\ "People love English!" said the farmer with a strange sort of deep voiced \\ giggle. "If you talk in English, you are a king. The more people you can \\ mystify, the more people will respect you." He turned back to his tobacco.
}

Vikram Seth A Suitable Boy 543

Tremendous progress has been made in composition studies scholarship over the past decade or so through bringing to light the challenges and pressures faced by multilingual scholars or students working with English either inside or outside the AngloAmerican sphere. The question of language difference is increasingly coming to the fore of intellectual and scholarly conversations in leading conferences and publications in Composition Studies ${ }^{1}$, thereby suggesting a growing concern in the field about the nature

\footnotetext{
${ }^{1}$ For example, the theme of the last Thomas Watson conference "Working English in Rhetoric and Composition" and the theme of the 2011 Penn State Conferences on "Rhetoric and Writing Across Language Boundaries" (July 2011) and "Writing Education across Borders" (Sept. 2011), in addition to the growing number of recent journal articles and edited collections that deal with various writing issues across cultural and linguistic difference, including Horner et al. "Cross-Language Relations in Composition," "Language Difference," "Toward a Multilingual Composition Scholarship;" Tardy "Enacting;" Young ""Nah, We Straight";" Martinez and Young "Code meshing as World English;" Pedersen "Negotiating Cultural Identities through Language;" Canagarajah "Translingual Practice," "Translanguaging," "Multilingual Strategies of Negotiating English," and "The Place of World Englishes
} 
of linguistic and cultural diversity in the college writing classroom and about its possible implications for pedagogy and assessment. We see booming scholarship in the field not settling for a slight accommodation or tolerance of language difference but aggressively calling for a fundamental rethinking of linguistic paradigms, of dispositions towards language difference, and of the politics and practices of academic and professional knowledge production. We see strong critiques of the hegemony of an English-only monolingual ideology in current publishing and researching practices ${ }^{2}$, in the unidirectional flow of academic exchange of ideas and knowledge ${ }^{3}$, and in writing pedagogies and administrative and curricular structures ${ }^{4}$. These critiques have not been targeted towards individual writing programs, courses, journals, teachers, and researchers but have addressed a long history of working conditions sustained by institutional and national systems that editors, academics, and administrators have to contend with. While these critiques acknowledge the force of a longstanding monolingual ideology, they also recognize the perceived immediacy and necessity for literacy laborers to respond to changing geopolitical relations and social, linguistic, educational, and institutional arrangements through taking a more multilingual and global stance. There is an increasing recognition among writing specialists that the hegemonic and exclusionary theory of writing based only on one rhetorical tradition and one language, that predominantly guides curricular design, instruction, and assessment in most mainstream

in Composition;" Shuck "Combating Monolingualism;" Hesford et al. "Laboring to Globalize a First-year Writing Program;" Lillis and Curry "Academic Writing in a Global Context;" Schroeder et al. "Alternative Discourses and the Academy;" Kells et al. "Latino/a Discourses;" Smitherman and Villanueva "Language Diversity in the Classroom;" and many others.

${ }^{2}$ See Horner et al. "Toward a Multilingual Composition Scholarship;" Lillis and Curry Academic Writing in a Global Context.

${ }^{3}$ See Donahue "Internationalization," "Cautionary;" Hall; also Lillis and Curry.

${ }^{4}$ For example, Hesford et al. "Laboring to Globalize a First-year Writing Program;" Shuck "Combating Monolingualism;" Canagarajah "Place", "Toward"; Horner and Trimbur; Lu "Professing;" Horner et al. "Cross-Language Relations in Composition," "Language Difference." 
writing programs and courses, can "at best be extremely tentative and at worst totally invalid [and unviable]" (Silva and Leki 402). Examining how globalization is affecting education policy, pedagogy, and politics in nation-states worldwide, Burbules and Torres insist on more "equitable" and "just" changes that resist what they describe as "the rhetoric of "inevitability,"” which drives and justifies particular prescriptions at the level of policy, pedagogy, administration, and research traditions (4). In most educational systems, the same dynamic seems to be at work: Policies and practices enforce "conformity," "homogeneity," and "identification with a national tradition, a larger community, and a broader context of citizenship and work responsibility" (3).

Global mobility of goods, services, and people (tourists, students, immigrants, refugees, business and expatriate workforces, etc.) and the instantaneous circulation of knowledge and resources have all increased the need for facing arising linguistic changes in both local and transnational spaces. As globalization is leaving no landscape unaltered, protection against these social changes that have no clear-cut configuration or direction, language practices among them, is gradually getting harder and near impossible in our recent times. Though linguistic and cultural diversity have historically been characterizing human language worldwide for a long time, new conditions of current life are producing multilingualism in somewhat different ways and at an unprecedented acceleration. Building on James Paul Gee et al., Monica Heller argues that what is apparently shifting is not the "globalization of language practices" but rather "the centrality of language in the new economy," which places a premium on new modes of linguistic communication and finding strategies for dealing with language diversity in all its manifestations (539). Also looking at the dire consequences of constant local-global 
changes on the nature of learning, knowledge, and literacy, the New London Group argue that "[w]ith the new worklife comes a new language" (66). As a result of revolutionary changes in new media technologies and in social arrangements and relationships, new economic and working conditions are placing language communication at the heart of economic activities and contributing to the increasing need for confronting multilingualism. Sociolinguistic and multilingualism scholarship have spoken of global linguistic tensions existing between the hegemony of English on one hand and the development of various kinds of multilingualism on another, both of which are produced and maintained by various forces of globalization ${ }^{5}$. These tensions and paradoxes that traverse language contact situations are negotiated or even resolved differently by different individuals in different contexts. As Monica Heller in "Multilingualism and Transnationalism" puts it,

every push towards monolingualism is countered by a pull towards multilingualism; every push towards standardization is countered by a pull towards diversity. These tensions have both local and transnational dimensions, of course, as people draw on linguistic resources from a wide variety of sources to address both local and translocal issues under specific, and variable, conditions (540).

Emerging developments in linguistic and textual hybridity are far from new (and the hallmarks of globalization, i.e. planet-wide mobility of ideas, goods, and people, are not in themselves new either), but they are recently gaining a more intense and pronounced presence at a global level (see Canagarajah, "Reclaiming;" Yildiz; Heller). In light of the dynamics of today's globalized and technologically enriched world, we are

\footnotetext{
${ }^{5}$ See Heller "Multilingualism and Transnationalism;" Dor "From Englishization to Imposed Multilingualism;" Burbules and Torres "Globalization and Education;" Apple et al. "Globalizing Education."
} 
facing new sociolinguistic landscapes ${ }^{6}$ with the increasing dominance of especially World Englishes but also French, Spanish, Chinese, German, Arabic, etc. that are gradually establishing their virtual presence on the Internet. Ofelia Garcia in Bilingual Education in the $21^{\text {st }}$ Century mentions that between the year 2000 and 2008, the greatest language growth on the internet was experienced by $\operatorname{Arabic}^{7}(2,062 \%)$, followed by Portuguese (668\%), Chinese (622\%), and then French (452\%) while English experienced only a $201 \%$ growth in the last decade. According to Garcia, approximately $50 \%$ of internet users worldwide choose a language other than English to access the Google websearch utility (28). The changing realities of popular culture with increased engagement with globally consumed movies, sitcoms, and TV series, closed captioning and subtitling services, graffiti production, hip hop-style music are all allowing for new multilingual experiences. Language users are now exposed to and engaging with a broader range of language practices than those offered by the so-called academic discourse community, and they are shaping and reshaping language in ways that are not reflected in more standardized and institutionalized language practices and research traditions of the academy. Suresh Canagarajah in Reclaiming the Local in Language Policy and Practice draws attention to the fact that not only language users of the outer or expanding circle (under Kachru's paradigm), but also those in the inner circle are forced to negotiate multiple dialects, registers, discourses, and when needed, even languages, to function effectively in increasingly multilingual contexts (xxv). In quantitative terms, then, as

\footnotetext{
${ }^{6}$ I adopt Alastair Pennycook's notion of "language landscapes" that transport us into the temporality and spatiality of language, thereby allowing us to closely "see how different linguistic resources are used, different worlds evoked, different possibilities engaged in as people use the linguistic wherewithal around them" (Language as a Local Practice 69).

${ }^{7}$ The Arabic language has also had an influential international presence in the news media, as Garcia argues, especially after the establishment of Al Jazeera in Qatar in 1996 and Al Arabiya in Dubai in 2003, with backing from Saudi Arabia.
} 
Auer and Wei argue, under the complex communicative networks of the twentieth century, "monolingualism is the exception and multilingualism is the norm" (1).

In the realm of language practice, however, even the breadth and wealth of the newly recognized multilingual scene still functions under the more dominant monolingual ideology, which with all its restrictions and barriers continues to exert a strong influence in the academy and many spheres of society and public life. This "new visibility of multilingualism" (emphasis in original), as Yasemin Yildiz explains in Beyond the Mother Tongue, has been enabled as various forces of globalization in the twenty-first century started to a large extent contributing to "loosen[ing]the monolingualizing pressure" that has propagated a monolingual norm among societies, communities, institutions, and individuals (3). Without being fully eradicated, multilingualism ${ }^{8}$ has been obscured throughout history by a forceful monolingual paradigm that echoes the monolingual bias of the European thinking about language that came into being during a period when one (standard) language was chosen as a symbolic expression of the unity of the nation states (see Yildiz; Auer and Wei). Monolingualism, according to Yildiz, which first emerged in the $18^{\text {th }}$ century under the European nation state ideology, resembles much more than the presence of one language but rather "a key structuring principle that organizes the entire range of modern social life, from the construction of individuals and their proper subjectivities to the formation of disciplines and institutions, as well as of imagined collectives such as cultures and nations" (2). Through maintaining language standards, schooling and educational systems at all levels are among the principal instruments for perpetuating a monolingual ideology that serves

\footnotetext{
${ }^{8}$ Multilingual relations, practices, and environments in the day to day life of ordinary people, as distinguished from the ideology of multilingualism, which could still be dominated by the ideology of monolingualism.
} 
an economic ideological function (see Yildiz; Wiley and Lukes; Lippi-Green). A longstanding monolingual ideology is in effect, and is based, however loosely, on shared assumptions about language and on a network of mechanisms other than the school system, such as a common historical narrative, and perhaps most importantly, the standardizing effects of printing, the trade publishing industry, and media and communications technologies which literally prioritize and stabilize not only one language but even one variety of that language. The effects of a monolingual ideology are so powerful that even individuals who are themselves bi- or multi-lingual still have common misconceptions about bilingualism as being the sum of a "two-sided monolingual talk" (Auer 321) and multilingualism as the combination of three or more pre-existing monolingual language systems, with the most prestigious language always dominating "public" space. Under the pressures of a monolingual ideology, the hegemony and centrality of English, according to Parakrama, has been "mystified by its elite practitioners who confuse the classed benefits it confers on them with an intrinsic value in the language" (177). The introductory short exchange in a local dialect of Hindi between an Indian farmer and the character Mann in Vikram Seth's much acclaimed novel A Suitable Boy captures the symbolic power of global English even to the nonelites, as a saleable commodity and the language of opportunity and capital which enjoys a mass appeal and a widespread acceptance through its hybridity. Though there's nothing intrinsically superior about English, we often lose sight that its utilitarian value in the academic and professional world, which is highly dependent on the linguistic market, is commonly mistaken with an intrinsic virtue in the language itself (Bhatt 30 ). The multilingual reality of modern societies, like that of India for example, is cast according 
to a monolingual model that results in hegemonic value judgments and ideologies that represent the interests and the privileged language of only those in power.

In her implicit critique of the growing popularization of societal multilingualism in a globalizing world, Yildiz argues that not all forms of multilingualism automatically carry critical and altering potential since monolingualism and dominant monolingual norms and practices continue to inflect the way multiple languages are configured, perceived, and thereby managed. Yildiz demonstrates the difficulty of moving into a new critical multilingual paradigm without ultimately having to grapple with the monolingual equation of language, identity, and culture through the example of a conceptual artwork called Wordsearch: A Translinguistic Scultpture previewed in the New York Times. Though the magazine insert documents the multiplicity of the 250 languages that coexist and interact in New York City and the individual contributions of native speakers of each language to a word list of personally meaningful "mother tongue" terms, it represents the resulting 62,500 translations of each "mother tongue" word into all the other "mother tongues" in separate, orderly columns in stock market tables that were also published in the same magazine's business section. The way multilingualism is performed in an aesthetic work like Wordsearch with the monolingual staging of languages as separate, "untouched," and stable entities in global financial activities propagates the myth of universality of financial and linguistic markets and the fallacy of translation across languages as that of complete "equivalency" (24). This particular form of multilingualism, according to Yildiz, "recasts" and "retains" the monolingual paradigm in a new light more suitable for the new age. The New York Times art piece points to the top-down view towards the working of language and language users, which propagates 
images of the fixity and singularity of the business market and assumes that market exchange value and profit is the only concern for all language users at all times, as also acknowledged by the Indian farmer's response. Foregrounding the discrepancy between the picture we get about language relations from such top down projections and what is actually taking place with language practices on the ground, my data in this dissertation illustrates that actual language users on the ground almost always have other priorities besides economic investments that get dismissed and undervalued by monolingualism in order to perpetuate its own validity.

Yildiz argues that these monolingually driven configurations of languages endorse "the tension between reemergent multilingualism and persistent monolingualism" that specifically defines her vision of a "post-monolingual condition" (25). To better understand the functioning of multilingualism today, Yildiz proposes a "post-monolingual mode of reading" that is simultaneously attentive to both reemerging multilingual competencies and practices and the continued workings of the monolingual paradigm. We get a clear glimpse of Yildiz's notion of a "post-monolingual condition" at work in Composition Studies, especially through the ongoing scholarly appraisals and renewed attention to multilingualism that have been the hallmark of the past decade or so and that are situated differently in relation to the dominant monolingual paradigm (more on this issue in Chapter 2). Even amid the unprecedented powerful emergence of new directions in Composition Studies towards active multilingualism, U.S. composition continues to preserve its monolingual, monocultural, and ethnocentric identity as "almost entirely a U.S., English monolingual phenomenon" (Horner and Lu "Working" 488).

Even in discussions about cultural and linguistic heterogeneity in literacy education, very 
few in composition studies pay special attention to the complexities, contradictions, assumptions, and ideological, political, and pedagogical consequences behind certain usages of the concept of multilingualism. The widely used term "multilingual" and the consequences of its use to either describe societies, scholars, students, or their textual productions are more slippery than current disciplinary discourse and scholarship suggests (see Horner et al., "Toward" for a more thorough critique). Dominant understandings of multilingualism in the field as equivalent to the "pluralization of monolingualism" (Makoni and Pennycook, Disinventing) carry a number of theoretical and practical implications for our understanding of language. Predominantly guided by monolingual ideologies, such traditional multilingual orientations risk the danger of leading to the territorialization of language and turning into mere addition and pluralization of languages where each language remains separate, isolated, and hierarchized in "public" spheres. Seen through a postmonolingual lens, the dominant monolingual language ideology continues to operate even in the way we study multilingual writing and respond to its presence, value, and validity in our pedagogies and assessment practices, as I more elaborately discuss in the next chapter.

An emerging paradigm of translingualism that is currently gaining ground among writing scholars, which in this study I define as engaging and creating the diversification of meaning across languages, discourses, genres, disciplines, and media, aims to unsettle the treatment of language and language difference under a surviving monolingual paradigm. A translingual predisposition indeed contests monolingual ideologies signaled through problematic treatments of language difference in writing either as resulting from ignorance and linguistic imperfections that require eradication or remediation or as 
instrumental means towards the ultimate mastery of Standard English. The normative pattern under which language and language use are discussed and against which emerging translingualism seems to be situated continues to be that of longstanding monolingualism. Following Yildiz's framework, then, pursuing translingual initiatives in writing programs, courses, and centers is most productive and promising when we enact a postmonolingual reading that takes into account the coexistence of actively translingual language practices on the ground and residual monolingual assumptions in official accounts of linguistic realities.

In the context of the present study, a postmonolingual analysis will be conducted of the presence of premises of a translingual perspective towards language difference in the decisions that writing teachers make ${ }^{9}$ and the policies they enact and how these both shape and are shaped by the broader social order outside the classroom. Engaging the timely and pressing question of what a translingual model actually looks like in the writing program and classroom, this dissertation offers cross-language, cross-national, and cross-disciplinary perspectives that can better guide emerging translingual directions in U.S. composition towards rethinking current trends at the level of language perceptions and policies, and teaching practices. In this project, I use the multilingual location of Lebanon, and the particular institutional setting of the American University of Beirut (AUB), as a case study for exploring the coexistence of competing language ideologies in writing programs and courses and the possible consequences for local language policies, curriculum design, and writing pedagogy. What can be of particular interest to U.S. compositionists pursuing translingual directions in their own writing programs and

\footnotetext{
${ }^{9}$ For example, pedagogical choices about curriculum development, course content, reading materials, writing assignment prompts, assessment strategies, and classroom interactions.
} 
classroom is the room for combating monolingualism opened up by three significant aspects of language practice in Lebanon, and at AUB in particular: (1) the vitality and viability of multiple language resources that have become both a statistical and cultural norm $^{10}$; (2) actively multilingual official language and language-in-education policies that enable and promote foreign language learning and translation ${ }^{11}$; and (3) strong curricular focus on the theory and practice of translation in postsecondary educational sites $^{12}$. I argue that the academy's (in)ability to fully utilize these crucial aspects of language practice in Lebanon can shed insight on what U.S. compositionists might expect to face in their growing concern to combat monolingualism. A close look at similarities and differences in degrees of commitment to and investment in translingualism at the level of language perceptions, policies, and practices in this specific location is ideal for U.S. compositionists to investigate questions about the operation of conflicting language ideologies in their own writing program and course designs and for considering possible shifts from a longstanding monolingual paradigm into more translingual approaches and policies. Such lines of inquiry yield insights for exploring important questions in our growing efforts to plan the proper course for the gradual incorporation of more translingual work into existing writing programs and courses: In our emerging attempts to institutionalize U.S. translingualism, how do we deal with residual monolingual ideologies? How do we make use of the emerging linguistic ideology of translingualism? And how can we better revise an existing translingual model in Composition Studies in

\footnotetext{
${ }^{10}$ See Bou Ayash for a more detailed description of translingual language relations emerging in Lebanese sociolinguistic and business landscapes and the politics of translingual meaning making by ordinary language users as day-to-day affairs on the street are being conducted.

${ }^{11}$ For more about language policies, refer to Chapter 3.

${ }^{12}$ As well as at the secondary level, as is evident in Chapter 3.
} 
order to gradually break from the hegemonic monolingual paradigm and reductive notions of multilingualism in the U.S. academy?

Presenting data that shows how both writing teachers and multilingual students themselves relate to translingualism in their own teaching and literacy practices, this study enables us to explore how both teachers and students handle and negotiate tensions between the management of multilingualism in language policies and educational practices on one hand and growing multilingualism in everyday lived experiences on another. This dissertation provides an ethnographic description of translingual language practices, their specific purpose, and how they directly influence and are influenced by various facets of work with language, such as translation, language policy and planning, and writing pedagogy and assessment. In order to accomplish that, I look at both specific translingual communication practices on the ground and institutionalized spaces for language learning, which are typical sites for the management of new translingual and transnational experiences. With that in mind, the current study embraces the importance of looking at the continuities between actual language use and language learning and at the necessity of adapting more responsive curricular designs that pay special attention to the continual domination of a monolingual paradigm in institutional settings and the dynamic translingual language practices of actual language users within and outside those settings. Put differently, invested in showcasing the expertise, motivations, alignments, and affiliations of multilingual language users, this study calls for a closer alignment between language and literacy practices in students' lifeworld and the world of academia.

I particularly address questions about how literacy labor in the specific location of Lebanon is situated differently in relation to the workings of a monolingual paradigm, 
pressing questions that lie at the core of rethinking language policies and current composition pedagogies and assessment practices along translingual lines: How are language policies in education helping to create, sustain, manage, or even reduce language difference with and/or against the grain of monolingualism? What are writing teachers' and students' assumptions about language and language practices and the relative statuses of their speakers? How are these language perceptions currently informing and being informed by actual classroom policies and practices? What models of translation and theories of the trafficking of meaning are being tapped into in writing and literacy practices and pedagogy? What incremental changes need to be enacted in local language policies and composition pedagogies in order to gradually break from dominant monolingual assumptions about language and social identity and how can the promises and shortcomings of those changes be best evaluated?

Considering effects of language policies and practices across national borders, this project will add to the knowledge pool of U.S. scholars and compositionists whose views on writing research and instruction may have been informed until now almost exclusively by monolingual, U.S.-centered composition theory and pedagogy. Despite differences in national priorities, institutional structures, and the makeup of sociolinguistic landscapes, those interested in developing a better understanding of student writing along translingual and transnational lines can learn from and with academic writing theory and pedagogy developed in other national contexts. After all, as Canagarajah has argued, these are communities that have experienced a longer history of multilingualism (Reclaiming 19). Interests in writing instruction and research across linguistic and national borders, however, remain initiated by individual efforts and 
motivations and have not yet fully expanded into what Jonathan Hall describes as a systematic and "mutually transformative relationship" (34). In view of such deficiencies in current disciplinary inquiry, I focus in this essay on what U.S. compositionists wishing to labor along translingual lines can learn about the possible ways to address language difference in the design of their own writing programs from and with other multilingual countries, like Lebanon, rather than merely learning about these countries' work with language diversity. I particularly make a distinction here between the different trade models ${ }^{13}$ of international academic exchange and research for the sake of teasing out the underlying power dynamics and differential basic motivations driving each. The U.S. educational trade tradition commonly comprises "international exchanges in order to learn about other countries" often for the sole purpose of "provid[ing] technical assistance in development" or educational consultancy (Ninnes and Hellsten 3; emphasis added). Portraying overwhelmingly imperialist and colonial exchanges, learning about the 'other' presumably suggests that nothing worthwhile is to be learned in return unless such inquiries across national and linguistic borders are predominantly driven by national security motives (see Wible) or by the advancement of economic and geopolitical selfinterest. Learning from the 'other', on the other hand, implies "peeling back taken-forgranted practices and beliefs" (Ninnes and Hellsten 4) and going against the dominant politics of the economy of international trade of knowledge in the interest of growth, transformation, and self-revision. Yet such waves of inquiry, though progressive, still resonate with the same tones of inequity if not coupled with more equitable and responsible academic exchanges through intentions to learn with the 'other', as a palpable

\footnotetext{
${ }^{13}$ This refers to a dominant international exchange framework of pure import or export.
} 
marker of reciprocity and collaboration in addressing shared-concerns, which is increasingly becoming absolutely necessary to the chances of peace and justice worldwide. Tiane Donahue in "Cautionary Tales", for instance, warns against the pernicious effects of international collaborations if one is not "politically savvy about the stakes" and wary of the colonialism that might unwittingly be imposed through knowledge construction and exchange (553). Pivotal to such internationalization efforts is the recognition of "blind spots" in the work of U.S. composition through refraining from conventional investigations about "where our work fits in the world" and reorienting focus towards "where the world's work fits into ours," as Donahue argues ("Internationalization" 214).

In order to best capture the patchwork of macro and micro forces at work in this particular geographic site, I consider the different stakes various language users from different social positions have in either preserving or contesting specific ideologies of language and not others and I then situate these dimensions within broader social, cultural, geopolitical, and economic changes. As Monica Heller and Marilyn MartinJones demonstrate in Voices of Authority, it is important to understand and critically analyze the policies and practices of language and education in terms of the "wider interests they serve and... their consequences for differentially positioned groups of learners" (25). Along the same lines, Alastair Pennycook argues that "the ways in which languages are described, legislated for and against, policed and taught have major effects on many people" ("Language, Ideology" 6). As I illustrate how pedagogy should always mediate between language policy on one hand and the actual translingual practices of language users on another, this research study critically examines the operation of 
conflicting language ideologies in writing program and course designs. I examine teachers' perceptions of their own instructional practices and educational responses to language difference, and the specific nature of the teaching strategies they ideally see as most helpful to their multilingual students, in addition to getting insights from students on the nature of and reason behind the writing and language practices they utilize and their perceptions of the pedagogical responses to these in their own writing courses.

This study embraces emerging disciplinary discourses on the fundamental problematic of "imagining internationalizing composition as [solely] export" (Donahue, "Internationalization" 215) and informs future directions of U.S. translingualism with the kind of special focus on the labor of literacy workers handling and working with diverse languages from outside the Anglo-American sphere. In addition, it combines perspectives from both composition and translation courses on the actual traffic between languages and meanings and on how the theory and practice of translation can best inform composition pedagogy and curriculum design. As I argue, differences in the commitment level to translingualism in various approaches to translation directly speak to the residual force of monolingual ideologies seeping even into heavily-based translingual work. Finally, I pay close attention to the contributions of insights from literacy workers engaged in the labor of language crossing along with their students in this site to an emerging translingual approach in U.S. writing programs. Writing pedagogy that is fully attuned to the transcultural and translingual literacies of our students is the dream of many U.S. writing scholars, teachers, and program administrators, especially those aligning themselves with a translingual model, as our writing programs and writing centers are gradually forced to adapt to the new changes 
brought upon by an era of increasing multiculturalism, multilingualism, multimodality, and multiliteracies.

\section{Contested Concepts in the Study of Language and Language Communication}

In order to be able to closely explore the prevalent understandings of and assumptions about language in the writing classroom, I need to first engage with the particularly difficult and contested notion of language ideology. ${ }^{14}$ Though the term language ideology carries a great deal of weight, I turn to it throughout my dissertation as a theoretical framework that can provide a better understanding of how literacy laborers from varying positions and locations think about, situate, and use language, and particularly English in relation to the dynamic use of other languages. Building on Raymond Williams' dynamic model of ideology, and more particularly his notions of the dominant, the residual, and the emergent, I approach in this dissertation an emerging translingual paradigm that is currently gaining ground in U.S. Composition Studies as an alternative linguistic ideology to the hegemonic ideology of monolingualism and reductive notions of multilingualism in the U.S. academy.

It is no surprise that several competing definitions of language ideology have emerged in scholarly discussions sometimes arising from endless debates about the single

\footnotetext{
${ }^{14}$ Linguistic ideology, or language ideology, or ideologies of language are all terms currently in play in a rapidly growing area of scholarly inquiry in Applied Linguistics which bridges linguistic and social theory. Despite my awareness of some of the key dimensions of difference signaled by these terms, with the first two predominantly invoking perceived language structures and use and the last term concentrating more on the enactment and representation of a collective order, I use these terms interchangeably throughout my work.
} 
most contested concept of ideology itself ${ }^{15}$. However, there is an emerging consensus about the importance of moving beyond notions of linguistic ideology as a fixed, shared, and "homogenous cultural template" into what Kathryn Woolard and Bambi Schieffelin describe as a dynamic "process involving struggles among multiple conceptualizations and demanding the recognition of variation and contestation within a community as well as contradictions within individuals" (71). In keeping with these new research directions in the area of language ideology, Ofelia Garcia in Bilingual Education in the $21^{\text {st }}$ Century argues that the notion of linguistic ideology links language practices to broader sociopolitical and sociocultural systems and forces. It represents "the cultural system of ideas about social and linguistic relationships, in addition to political and moral interests" as attitudes, perceptions, and beliefs about language are always ideological and enmeshed in larger social systems of domination and subordination among individuals and groups along the lines of ethnicity, class, gender, race, etc. (84). Bambi Schieffelin, Kathryn Woolard, and Paul Kroskrity in their edited collection Language Ideologies: Practice and Theory define language ideologies as:

Cultural representations, whether explicit or implicit, of the intersection of language and human beings in a social world. Mediating between social structures and forms of talk, such ideologies are not only about language. Rather, they link language to identity, power, aesthetics, morality and epistemology. Through such linkages, language ideologies underpin not only linguistic form and use, but also significant social institutions and fundamental notions of person and community.

In framing their definition and discussion of language ideology, Schieffelin et al. build on Raymond Williams' germane assertion that "a definition of language is always, whether

\footnotetext{
${ }^{15}$ See Woolard and Schieffelin for a detailed scholarly review of varying theorizations of the notion of language ideology, particularly in Linguistic Anthropology, Literacy Studies, and several areas of Linguistics.
} 
implicitly or explicitly, a definition of human beings in the world" (qtd. 22). What is noteworthy about similar contextual characterizations of language ideology ${ }^{16}$ is their ability to capture what Pennycook describes as the "locatedness" of language and its users as firmly inseparable from identities, histories, relationships, polities, cultures, hierarchies, injustices, trajectories, and spaces. Aligning with such conceptualizations of language ideology as a mediating linkage between linguistic processes and socio-cultural structures, my own use of the term language ideology in this dissertation mainly emphasizes the dialectical relation between social, cultural, discursive, and linguistic practices emergent in contact situations and brings together both the micro- of lived experiences and communicative action on one hand and the macro- considerations of power in a global multilingual world on another. In the next chapter, I review both dominant and emerging positions and approaches towards the treatment of languages and language practices in the teaching and assessment of reading and writing and explore the kind of ideologization of language promoting English Only monolingualism, which is enacted in underlying writing pedagogies and assessment practices, whether explicitly or implicitly. More specifically, I critically explore and question the kinds of assumptions, perceptions, and beliefs about the nature of language and its users each of the conflicting perspectives in composition studies reveal and their direct material and political consequences for literacy laborers, both teachers and students, in the very specific contexts in which they operate. An exploration of the nature and working of language ideology in the context of composition instruction is made possible in this dissertation

\footnotetext{
${ }^{16}$ Also echoed by Woolard "Introduction: Language Ideology as a Field of Inquiry," "Is the Past a Foreign Country;" Irvine "When Talk isn't Cheap;" Irvine and Gal "Language Ideology and Linguistic Differentiation;" and Makihara, and Schieffelin "Consequences of Contact" (14).
} 
through an extensive analysis of the ways of thinking about language in both policy and practice in relation to the actual workings of language in the real world.

This brings me to another contested term that I use repetitively throughout my dissertation, which is the notion of practice. The term practice cannot be treated as though its meaning is fixed and stable. Some slippage in the usage of this concept is expected as I myself in this work don't use it to mean the same thing in every instance of its use. There has been a growing interest in the notion of practice and its plural form 'practices' in contemporary theories of language and literacy, especially after the emergence of what is commonly known as 'the practice turn' in the social sciences, which introduced new ways of thinking about language and its users. Alastair Pennycook, among many others like Claire Kramsch, shows a particular interest in the term practice in ways that further problematize structuralist orientations towards language initiated in the twentieth century by Saussure and generativist views towards grammar popularized by Chomsky. Characterizing the types of cognitive structures that account for the unique human ability to know, acquire, and use language ("Knowledge of Language" 3), Chomsky, for instance, developed a theory of Universal Grammar under which mental structures are viewed as "consisting of a system of rules and principles that generate and relate mental representations of various types" ("Rules and Representations" 48). A structuralist thinking, therefore, is essentially concerned with language as a shielded system and a fixed entity or structure that remains in a frozen state locked in the universal and thereby driving attention away from the individual, the particularities of 
language use ${ }^{17}$ and all aspects of difference that are deeply intertwined with the macroframe of the social, cultural, and ideological. Distancing his framework from the kind of systematicity and internalization (represented by Steven Pinker as the "language instinct") embedded in assumptions of structuralism and transformational-generative grammar that tend to overshadow all signs of agency and difference among language users, Pennycook, building on Theodore Schatzki, develops the view of language as a "local practice" and argues by contrast that language is the product of "meso-political action" mediating between repeated individuated activities of the everyday and larger social structures (29). Suresh Canagarajah takes a similar position in "Lingua Franca English" when he argues that "there is no meaning for form, grammar, or language ability outside the realm of practice" (928). In this respect, Canagarajah theorizes language, particularly Lingua Franca English, as a form of "complex social action" and not "a product located in the mind of the speaker" (928). With attention to individual action but also the social repetition of certain forms of action, we see evidence of language as a social and cultural practice in the areas of language policy, language teaching, and translation, all of which receive equal focus in this study.

The usefulness of taking up such directions in language studies through looking at language as a local practice lies in capturing the locality of the language of the everyday and the complexity of meanings, i.e. the way language is being shaped and reshaped by actual language users in light of their day-to-day lived experiences and social relations. In this sense, the idea of language as a local practice helps make a case against one of the

\footnotetext{
${ }^{17}$ Though there is a growing use of the term practice to describe the notion of language use, it is worth pointing out that this term in my dissertation does not refer to all language use (see Pennycook, Language as a Local Practice 8).
} 
potential limitations in the way the notion of practice has been frequently invoked as merely a casual, empty "add-on" after broad abstract concepts like culture, literacy, language, and discourse that seem to carry all the weight. In light of other central concerns about the limited focus of a practices view of language, Pennycook reminds us that an analysis of language as a local practice should remain the starting point, and not the end point, for further in-depth analysis of language in action with a central focus on broader social concerns, such as inequality, power, politics, and the changing material conditions of the real world.

Following Pennycook's theorization of language as a local practice, it is particularly useful in this work to also consider the notion of practice as not only involving a bundle of everyday activities and coherent, regulated doings but also a higher-level combination of thought, knowledge, and repeated action (21-24). In this sense, though there has been a great deal of continuing debate across disciplines over the exact relation between theory and practice (another dichotomy that comes into question here), my dissertation builds on the idea of the inseparability of practical work by ordinary users and the potential effect of that work on the formation of language and the organizing frameworks and principles behind it. This dissertation affords a closer look at the interrelationship between the local language situation, language policies, and pedagogical practices and the nature and effects of the kind of language ideologies materialized and enacted in all three dimensions. ${ }^{18}$ It is part of the goal of this dissertation to bridge the divide between what individual readers and writers say they do

\footnotetext{
${ }^{18}$ One critical consideration, however, about ideological stances as represented in complex language policies and practices is that the ideological is not always "reducible to the material," as Pennycook argues in "Language, Ideology, and Hindsight: Lessons from Colonial Language Policy" (49).
} 
in theory and mission and what they do with language in actual practice. Despite the difficulty of making broad-level and generalizable conclusions based on a local view of the workings of language, a more critical examination of all the perceptions about literacy, language use, and language learning that are propagating among language and literacy laborers is enabled with a more localized lens towards the perspectives of individual, ordinary language users, their language practices, their language affiliations, and their efforts towards and motives in preserving these.

\section{Summary of Chapters}

This dissertation is organized as follows:

Chapter 2, entitled "Writing Instruction and Rewriting English through Translingual Meaning Making," presents translation as a site for working against a monolingualist ideology and moving toward translingual dispositions in writing instruction. In contrast to uncomplicated views of translation as a mechanical, unidirectional transposition of texts from the source language into a target language, I align my work with oppositional approaches in translation studies (put forward by Lefevere; Bassnett and Trivedi; Venuti; Dingwaney and Maier, among many others), which think of translation as a rhetorical act of "re-writing" that challenges traditional notions of "transparency," "neutrality," and correctness in any translation process. In order to show the relevance of the theories and practices of translation in the design and development of writing curricula along translingual lines, I examine various theories of language in composition studies and describe how their advocates have theorized, studied, and represented various investments in cross-language work. I particularly 
emphasize the way conflicting language ideologies get played out differently by each pedagogical approach, and I explore how these various models have conceptualized notions of error, language standards, language competence, and agency in writing and language learning. Attending to ideological underpinnings alongside the operation of power relations, I examine existing models of language, multilinguality, and translation that circulate in disciplinary conversations about language difference in writing and how these have been showing up in discussions on writing program administration, curriculum design, and specific teaching and assessment practices. As I demonstrate in this chapter, the dominant monolingual language ideology not only continues to operate at the level of institutional and programmatic policies but also in the way we perceive multilingual writing and respond to its presence, value, and validity in our pedagogies and assessment practices. In this way, I discuss how a translingual approach to translation (across languages, language practices, cultures, genres, and disciplines) in the composition classroom can provide a way of approaching English as a language "always in translation," as Pennycook puts it, and as emerging in response to various linguistic, cultural, political, and economic relations of difference.

Chapter 3, "A Study on Language Difference and Language in Use in Writing Practices and Instruction," presents detailed information about research design and methodology, the specificity of the research site and its writing program design, research participants, data collection procedures, in addition to methods of data analysis. This chapter also traces the ideological, political, and economical underpinnings of the historical and contemporary development of the Lebanese national language policy while also drawing attention to the intricate cross-language relationships emerging there in 
various domains of life. In order to get a better idea about language policies and curricular design in higher education, it is also necessary in this chapter to provide a brief overview of the history and current state of official language and education policies and practices at the primary and secondary level, and particularly those that address the foreign language learning component.

In Chapter 4, "Representation of Language Ideologies: Language Policies, Perceptions, Writing Pedagogies, and Curriculum Design," I combine perspectives from both writing faculty and students of communication skills courses and courses on the theory and practice of translation at AUB. Based on data from semi-structured interviews, student writing samples, classroom observation notes, course materials, and institutional documents, I analyze the various perceptions of language difference and the attitudes towards the role and place of a range of language practices in the writing classroom. I examine writing teachers' perceptions of their own instructional practices and educational responses to language difference, and the specific nature of the teaching strategies they ideally see as most helpful to their multilingual writing students. Of particular interest in this project is examining how language perceptions and official claims about language policy and practice compare to the actual workings of these in the writing program and classroom. I also analyze students' insights on the nature of and reason behind the literacy and language practices they utilize both inside and outside the writing classroom and their perceptions of the pedagogical responses to these in their own writing courses. Additionally, I conduct a close reading of selected student texts and examine the kind of translingual meaning making strategies they adopt and how exactly they demonstrate their linguistic action in either maintaining difference or reiterating 
standardized forms in written compositions. In this way, I focus on capturing the various negotiation strategies multilingual writing students utilize when revising and (re)composing instances of language difference in their writing in light of their teachers' written comments and feedback. Additionally, drawing on perspectives from the design of translation courses at AUB, I explore how translation work in those courses can best inform composition pedagogy and curriculum design. Specifically, I argue that differences in the commitment level to translingualism in various approaches to translation directly speak to the residual force of monolingual ideologies seeping even into translingual work.

In the final chapter, "Reworking English as a Language of "Translingual" Practice," I demonstrate how perspectives from Lebanon about the promises and challenges of translingual work to both writing teachers and students can be translated into the U.S. context with different local investments in English and other languages and language practices. Drawing on specific examples from the successes and struggles of literacy laborers in Lebanon, I offer practical suggestions for future programmatic and pedagogical changes for U.S. compositionists with a translingual take on language difference. 


\section{CHAPTER TWO}

\section{WRITING INSTRUCTION AND REWRITING ENGLISH THROUGH TRANSLINGUAL MEANING MAKING}

Living in an increasingly multicultural and multilingual world with the sweeping forces of globalization has rendered the vibrant interaction and intermingling among English, World Englishes, and other languages in U.S. composition classrooms inescapable. The boundaries among language(s), English (es), and their users are becoming increasingly perceived as very fuzzy, fluid, and "porous," for as Daniel Villa describes in "No Nos Dejaremos," "language leaks" (87). This lack of neat separation between the languages that students import into the composition classroom and the growing "permeability of cultural and institutional boundaries" separating "native" and "non-native" English speakers (Horner et al. 3) has increased interest among various compositionists in the actual nature and work of what Min-Zhan Lu describes as "living English." In response to this multiplicity of languages, of Englishes in our writing programs, classrooms, and centers, there have been burgeoning scholarly work in the discipline on recognizing multilingual students and better understanding their identities, texts, language designs, and linguistic and cultural negotiation strategies and the interdependent relations of all these to one another. What seems to bring these ongoing disciplinary conversations and publications together is a common recognition of the following indisputable sociolinguistic projections: (1) the complexity and richness of the 
various discursive practices and language resources college students bring to the academic and educational experiences; and (2) the lack of continuity between the nature of language use at home and language learning at school. Perhaps most obviously, the existing prevalent pedagogical approaches, textbooks, handbooks, and evaluation and assessment strategies employed in composition programs and courses seldom reflect and pay special attention to differences in the language background of students and the robust dynamics of the countless discursive and linguistic practices they actively utilize outside the college composition classroom.

Such demonstrable attention to the accelerating growth of multilingual writing in composition studies remains incomplete in the absence of crucial questions about how best to translate this growing knowledge about the complexity and diversity of the makeup of the academic population in U.S. college composition classrooms in terms of number and intensity into responsive language policies and practices in writing instruction and assessment. The consequences of globalization for transforming literacy education are of great concern to all those involved in the educational endeavor from program administrators, curriculum designers, teachers, and policymakers. How do we actually move beyond mere descriptions of the current and needed language policies and pedagogies into active conversations and activities of self-reflection about how to materialize and enact changes in order to develop more responsive and inclusive policies and practices in writing programs and courses? At the very least, it is important to be aware of the "mismatch" between sociolinguistic realities in a multilingual society, like Lebanon as well as the U.S., and existing educational responses in policies and practices. To accomplish the essential but complicated task of rethinking policies, pedagogies, and 
curriculum designs in light of the "effects of global social change on language use" (Ball and Lardner 552), it is first necessary to tease out the conflicting language ideologies perpetuated by the field's labor through critically examining current, emerging, or desired theories of language and translation in composition studies and describing the manners in which their advocates have theorized, studied, and represented investments in language difference. ${ }^{19}$ Building on and extending an emerging translingual paradigm in writing instruction, this study presents the ways by which translation can (and cannot) be a site for unsettling and working against monolingualism and moving toward translingual dispositions. Translation, as I advance it in this study, involves a process of transformation of linguistic norms, written texts, and their corresponding readers and writers in response to asymmetrical power relations along the lines of culture, economy, geopolitics, history, etc. Such a reconceptualization of translation breaks from traditional approaches built around monolingual ideologies of translation as ultimately achieving equivalence and more balanced writing. As I argue in this study, translation can serve as a useful focal point for engaging both students and faculty, who are both operating under a post-monolingual condition, in negotiating shifting tensions between competing language ideologies in their own work with language and language difference.

\section{Writing Instruction and Translation}

Bringing the theory and practice of translation and the broader framework of rhetoric, literacy, and composition studies together is not a completely new line of interdisciplinary thinking and collaboration. Questions about the kind of insights that

\footnotetext{
${ }^{19}$ The use of the term difference in the recurrently used notion of language difference does not convey an abnormal departure from cultural and linguistic norms or a peripheral relation? to conformity.
} 
compositionists can gain from understandings of translation theories and approaches have been raised as early as 1986. In "Composition Strategy as Translation," Sandra Schor establishes close relationships between composition and translation. Clearly, the deeper we get engaged in education and literacy instruction, the more we realize that our work as writing teachers brings us closer to the work of translators as we are constantly mediating between students and texts across differences among language, cultures, disciplines, discourses, media, and genres. According to Schor, "there are significant elements of the composing process that precisely parallel translation theory and practice" (187). Translation is indeed a form of composition (also see Grossman; Rothenberg), and writers, just like translators, even in the traditional sense of translation, are always working amidst similarities and differences, negotiating various tensions between colliding voices and interpretations, and continually discovering and creating meaning in the process (187-188). As Sherry Simon in "Translating and Interlingual Creation in the Contact Zone" argues, "writing and translation meet as practices of creation" (58).

In a review of two anthologies in Translation Studies, Janis Forman joins Schor's calls for rethinking reading and writing in light of perspectives from translation. Though these collections do not explicitly address the impact of the theory and practice of translation on composition, Forman identifies complex resemblance and interconnections between issues of interpretation and translation on one hand and composition on the other suggested by these texts on literary and non-literary translation. At the heart of both translation and composition, Forman argues, are the conscious "choices and the premises upon which they were made" (677). Viewing the translation process as the "comparative making of meaning," Forman suggests that doing translation exercises can help literature 
and composition students at all levels learn to "go native," that is acquire "the other discourse (s) with the ultimate aim of contributing [their] insights about language to these communities and of rethinking [their] assumptions about language" (679). Further highlighting the power of comparative study in translation, Forman adds that "the limits, peculiarities, and unique capabilities of English syntax, semantics, and poetics may be partially defined when placed against another language which is itself illuminated by comparative study" (679). In her attempts to establish more explicit connections to composition pedagogy, Forman asks in an earlier work "How specifically, then, can translation help composition students become better readers and writers?" ("Translation, Reading, and Writing" 12). Offering perspectives from writing across the disciplines courses, Forman draws upon a sequence of translation assignments in the writing classroom that have helped undergraduate mathematics majors and graduate business students become better readers and writers of "at least two [specialized] discourses--that of their major discipline and that of what might be called the language of the educated general public" (16) instead of just "[w]orking exclusively in a single discourse community" (17).

Undoubtedly, the works of Schor and Forman have initiated important conversations about the need to revive the role of translation in composition theory and put translation at the center of our pedagogical agendas, necessary directions and transformations for enacting a translingual model in U.S. writing programs and writing classrooms. At the very least, they show, though not explicitly, exactly why translation should not remain at the margins of research, debate, and pedagogy no matter how much it is "depreciated by the academy," as Venuti reminds us (1). Under the burden of 
dominant fears in the academy of "inauthenticity, distortion, contamination" (Venuti 31), translation has long been considered a rather "questionable tool" for language learning (Dingwaney, and Maier 304) and a stigmatized form of writing, since it is often construed as a practice that simply "copies," "imitates," "mimics," or "repeats" pre-existing texts and materials. Against such fears, Pennycook's notion of "fertile mimesis" (43) that sees language creativity in "sameness that is also difference" $(51)$ reminds us that we need to redefine translation as "a form of authorship" and not as "derivative" or lacking "originality" and uniqueness. In addition, Pennycook's characterization of English as becoming now more than ever "a language always in translation" suggests the need to find ways for approaching English as always emerging in response to various linguistic, cultural, political, social, and economic relations of difference. Though the work of Schor and Forman challenges dominant views that something will be lost in translation and shows that in fact, there might also be a process of gain, they seem to reinforce unidirectional monolingual assumptions about language and languaging. While I do see the value of translation activities in enriching students' understanding of the acts of reading and writing as intertextual, "recursive, interdependent, and mutually enhancing," as Forman argues (681), I do not agree with her claims about the benefits of a "comparative understanding of two language systems through translation" (680). A comparative approach to translation, where English is always the core linguistic code against which all other language systems are compared, sustains monolingual assumptions about languages as distinct and homogeneous "linguistic utopias" (Pratt) that can be compared to and contrasted with one another (in terms of linguistic features, syntactic patterns, lexicon, etc.) but are never in relation with one another. Such 
orientations are in stark opposition to the view of "English as a language always in translation" that Pennycook advances with an eye toward the "flow of languages in and out of each other" ("English" 34). The guiding assumption behind the deeply infiltrated monolingualist views of language we see in the works of Schor and Forman is that languages are fixed entities separated by clearly delineated boundaries of cultures and disciplines. By contrast, prominent studies and research in linguistics have convincingly shown that the boundaries around languages are political and ideological rather than natural and stable (see Gal and Irvine; Pratt). Opposed to a translingual approach that resists a utilitarian view of languages, translation under Forman and Schor's approaches seems to be valued only instrumentally, as a skill to be used in order to help students "acquire the rhetorical skills necessary for their initiation into an academic discourse or discipline" (Forman 10) and "fit [their work] into English grammar (Schor 189). Other questions pertaining to translation, the "myth of English-language superiority" (Spack 766-767), and work that seems to always turn texts, writers, and languages back toward the center that don't get explicitly addressed in the work of Forman and Schor are: What implications does the infiltration of translation theories into the teaching of writing have on the role of English in the writing classroom? Would this recommended work be dominated by the common presumption that all translation is into English? or out of English? or would it extend to thinking of translation in terms of working across multiple languages?

Under the translingual approach to writing I propose in this dissertation that places at its center the work of translation, with the knowledge of limitations comes the awareness of possibilities, different ways of understanding texts, and different ways of 
shaping and re-shaping language and creating and re-creating meaning. In this sense, translation activities in the writing classroom following a translingual framework help students realize that language and culture are not monolithic and unchanging but are characterized by porous, permeable boundaries where a diversity of histories, voices, experiences, languages, and language practices interact and intermingle in light of asymmetrical power relations. This view of translation does not treat translating readers and writers, or what Forman calls "composition student-translators," as mere "comparatists" working on the "new texts-in-the-making" (678), but rather as agents repeatedly faced with the translatable and the untranslatable and negotiating the tensions of tinkering with the boundaries and limitations of Standard English or reproducing the so-called conventions of academic discourse. In contrast to conventional views of translation as transposing written texts from one language into another, the kind of translation I foreground in this study is aligned with critical approaches to translation treated as a political act of "re-writings," as Andre Lefevere has called it, or as "“new writing'" (qtd. in Bassnett and Trivedi 8) and challenges conventional unrealistic notions of "transparency," "neutrality," (see Dingwaney, and Maier 315; Venuti 25; Cronin 35; Bassnett and Trivedi 2), "fidelity" and "faithful[ness]" (Dingwaney, and Maier 313), "accuracy" (Dingwaney, and Maier 82, 103), and correctness in any translation process. A view of translations as always being embedded in cultural and political systems, in history, contexts, and ideologies across boundaries of time and space (physical, cultural, or linguistic) is exactly what is missing in Forman and Schor's approaches to translation. As Bassnett and Trivedi remind us,

translation does not happen in vacuum, but in a continuum; it is not an isolated act, it is part of an ongoing process of intercultural transfer... Translation is not an 
innocent, transparent activity but is highly charged with significance at every stage; it rarely, if ever, involves a relationship of equality between texts, authors, or systems. (2)

A translingual approach is in keeping with an ideology of diversalité or créolité that presents language practices as "hors donc de tout fétichisme" (Bernabé et al. 47) and celebrates "la diversité des significations" (52). Against traditional notions of multilingualism that present a "disguised adherence" to standardized forms and an unrealistic treatment of languages and language practices as discrete and compartmentalized, Caribbean literary writers Jean Bernabé, Raphaël Confiant, and Patrick Chamoiseau insist on an orientation of diversalité in their book Éloge de la Créolité:

La créolité n'est pas monolingue. Elle n'est pas non plus d'un multilinguisme à compartiments étanches. Son domaine c'est le langage. Son appétit: Toutes les langues du monde. Le jeu entre plusieurs langues (leurs lieux de frottements et d'interactions) est un vertige polysémique.... Vivre en même temps la poétique de toutes les langues, c'est non seulement enrichir chacune d'elles, mais c'est surtout romper l'ordre coutumier de ces langues, renverse leurs significations établies. (48)

Creoleness is not monolingual. Nor is it multilingualism divided into isolated compartments. Its field is language. Its appetite: all the languages of the world. The interaction of many languages (the points where they meet and relate) is a polysonic vertigo.... Living at once the poetics of all languages is not just enriching each of them, but also, and above all, breaking the customary order of these languages, reversing their established meanings. (108-109 "In Praise of Creoleness" trans. Taleb-Khyar)

Against the additive orientation of the diversification of languages as represented by diversité, Bernabé et al.'s framework of diversalité captures the creativity of creoleness and the traffic of meaning and degree of "opacite" (52) involved in languaging. In this sense, under the translingual writing pedagogy that this dissertation proposes, even 
monolingual speakers can be drawn into translation through work that foregrounds the diversification of meanings across languages, discourses, cultures, locations, time periods, economies, inequalities, histories, alternative epistemologies, contexts, texts, and selves as a strategy for provoking translation.

Throughout these twenty years or so since the publication of Schor and Forman's work in College English that crosses disciplinary lines, very little has been done to further pursue these ambitious interdisciplinary intellectual endeavors with the "complementary" field ${ }^{20}$ of translation studies. Direct connections with our own research and pedagogies and the relevance of the theories and practices of translation in the design and development of writing curricula along translingual lines are yet to be established. Translation work in rhetoric and composition either takes the form of timed exams taken in fulfillment of the foreign language requirements of doctoral programs or is sidestepped as "outside" the confines of the traditional English department. Even in the study of comparative literature, translation is predominantly neglected, and when translated literary texts are actually used, there is rarely any mention of the theory and practice behind such translations or any attention to the situatedness of these texts and interpretations in their own cultural, linguistic, and historical moments.

With a localized lens towards sociolinguistic landscapes and the traffic between languages and meanings in students' life worlds, this dissertation project purposefully highlights the need to establish translation more firmly as part of writing instruction and to bring it to the heightened attention of a larger number of writing specialists and writing teachers in designing their programs and course curricula. The practice of reflective

\footnotetext{
${ }^{20}$ Borrowing Bronwyn William's description in "Seeking New Worlds" (136).
} 
translating can enable writing students to think critically about different textual practices, thereby fostering their understanding of what their own practices enable and limit, who they admit and exclude, and what social relations and meanings those practices do and do not make possible. Giving special attention to the problematic of translation in writing instruction can provide a productive environment for working with the complex tensions characterizing betweenness and self-consciously mediating these to achieve a "dialectical interaction" (Dingwaney and Maier 10). Fostering critical language awareness and challenging dominant predispositions toward norms that exclude the heterogeneity of language and meaning and that deny writers' agency in reconstructing and relocalizing language, a translingual approach to writing presents language and culture not as monolithic and unchanging but rather as fluid, ideological, and characterized by porous, permeable boundaries where a diversity of histories, voices, and experiences interact and intermingle in light of asymmetrical power relations. As the question of linguistic and cultural difference lies at the heart of translation, this study describes what a culturally and statistically sustained translingual space like Lebanon has to offer to emerging translingual directions towards rethinking current trends at the level of perceptions, policies, and practices.

For a better discussion about how translation can (or cannot) serve as a site for working against a monolingualist ideology and moving toward translingual dispositions in writing instruction, it is crucial to consider some possible initiatives towards programmatic and pedagogical reform along translingual lines. As we strive to move forward toward more contextual and meaningful policies and practices, I investigate questions about the operation of language ideology in language policies and pedagogical 
practices that have developed in composition studies in response to increasing language diversity in writing programs and classrooms and to national debates on language-related issues. To get this conversation started, I provide in the next section a brief overview of disciplinary conversations around the working of a pervasive, tacit English Only policy in the study and teaching of multilingual writing. In the last two sections, I offer a discussion of the ways compositionists have differently understood and responded to cultural and linguistic difference and delve deeper into the various conceptualizations of these underlying each pedagogical response. I first explore how notions of error, language standards, language competence, and agency in writing and language learning have been conceptualized differently in composition instruction. In the final section of this chapter, I emphasize the way conflicting language ideologies get played out differently by various theories of language in composition studies and describe how their advocates have theorized, studied, and represented various investments in cross-language work. It is the coexistence of conflicting language ideologies even among seemingly inclusive writing pedagogies that further foregrounds my work in this study that aims to situate current work in composition in a post-monolingual state, characterized by negotiating tensions between a still powerful ideology of monolingualism and emerging translingual orientations.

\section{Language Policies in Composition Studies and Emerging Translingual Directions}

As Paul Kei Matsuda brings to our heightened attention, what has blinded U.S. composition from recognizing the massive presence of growing linguistic and cultural difference in the academic work of students who do not necessarily fit the dominant norm 
of typical mainstream college students, i.e. native speakers of a privileged variety of English, is what he describes as the "myth of linguistic homogeneity," which has pervaded the field's dominant vision and response towards differences. Operating within a larger cultural ideology of monolingualism and particularly under a "policy of linguistic containment," FYC teachers and program administrators have taken various preventive measures in order to keep language difference invisible in the writing program and course through: either filtering these differences out through the admission process, entrance examinations, and placement tests; dismissing them as signs of limited language ability and deficient academic aptitude and preparation; or dumping the load of dealing with such issues on the writing center and its tutors or on ESL specialists.

A growing number of scholars studying language difference in literacy education have been critiquing the dominant politics of language within composition studies and contesting the underlying monolingual orientation of U.S. composition that is driven by tacit English-Only policies in the academy and society at large. In their Braddock awardwinning essay "English Only and U.S. College Composition," Bruce Horner and John Trimbur highlight the history and cultural logic of a tacit English-Only policy built upon the modernist ideology of "one nation, one language" that have all gone unnoticed in our disciplinary histories and therefore, continue to pervasively inform our contemporary writing instruction, research, and program administration. It is no surprise that as a result of a policy of unidirectional monolingualism, a chain of reifications of languages and social identity where one's social identity is determined by nationality, which itself is defined in terms of a single language, have sedimented and settled into our policies, perceptions, and practices. Upon examining the subtler workings of a tacit English-Only 
policy and its seeming inevitability in the work of composition, one can find deterministic and instrumentalist views of language that do not take into account the complex relationships between language and culture. With its reified view of language, a unidirectional tacit English Only policy is responsible for most if not all of the limitations in how compositionists predominantly think of and respond to language difference in their day-to-day work and in the arguments made in defense of this work.

The dilemma of a pervasive monolingual English-Only ideology, which mirrors national linguistic ideologies in the U.S., lies in propagating idealistic representations of English as a unified, stable, and homogenous language ${ }^{21}$ having discrete boundaries. Bounded and inscribed by notions of dominance, such monolingual language ideologies have contributed to sustaining a homogeneous and hierarchical view of English in the academy at large and in composition programs and courses in particular. Our composition curricula, pedagogies, and assessment practices have predominantly treated English as the "unquestioned" linguistic medium that is monolithic and unadaptable (Horner and Lu, "Working" 488; Rubdy and Saraceni 6) and have failed to tinker with English as a "living language" (Lu, "Living" 607). Though both the global and local use of English have underlying political and ideological orientations and immense sociopolitical, geopolitical, economic, and sociolinguistic implications that need to be thoroughly addressed, English continues to treated as a neutral, non-ideological, and "value-free" language that mediates science and technology and international, crosscultural communication.

\footnotetext{
${ }^{21}$ In fact, this is the case for the imposition of all monolingualist policies in educational contexts and their essentializing agendas as they fail to recognize that "the local itself is not unitary and homogenous," as Canagarajah argues in Reclaiming the Local in Language Policy and Practice (e.g. the Malay-Only policy in Malaysia and the disservice it has done to the local people through denying them the necessary resources of English for global opportunities of advancement (xx)).
} 
Against the effects of an English-Only ideology that have been very powerful and profound in composition, our professional organizations have shown commitment to policies that are opposed to and move beyond unidirectional tacit English Only legislations, particularly CCCC's explicit statements and pronouncements regarding language, language use, and language policy in education (e.g. the 1974 Students' Right to Their Own Language (SRTOL) resolution; the CCCC Guidelines on the National Language Policy). Geneva Smitherman in "CCCC's Role" acknowledges the role of language policies from a leading disciplinary organization in changing, at least to some extent, the deeply entrenched myths and misconceptions about language that continue to plague the field and its labor (33). Though these organizational policies and positions were far ahead of their time in articulating the connections between language, power, and pedagogy, they show the traces of the dominant ideologies of their original sociopolitical context. Undoubtedly, $\mathrm{CCCC}$ has played a significant role as a professional organization in stating its position regarding language diversity; however, as SRTOL recognizes only systematic, stable varieties of English and the "heritage of dialects" in this "nation" while excluding varieties of English from outside the U.S. and other languages, it is quite obvious that "English" is still defined with vagueness in U.S. college composition. Horner in " Students' Right"” demonstrates the presence of monolingualist ideological beliefs in the CCCC statement, which strictly focuses on "dialect differences within English" (742; emphasis in original). This resolution encourages us to forget the history and current realities of the diversity of language use and language users in the Unites States, which has a longstanding and continuing tradition of multilingualism. Through completely denying the actual multilingual character of the U.S. population, a policy of 
language rights and social justice like the SRTOL is very comparable to the work of what Trimbur describes as a U.S. policy of linguistic necessity and expediency ("Linguistic Memory"). Encouraging a "status quo, laissez-faire" approach to language that supports, maintains, and nurtures the dominance of certain languages and language users over others, the SRTOL treats language and its users as "individually homogenous, static, discrete, politically neutral yet tied indelibly to ethnicity" (Horner 743) while preserving the monopoly of English over "public" spaces.

More aggressively resisting any English Only hegemony, there have been rising voices in the discipline that celebrate the value and validity of the local and call for making a place for local knowledge on language and literacy in our language policies and practices (see, for example, Canagarajah, "Reclaiming"; Tardy). In order to best empower the local, language policies have to "wisely appropriat[e] the global" through being mindful of the "porous borders that open up each locality to people, goods, and ideas that shuttle across communities" (Canagarajah xx). We clearly see similar efforts to enact policy changes in local contexts based on local knowledge in the work of Christine Tardy in "Enacting and Transforming Local Language Policies" as her study examines the language practices, language beliefs, and language management within the context of a specific first year writing program in a specific U.S. university. Though Tardy's survey-based study is situated in a major metropolitan area with a considerable number of immigrant and international students but also resident second language writers and native speakers of underprivileged varieties of English, only 5 of the 59 instructor participants from Tardy's FYW program, i.e. $8 \%$ of them, indicated receiving training related to responses to language differences in the writing classroom. A very small 
number of the composition teachers there were actually aware of their own program's language policy, which suggests the need to better publicize programmatic language policies, especially among practitioners and their students. This also suggests that a considerable number of writing teachers in U.S. writing programs are not fully aware of various language issues and/or are not well-prepared to address the various implications of linguistic and cultural difference in the composition classroom. More importantly, based on the results of her study, Tardy stresses the importance of the process of drafting and constantly revisiting and revising language policy statements, crucial processes that need to be co-developed by both writing program administrators and writing practitioners. As Tardy seems to be endorsing, any kind of successful institutional change at the level of language policies and practices needs to be bottom-up and not forced upon the less powerful (teachers and students). Only then can we lay the groundwork for productive debates and dialogues among literacy laborers about the overdue recognition of the linguistic and cultural complexity of the composition classroom.

An overriding concern among opponents of the English-Only movement goes beyond tolerance of linguistic diversity and "discourses of linguistic rights" into the "status planning of languages" (Trimbur 587). In fact, there is an emerging movement within composition studies arguing for radical changes from a tacit English-Only policy into a more explicit policy of active multilingualism. ${ }^{22}$ Under this policy, all U.S. citizens would be able to use multiple languages and language practices when participating in their public, personal, academic, and professional lives and to fully utilize various ways of using English that articulate the expertise, motivations, alignments, and aspirations of

\footnotetext{
${ }^{22}$ See Horner et al. 3; Trimbur 587; Horner and Trimbur; Tardy; Matsuda
} 
language users eager to combat English-only doctrines. The 2007 MLA Ad Hoc

Committee Report echoes similar developments as it pushes for more radical curricular innovation and reform in ways that develop students' "translingual and transcultural competence" (2) in ways that promote the instruction of critical language awareness, oral interpretation, and written translation across "differences in meaning, mentality, and worldview" (5). Addressing the nation's prevalent foreign language learning deficit within academic disciplines as in the society at large, the MLA Report calls for reform and transformation at the level of the design of undergraduate and postgraduate curricula in light of reevaluating foreign language requirements to support students in developing and promoting their ability to operate between, within, and across languages (3-4).

New times, as Horner and Lu argue in "Resisting," necessitate alternative responses to tacit English-Only policies and increasing recognition of new sociolinguistic realities with a new demography of English as composition's monolingual nature is becoming less practical and more difficult to sustain than ever. It is becoming clearer that putting off arising questions about the strengths and weaknesses of local language policies in light of language difference is futile. Instead, we need to actively engage in advocacy for radical meaningful policy changes that are more locally and socio-culturally sensitive and that endorse a more productive negotiation of the local and global, not to forget the importance of explicit articulations of language policy statements in U.S. writing programs and institutions of higher education in order to move further towards those objectives. In the final two sections, I showcase the underlying language perceptions and assumptions that writing teachers bring from a long history of training in 
English Only legislations and how these emerge in the meanings they attach to particular policies and pedagogies.

\section{Prerequisites for a Translingual Framework in Writing Programs and Courses: Redefinition of Key Concepts and Old Categories Pertaining to Language and its Users}

Enacting a translingual approach to academic writing demands much more than curriculum design and revision of policies and practice - it also requires a deeper process of "self-transformation." In other words, there is a great need for ideological as well as pedagogical changes. In fact, radical changes to language policies and writing pedagogies and assessment practices along translingual lines cannot take place without a fundamental shift in language ideologies. Rethinking long-held assumptions about language practices based on correlations with socio-economic privilege and capital and socio-cultural factors can be a very challenging task, one that requires us to "question reflexive beliefs about language, teaching, and our own position in the world" (Lisle and Mano, "Embracing a Multicultural Rhetoric" 26). However, the fact that multilingualism is fast becoming a lived reality, and not merely a newly celebrated buzz-word in our professional and scholarly discourse and jargon, requires engaging in a self-reflexive process that involves questioning longstanding perceptions and assumptions about: language, linguistic norms, language standards, writers, errors in writing, and fluency and proficiency in writing and language learning in light of the patterns of exclusion and power that are embedded within.

A translingual approach that contests tacit monolingual English-Only policies, pedagogies, and politics aligns itself with recent reconceptualizations within scholarship 
on language pedagogy (see Leung et al., "The Idealised Native Speaker"), on SLA issues (see Firth and Wagner, "On Discourse;" "Second/Foreign Language Learning”), and on the global use of English as a lingua franca (ELF) (see Canagarajah, "Lingua Franca English;" House, "English as a Lingua Franca") that have all put into question dominant monolingual assumptions about the primacy of one ideal speaker, one language, one language variety, and one national culture. Juliane House in "English as a Lingua Franca" asserts that "there is a need for radically rethinking the linguistic norm with which ELF speakers' discourse behavior is to be compared," since the "yardstick for measuring ELF speakers' performance ["cannot be the monolingual speaker" but rather] 'an expert in ELF use,' a stable multilingual speaker under comparable socio-cultural and historical conditions of language use, with comparable goals for interaction" (573). The linguistic construct of a native speaker traditionally invested with a "mystical significance" (Paikeday 22) has been strongly questioned and critiqued among prominent linguists, psychologists, anthropologists, educators, philosophers, and lexicographers as early as the 1980's. Based on interviews and deliberations with over forty linguists, Thomas Paikeday’s 1985 book “The Native Speaker is Dead!” portrays this critical questioning approach as scholars systematically scrutinize "an ideal or a convenient linguistic fiction- myth, shibboleth,.... an etherlike concept with no objective reality to it, albeit embedded in a quasi-privileged class of speakers of each language" (107). More recently, Claire Kramsch in the "The Privilege of the Intercultural Speaker" argues that "this idealized native speaker/hearer monolingual discourse community, might still exist in people's imaginations, but has never corresponded to reality" (27). In keeping with these orientations that problematize "limited and unfair" native speaker norms 
(Canagarajah, "Lingua Franca English" 927) and the spectre of the native speaker's unrealistic "ownership" of English, a disposition of translingualism dismantles the mystique of the native speaker which confines proficiency in language and literacy to the limits of an imagined "native-like" fluency in producing an abstracted set of standard forms. Rather, as Horner et al. remind us,

translingual fluency in writing would be defined as deftness in deploying a broad and diverse repertoire of language resources, and responsiveness to the diverse range of readers' social positions and ideological perspectives. Translingual fluency in reading would be defined as openness to linguistic differences and the ability to construct useful meanings from perceptions of them. (308)

Against monolingualism's utopian view of fluency as the mastery of conventional forms, Horner et al. insist on a redefinition of fluency that captures the "variety, fluidity, intermingling, and changeability of languages" and language practices (301) and the ability of language users to "work across differences, not just of language but of disciplines and cultures" (308) and to actively negotiate these as they improvise ways to utilize a wide range of available linguistic resources to produce and convey meaning when reading and writing.

An emerging ideology of translingualism calls into question dominant monolingual orientations in higher education in general and rhetoric and composition in particular that have also reinforced the stratification of language users and writers into various labels, such as international/ traditional; mainstream/nonmainstream; native/nonnative; second/third, ESL, or foreign and their written productions into binaries of standard/nonstandard. At the very least, these linguistic categories that have been guiding our disciplinary conversations, research, and pedagogical practices for so long suggest the use of language and cultural background as a proxy to discriminate against, 
marginalize, and stigmatize individuals and groups, thereby leading us as literacy laborers to make inaccurate assumptions about what they can and cannot do with language (see Spack). At worst, as Vivian Zamel in "Toward a Model of Transculturation" argues, such dominant dichotomies based on a "deterministic stance and deficit orientation to what students can accomplish in English" (341) support a reified view of student identities and reinforce the idea that "each [i.e. language and culture] is separate from, even in opposition to, the other and keeps educators from understanding the complex ways in which the two intersect, mingle with, and give shape to one another" (341).

Under the ideology of monolingualism, uniform language standards are conventionally regarded as neutral, transparent, and universal signs of correctness and high quality writing. By contrast, through presenting standards as "historical, variable, and negotiable" (Horner et al., "Language" 307), a translingual approach to language difference redirects uncritical engagements with language standards, that we commonly see in "eradicationist" and "accommodationist" pedagogies, into "deliberative inquiry" (300) about how writing students are strategically drawing on the full spectrum of their linguistic resources and why. This suggests that U.S. writing teachers should not lose sight of "the historicity and variability of standards, which change over time, vary across genres, disciplines, and cultures, and are always subject to negotiation (and hence change)" (307) in their teaching and assessment practices. By learning that language practices are not static and discrete and language conventions are certainly not absolute but rather heterogeneous, contextual, fluid, and contested, students are offered a new lens through which to look at the work of language and the tremendously diverse ways it is 
constantly being remade. This way students can feel a greater sense of agency as writers, readers, and thinkers making informed decisions about their written language and their particular choices.

A translingual take on language standards necessarily challenges the ways in which written "errors" in student texts are defined and preconstructed as deviations from the fixed conventions of SWE. Such approaches to matters of "error" in writing have gained ground both within and outside the United States, especially among proponents of the notion of academic discourse community ${ }^{23}$ who argue that for students to become successful members of this community, they will have to give up the language practices that are identified according to dominant expectations as "non-standard" and learn to think, speak, read, and write following the conventions and expectations of the academy (see Delpit, "The Silenced;" "The Politics"). It is the same tacit English-Only orientation that is a historical and continuing curricular and pedagogical norm in writing programs and courses across U.S. colleges that has impeded compositionists' understandings of "error" (see Horner, ““"Students' Right”" 743 and passim). Whereas instances of language and cultural difference in students' written texts are generally presumed to be "unconscious" (Canagarajah, "Pedagogy of Shuttling" 591) or "unwitting" errors (Canagarajah, "Place" 609), a redefinition of the notion of "error" along translingual lines is an opportunity for writing teachers along with their students to explore the following questions about written texts and rhetorical moves: "What might this difference do? How might it function expressively, rhetorically, communicatively? For whom, under what

\footnotetext{
${ }^{23}$ See Guerra for a criticism of reifications of the notion of an academic discourse community as a "closed, unchanging entity" (252) that demands strict allegiance to its discourse strategies and expectations. Also see Joseph Harris' critique of the idea of a discourse community.
} 
conditions, and how?" (Horner et al. 300). What are ostensibly assigned to the realm of "errors" as signs of lack of conformity are not always truly mistakes but can rather be an indication of conscious decisions by authors to work against the grain in ways that are more responsive to their communicative purposes, ideological positions, and social relations. Hence, a translingual framework grants agency to writers who choose to "reiterate" and reproduce as well as those who opt for "deviat[ing]" in their writing from standardized academic forms (Horner and Lu, "Translingual Literacy").

In order to enact a translingual approach to language difference in literacy education, we need to rethink how and to what extent our assessment criteria are implicitly or explicitly based on any deep-seated monolingual assumptions about language and literacy. As Canagarajah argues in "Lingua Franca English," "changes in pedagogical priorities [in alignment with the realities of language difference in writing] suggest that assessment too must go through significant changes to evaluate one's ability to negotiate the complex communicative needs of... [translingual and transcultural] contact situations" (936). Through the collective efforts of individual post-secondary writing teachers and scholars and writing program administrators, we need to start revising and refashioning current assessment practices and standards and to develop new pedagogical strategies and assessment procedures that do not rely on the uncritical mastery of formal grammatical competence but rather on "principles of language variation, negotiation of identities, and communicative agility" across individuals, communities, and groups (Shuck, "Combating Monolingualism" 73). 


\section{Representations of Competing Language Ideologies in Approaches towards Linguistic and Cultural Difference in Composition Teaching and Research}

With the transformation of English as a result of its growing engagement with different parts of the world and branching into various Englishes, it is harder now than ever to ignore the influence of linguistic and cultural difference on composition theory, pedagogy, and writing program administration. There is an unprecedented concern among compositionists with the intricate interconnectedness of current disciplinary work with the changing nature of language and language use. Clearly, this sea of change is forcing questions about the ways in which contemporary composition theories and pedagogies can best handle and respond to growing language difference in scenes of reading and writing. Where do we situate English and various uses of English in the composition classroom, and how do we define its form and relation to other languages and language practices? With the image of the "native" English speaker increasingly becoming threatened as a global linguistic norm, what does writing in English actually mean and involve? How can we negotiate emerging tendencies to equate our understanding of "writing" with thinking, working, and composing in languages other than English and language practices other than Standard English on one hand with the gate-keeping concerns and English-Only projections of the academy on another? What are the affordances of emerging subversive writing pedagogies? What are the implications of these "new times" for the design of our writing curricula, our writing assignment prompts, and our current approaches to writing instruction and assessment?

English-Only ideologies continue to pervasively inform our writing instruction.

Dominant approaches that closely study the characteristics of multilingual student writing 
are heavily driven by English-Only monolingualist assumptions. Upon encountering non-conventional styles, linguistic structures, word choices, punctuation, sentence structures, organization patterns, or anything that does not "sound right" in terms of grammar and usage in student texts, writing teachers and scholars instinctively treat such instances of linguistic and cultural differences as "deviations" needing intensive instruction in the basics or the special attention of writing center consultants or ESL specialists. Suresh Canagarajah in "Toward a Writing Pedagogy of Shuttling between Languages" critiques hasty inferences that literacy and language educators working with multilingual writers tend to commonly make about the first or "native" language as being the source of writing "errors" in a multilingual text. Such "inference" models, along with their slightly modified "correlationist" counterparts, project a form of essentializing multilingual writing and fail to account for the "different types of mediation that can complicate the realization of texts in different languages" (589). In order to develop a multilingual orientation to literacy education, proper multilingual writing pedagogies under what Canagarajah calls a "negotiation" model should teach students "strategies for rhetorical negotiation so that they can modify, resist, or reorient themselves to the rules in a way favorable to them" (602). Rather than expecting multilingual students to blindly adhere to dominant rules and conventions in writing, Canagarajah recommends a pedagogy that encourages a critical engagement with these in ways that best represent their preferred personal, academic, and professional needs, "interests, values, and identities" (603).

Fundamental orientations to language difference that are sometimes conflated within writing programs across the U.S. can be distinguished: as a problem, a right, and a 
resource (see Garcia). These pedagogical approaches, which rest on contradictory language ideologies, are based on differing conceptions of language and vary drastically in the status and value they attribute to perceived differences between Standard Written English (SWE) (also referred to as Edited American English) and students' language practices and in the extent to which these support or counter long-held monolingual assumptions.

One pedagogical approach to language difference is what Horner and Lu in "Resisting Monolingualism in 'English"” and Bruce Horner et al. in "Language Difference" label as the "eradicationist" model, which projects language differences in writing as resulting from linguistic imperfections due to ignorance or student carelessness. This approach reinforces a tacit English-Only policy insofar as it approaches any deviations from the fixed conventions of SWE as "errors" that need to be eradicated. Under this ideology of language standardization, languages are treated as if they were "uniform" rather than variable entities and standard languages as representing ultimate uniformity and correctness among all language forms (26). This model represents an ideological force, which "equates language use with social behavior and correct usage with good citizenship" (Bex and Watts 7) and enforces one language variety for use in all situations regardless of medium, context, and purpose (8).

Another approach to language difference is the "accommodationist" model that shows more tolerance for and acceptance of difference than the eradicationist model but still resembles directions towards the "containment" of significant forms of language difference. Some prominent advocates of this approach are Peter Elbow in "Inviting the Mother Tongue" and "Wrong Language" and Janet Bean et al. in "Should we Invite 
Students to Write in their Home Languages?". What is most problematic about Bean et al. and Elbow's pedagogies is that they present invitations for students to compose in their home languages during the earlier drafting stages (i.e. low quality or status phases of writing) as an exploratory way to develop their own "voice" (Elbow 365; Bean et al. 228). A "finished, revised, copy-edited" and successfully polished draft under this model is always expected to be translated into SWE, thereby suggesting further division and separation between languages and language varieties (Bean et al. 236). Such "shy" invitations to compose in languages other than English or varieties other than SE further reinforce longstanding monolingual assumptions through: (1) propagating the image of SWE as the sole "language of power and prestige" (Elbow 358) and presenting its mastery as a necessary and sufficient condition for professional and economic growth ${ }^{24}$; (2) prioritizing form over meaning through adopting a problematic view of revision as “copy-editing" (Elbow 361, 368; Bean et al. 236) and ensuring correctness rather than as a recursive process of discovery and meaning-making through language; (3) further fetishizing home languages through the dominance of the rhetoric of "care," "love" (Elbow 360), warmth, and "softness" (367); (4) assuming stable and distinct language categories, including SWE and also students" "home languages," thereby overlooking the constant mediation of both language constructs in actual practice; and finally, (5) promoting unidirectionality in translation (i.e. from home language to SWE) as a one-toone correspondence between the "home" and "target" language and not a more complex "traffic[king] between languages and meanings" (Bassnett and Trivedi 13).

\footnotetext{
${ }^{24}$ See Delpit "Silenced Dialogue," specifically on how failure to indoctrinate the dominant arbitrary "codes" and formal linguistic conventions of the "culture of power" is equated with "dooming Black children to a permanent outsider caste" (285).
} 
A mere cognitive understanding and appreciation of language diversity remains insufficient if not coupled with dynamic translations into "meaningful classroom practices that can shape our students' view of language" and their experiences as critical writers (Lovejoy 94). Besides respecting and "honor[ing] the legitimacy and linguistic sophistication of all languages and dialects" (236), as Bean et al. claim that their approach achieves, it is necessary for these "accommodative" approaches to acknowledge students' agency in reshaping language and to invite more critical engagements with language standards through "deliberative inquiry" (Horner et al. 301) rather than mere literal translations into SWE. Most importantly, what these code-switching pedagogies overlook is that students are constantly rewriting language in their written texts in ways that are more true to the specific nature of the various micro- and macro- contexts operating in their life across temporal-spatial dimensions, ways that are discredited by standardized structures.

Therefore, while they claim to promote greater inclusivity and tolerance than the "eradicationist" models and seem to elevate the status of students' linguistic repertoires from "errors" to be eradicated into "home languages" (Bean et al.; Elbow) and rights (Delpit, "Silenced Dialogue" (292)), monolingualist ideological beliefs are still sustained in these "code switching" pedagogies as they represent languages as fixed, stable, internally uniform, and separate entities and devoid of interactive influxes. With students' home languages still being perceived and used in the writing classroom as only instrumental means towards the mastery of SWE, such accommodationist pedagogies ultimately present a dominant model of university literacy built around the "mastery" and not the "negotiation" of SWE. 
Lisa Delpit's work in "The Politics of Teaching Literate Discourse," for instance, echoes longstanding monolingualist ideologies through presenting SWE as the legitimate language of the "culture of power" (280). In this sense, Delpit's position of tolerance and sensitivity towards language difference rather than aggressive promotion is quite similar to that which the Students' Right to Their Own Language (SRTOL) resolution has effected. Through teaching minority students only the language of power, Delpit and advocates of her approach are not only determining and controlling the recommended choice and use of language but are most importantly depriving students of the promises of engaging in intellectually hefty work that involves the multiplicity of literacy traditions and ways in which they shape and reshape language. Through acknowledging and validating students' home language, without using it to "limit students' potential" (293), the African American scholar argues against denying and abandoning instruction in SWE and the intellectual habits of academic discourse, especially to students to students of color and from particular social groups that in her view need SE to gain access to social justice and full participation in American democracy.

What is particularly problematic about similar accommodationist approaches to language difference is that Standard English is being represented as a stable saleable commodity and an investment in cultural capital that students have to have access to because presumably in the long run, it will retain high exchange value in the educational and labor market. These typical monolingualist orientations go further in neglecting the fact that other widely used home languages in various parts of the world (like German, Spanish, French, Arabic, etc.) can also carry various forms of capital for their users. Clearly, such invitations for composing in home languages remain in the category of 
traditional multilingual frameworks as the "pluralization of monolingualism" described by Makoni and Pennycook in Disinventing and Reconstituting Languages where each language remains separate and isolated (22). As Horner et al. in "Toward a Multilingual Composition Scholarship" argue, it is time to start shifting one's "understanding of multilingualism from a traditional, additive model of multilingualism rooted in monolingualist ideology to a translingual model of multilingualism emphasizing working across languages" (270).

In brief, despite their differences, both "eradicationist" and "accomodationist" approaches reinforce assumptions underlying the politics of English-Only through: presenting languages as fixed and discrete entities; propagating unrealistic notions of correctness in language use; approaching fluency in and mastery of Standard English as the ultimate key to local and global opportunities in professional and academic life for all language users; and most importantly, in overlooking drastic changes in the realities of sociolinguistic landscapes with the constant intermingling and interpenetration of languages and language practices.

Traditional writing pedagogies that have historically characterized U.S. writing instruction and that approach literacy education as unidirectional and locate multilingual writers on a linear trajectory starting from a native or home language and moving towards competence in a target language, which is predominantly English (and particularly SE), are increasingly being questioned. Rising calls for what Canagarajah describes as the "pluralization" of composition ("Place") are pushing for more responsive revisions and reconfigurations of composition pedagogy and research in ways that better capture the "versatility" (Canagarajah, "Pedagogy" 591) of multilingual writers throughout their 
complex process of creatively "shuttling" between academic texts, various types of texts, literacy traditions, discourses, languages, and contexts (Canagarajah, "Pedagogy" passim). In keeping with new linguistic and demographic realities, Canagarajah in "The Place of World Englishes in Composition: Pluralization Continued" argues for making pedagogical and textual spaces in the mainstream composition classroom for the writing designs of students, especially those from marginalized backgrounds, that are a manifestation of sophisticated thinking about language and the diversity of meanings and rhetorical choices available. Contesting dominant monolingual orientations, Canagarajah argues for approaching unconventional forms of written production not as "unwitting error[s]" but as logical, "rule governed" (588), and legitimate as these spring out of conscious, deliberative decisions and are signs of "an active choice motivated by important cultural and ideological considerations" (609) and marks of "rhetorical independence and critical thinking" (611).

More recently, Horner et al. advance a translingual approach to language difference that invites "more, not less" (300; emphasis in original) work on, within, and across English(es) and other languages, thereby encouraging "conscious and critical" (300) explorations of the heterogeneity of language, genre, disciplines, cultures, discourses, and meanings in scenes of reading and writing. Translingualism contests monolingual ideologies signaled through problematic treatments of language difference as manifested through the traditional "eradicationist" models and the more tolerant yet still reductive "accomodationist" models that resemble efforts to merely increase the number of languages in scenes of composing. Setting itself apart from these conventional approaches to language difference, an emerging translingual model calls into question 
reifications of language and identity signaled through these two dominant types of approaches. Challenging dominant English monolingualist expectations for the teaching and learning of writing and language, the translingual approach Horner et al. call for directly confronts the monolingualist notion of Standard Written English and its hierarchical positioning in the language and writing classroom. Viewed as a "bankrupt" concept (301) and "a false ideal of a uniform language and language practice" (302), standards of written English are reframed under a translingual approach into more flexible and workable practices that language learners and writers are actively composing and reading "with and against, and not simply within" (301). Instead of a widely propagated and problematic sense of fixedness and stability, a translingual approach presents language and language practices as not only diverse but in a constant state of vibrant mobility, fluctuation, and interaction (303). Through responding to language difference "not as a problem but as a resource" (301), a new paradigm shift into translingualism in researching and teaching writing reconfigures the current nature of work in U.S. writing programs.

Under a translingual approach to language difference, to be asking whether or not to encourage students to compose in other languages in predominantly monolingual settings would be to invoke the wrong line of inquiry and the unfruitful kind of labor. Posing the "invitation" question is an indirect implication that home languages are not always already present and operating when students write in English. A more productive question of great concern to translingual advocates would not so much be the like of Bean et al.'s overarching yes/no question "should we invite students to write in home languages?" but rather "how do we best invite interactions among, within, and across 
languages and language practices in student compositions"? or how do we help students engage with and in these interactions productively? Whereas the first question preserves and nurtures monolingual ideologies through assuming that language practices of the "home" are fixed and compartmentalized entities and through questioning the acceptability of those in relation to and in the presence of one specific, discrete sphere only assigned to the language of the "academy," the second more favorable orientation further promotes cross-language relations in scenes of reading and writing. Such revised directions in the researching and teaching of writing entail initiating conversations with colleagues and even students about how readers and writers are already and always working with language and towards what specific ends and about the strategies used to actively tap into available linguistic resources that are valuable to the knowledge making process and more equitable social relations. Translingual pursuits in writing pedagogy redirect attention into erasing linguistic boundaries in addition to encouraging a critical engagement with both the enabling and limiting power of language standards alongside the motivations behind the need to either imitate or resist those.

An early pedagogy that best illustrates a disposition of critical "deliberative inquiry" (300) is described in Min-Zhan Lu's "Professing Multiculturalism: The Politics of Style in the Contact Zone." I see Lu's approach as an example of a pedagogy to literacy education that is in alignment with the tenets of a translingual approach, especially in viewing readers and writers as agentive creators of meaning and "designers" of English in light of the different temporal-spatial contexts of their lives. In her 1994 essay, Lu describes a classroom in which students through the practice of reading and writing examine their rhetorical and stylistic choices in a critical, interpretive lens with 
the aid of others. She presents an interactive approach to literacy which is in stark opposition with more traditional monolingual instructional procedures in teaching grammar and style through a series of separate drills in aesthetically valued correctness. Through prompting students to collectively unpack the exceptions in written texts while simultaneously being mindful of standardized rules and conventions, Lu complicates the interrelationship between form and meaning and purposefully brings the peculiar structure of "can able to" produced by a Malaysian student whose native language is Chinese to the fore of classroom conversations about the multiplicity of "colliding voices" (448) in the scenes of reading and writing. In more precise terms, Lu encourages the writer of "can able to" along with her classmates to perform a "close reading" (to borrow David Bartholomae's characterization of this way of reading student texts) and tease out the nuances behind the idiosyncratic structure. Under this pedagogy of critical deliberation, the writer of "can able to" is prompted to examine her idiosyncratic structure not only in terms of what it prevents her from attaining but also through what localized meanings it opens up, meanings that are discredited by standardized language forms. For instance, though the nonmainstream structure of "can able to" deviates from the conventions of SWE, it helps its creative author enact a different approach to "ability" than the hegemonic attitude toward "ability," and it is more true to her conviction that resistance against dominant social relations can empower the less powerful to advance towards their goals and aspirations. In the student sample, the writer used "can able to" instead of either the more standardized "can" or "able to" in order to enact a different approach to "ability" than the hegemonic attitude toward "ability." According to the multilingual student writer, the idiosyncratic structure of "can able to," which deviates 
from the official codes of academic discourse, is more true to her sense of how one's goal-reaching attempts can be limited by various "conditions of life" such as sexism and racism (i.e., "able to" in the sense of having permission to) and to her conviction that resistance against dominant social relations can empower people to advance towards their goals (i.e., "can" in the sense of having the ability to). Lu also describes how her students engaged in a process of collective critical deliberation as they helped the Malaysian writer decide how or whether to revise "can able to" and as they revised their own readings of such idiosyncratic structures in light of the writer's critique of dominant forces and the specific nature of the micro- and macro contexts operating in her life. Instead of pushing the author of "can able to" to conform to more "correct" structures according to the standards of written English or simply correcting her, we see Lu guiding both the writer of "can able to" and its readers to recognize, examine, exploit, and complicate instances of linguistic and cultural differences, all of which are valuable teaching moments that lie at the heart of critical and conscious revision in the writing classroom.

In keeping with most recent developments in theories about language and language use in Second Language Acquisition, Applied Linguistics, Foreign Language Learning, and Translation Studies, a translingual model that I advance in this study represents a distinct move away from longstanding monolingualist ideology in its special attention to the utilization of: (1) the complexity and richness of students' local language practices; (2) the actual "traffic" (Kramsch; Pennycook) among home and academic literacy/language practices, of the fluidity and variability of each, and of the interdependent relations between these practices; and (3) the potential role and wide pedagogical possibilities of 
the theory and practice of translation in writing instruction, a key component which this study mainly foregrounds.

Based upon the confessions of its advocates, this emerging project of translingualism is still "at the beginning stages of [its] learning efforts..., which by definition will require the ideas and energy of many - including literacy workers using diverse languages, from outside as well as within the Anglo- American sphere" (Horner et al., "Language" 306). The implications and logistics of such a paradigm shift of institutionalizing a translingual model in writing programs and courses has yet to be worked out and translated into actual practices and action. Addressing these gaps, the current study attempts to outline a pedagogical application of translingualism that is in tune with the cross-language relations already flowing into writing programs and classrooms and that involves the integration of translation into existing writing course designs. With the productivity of translingual work in U.S. writing programs being closely bound to perspectives on language relations in writing in higher education settings from countries outside the U.S. and from labor with languages other than English, the current study highlights the contributions of perspectives from Lebanon to future directions of translingualism in U.S. writing programs and courses. Re-imagining writing programs and courses as active translingual spaces that contest longstanding monolingual ideologies, this study shows that the success of future translingual work in U.S. writing programs depends on a radical ideological transformation in our perceptions of language alongside subversive changes in local language policies and pedagogical approaches in ways that promote the full utilization of available language resources at all times in acts of reading and writing. 


\section{CHAPTER THREE}

\section{A STUDY ON LANGUAGE DIFFERENCE AND LANGUAGE IN USE IN WRITING PRACTICES AND INSTRUCTION}

This chapter traces the ideological, political, and economic underpinnings of the historical and contemporary development of:language policies in the multilingual site Lebanon while also drawing attention to the intricate cross-language relations emerging there. I begin by delineating a history of language relations in Lebanon through a description of the wealth of cultural and linguistic heterogeneity on the ground and how these inform and are informed by the official language policy and contemporary language-in-education policies. The final section in this chapter presents detailed information about the current study's research design and methodology, the specificity of the research site and its writing program design, research participants, and data collection procedures, in addition to methods of data analysis.

\section{Language Diversity in Lebanon}

Lebanon is a multilingual nation with a dynamic linguistic use of major languages-- Arabic, French, and English--that serve basic communicative, vocational, and educational purposes. The native language, Arabic, in Lebanon is considered diglossic with two genetically related linguistic varieties that coexist among its discourse 
communities, following Charles Ferguson's terminology and description of such a sociolinguistic phenomenon in modern times. A colloquial Lebanese Arabic variety, for instance, is used for various conversational purposes and another Modern Standard Arabic version (MSA) is used only in religious, educational, literary and other formal domains. Despite some syntactic variations and noticeable semantic, morphological, and phonological differences between both varieties, the colloquial version, unlike MSA, is unwritten. In addition to the native Arabic language, the majority speaks French as a second foreign language after English or as the first foreign language and English as the second. Other languages, including Armenian, German, Kurdish, and Farsi, are also actively used by various minority groups in the Lebanese society mainly as home languages and sometimes as the language of instruction in certain regions.

While English and French were introduced into Lebanon through Western missionaries, the Armenian language is used by the descendants of thousands of Armenians who came into the country in the early twentieth century as refugees fleeing the atrocities of the genocide of 1915-1923 under the Ottoman rule in Turkey and who settled in suburbs in East Beirut like Dora and Burj Hammoud and in Anjar in the Beqaa. Though a considerable number of the first generation of Armenians showed no urgent need to learn Arabic for cultural integration when knowledge of English and French rendered daily communication possible, Armenians nowadays learn Arabic as a second language and use it as a lingua franca for interactions with non-Armenian Lebanese. Despite the dissemination of common local linguistic stereotypes of "speaking Arabic like an Armenian" in reference to the Armenians' "broken" Arabic and gender marking confusion, the Armenian community is currently an integral part of the Lebanese society 
and its diverse demographic, ethno-linguistic, and political landscapes (Arda-Ekmejki 23). Lebanon had also been a safe haven for Kurds, who arrived in the early 1920 s to escape low socioeconomic conditions and political and cultural repression in neighboring countries like Iraq, Syria, and Turkey. The Kurdish community mainly residing in the northeastern part of the country speaks the Kurmanji or Bahdinani dialect, while others speak a unique "Arabic dialect imbued with Kurdish, Syriac, and Turkish influences" (Kawtharani and Meho 138). Embracing their Kurdishness despite linguistic differences among their community, the Kurds still struggle to assimilate into Lebanese society due to poor socioeconomic conditions and educational resources. As for the German language, what started as attempts to accommodate the language and educational needs of German-speaking citizens living and working in Lebanon flourished over three decades into ongoing cultural and educational exchange between Germany and other German-speaking countries in Europe and Lebanon through institutions like The German School of Beirut (Deutsche Schule Beirut) and the Lebanese German University that teach German to a large portion of Lebanese society alongside Arabic and English. As a language with less historic presence in Lebanon compared to Armenian, German, and Kurdish, learning Farsi has increasingly become popular among Shi'ite Lebanese in Southern parts of Lebanon over the past decade or so. Alongside efforts to gain needed cultural capital associated with knowledge of English and French, the teaching of Farsi as a third foreign language is integrated into the tenth grade curriculum of Shi' ite muslim schools affiliated with the Islamic Republic of Iran as a key dimension of transnational religious and political networks and a prerequisite for the persistence of financial support from Iran (Shaery-Eisenlohr 61). As Roschanack Shaery-Eisenlohr mentions, the 
launching of this project in 2002-2003 originally initiated parental complaints about the language "overload" where Farsi was deemed "irrelevant to the immediate needs" (61) of its new learners and fears of interference with their children's English and French, both highly indispensible and relevant to their futures (60). Amidst the active use of this specific variety of languages, colloquial and formal Arabic alongside English and French remain the most widely utilized languages in sociolinguistic landscapes and educational sites in contemporary Lebanese society. In the next section, I consider the nature of ideological and educational landscapes informing and informed by such active multilingualism on the ground.

\section{History of Language and Language-in-Education Policies}

One of the major landmarks of language diversity in Lebanon, as Kassim Shaaban and Ghazi Ghaith thoroughly describe, is the introduction of French and English as foreign languages into Lebanese society through the arrival of missionaries, which started in the first half of the nineteenth century and still persists to the present. Various missionaries, among which the French Jesuits and the American Evangelical Protestants were the most prominent, introduced Western influences into the Lebanese educational system through establishing various bilingual schools and institutions of higher education around the country. The English-medium missionary schools, the most significant of which is the Syrian Protestant College (now the American University of Beirut established in 1866 and on which the current case study focuses), were far more prominent than the French-medium ones (Shaaban, "English Language Teaching" 104). However, the status of the English language in Lebanon altered drastically amidst the 
consequent French rule in the middle of the twentieth century following the break-up of the Ottoman Empire. French colonialists in Lebanon, as in the case of other French colonies, strategically foregrounded their political, military, and economic presence with cultural and linguistic pollination by imposing French educational systems and a strict language policy chiefly promoting the use of French alongside Arabic as official languages with the far-reaching dominance of the former (see Calvet). After reclaiming its independence from French colonization in 1943, the first Lebanese government issued various declarations for strengthening the native language and reviving its high status, establishing independent educational institutions, and designing new national curricula.

Up until the late twentieth century, discussions about language planning and language policy in Lebanese society spurred a series of heated debates among various groups. With the country emerging from an extended civil war period, the choice of language of communication and education was immediately associated with ideological orientations and political affiliations with either France or the U.S. along with religious backgrounds. During that period, Shabaan and Ghaith indicate that "foreign languages spread along sectarian lines" where Catholics and Maronite Christians who held strong affinities for France as their "savior" in a Muslim dominated Arab region learned only French, most Muslims studied Arabic, and the Druzes, the Greek Orthodox, and some Muslims who had strong ties with American Protestants preferred English (qtd. in Diab, "Political and Socio-Cultural Factors" 178). However, such controversial issues of national identity and belongingness in correlation to language status and the choice of language media of instruction were resolved through declaring Arabic as the only official language in the country besides placing equal emphasis on the teaching and learning of 
French and English at all levels of education. Such measures were deemed necessary given the failure of a unique Arabic-only educational policy experiment implemented in 1975 with an imposed shift into the teaching of all content areas in the native language, which, according to Diab, lacked "careful planning" and overlooked the fact that French and English have throughout time become deeply rooted in Lebanese culture and its educational system ("University Students' Beliefs" 82). Current Lebanese educational policies advocate Arabic-French-English trilingualism despite the persistence of a minority of resisting voices calling for what Shaaban describes as the "Arabization" of Lebanese education (qtd. in Diab, "Political and Socio-Cultural Factors" 183). This official movement towards trilingualism, according to Shaaban, reflects "a utilitarian attitude based on giving priority to economic considerations, such as finding better jobs, surviving in the new world order, and fitting within the globalization movement" ("Language and Education").

In their discussion of the various decrees and legislations issued by the successive governments in Lebanon, Shaaban and Ghaith argue that such official decisions for the preservation of the adoption of foreign languages as media of instruction were a practical reflection of the insistence of the Lebanese majority given the proliferation of foreign languages in daily functions and the various privileges that such trilingual competence ensured both locally and globally (6). This propagation of English and French in Lebanese society can be attributed to earlier institutionalization efforts in addition to people's identification and attachment to these languages and the valued kind of cultural openness they seemed to offer, the influences of which were largely underestimated by the well-intentioned 1975 experiment. It would also be relevant here to question the 
complex status of English and French in Lebanon. While French and English are officially designated "foreign" languages, residents of Lebanon may in fact see them as "home" or "first" languages instead.

Under such pre-university educational reform, in addition to emphasis on proficiency in the native Arabic language, instruction in one of the two foreign languages is mandatory at the primary and secondary levels and receives equal weight with Arabic instruction. The achievement of equal status for French and English in Lebanese society gave rise to two dominant types of schools: English-medium and French-medium (Diab, “University Students' Beliefs" 83). Both types of schools give equal weight to the native language and either one of the two foreign languages, and instruction in the other foreign language is first introduced in Grade 7. Most private schools usually start introducing the second foreign language as early as Grade 4 or Grade 1 and some even earlier depending on the availability of staff and educational resources. While Social Studies is taught in the native language in both English-medium and French-medium schools, all other subject areas (e.g. Mathematics, Science, Philosophy, Computer Literacy, etc.) are learned in either English or French depending on the main medium of instruction in each school. Similar segregations and divisions of languages into separate entities at different times and into discrete spaces in "border-making" curriculum design are mainly critiqued by Alastair Pennycook for significantly influencing the way these languages are utilized and developed ("Language" 140). This unnatural linguistic differentiation in which languages are not allowed to interact and inform one another is produced through "scheduling different languages at different times of the day, or creating spatial 
boundaries around languages in classrooms." It is in this sense that, as Pennycook argues, "spatial practices, time practices, and language practices all inform each other" (140).

It is also worth pointing out that several interrelated sociopolitical, sociocultural, and religious factors at work in the Lebanese context usually influence parents' choice of language-medium educational background for their children. For instance, Diab argues that most Christians, particularly Catholic and Maronite communities, in Lebanon who have had a long history of affiliations with the French culture and its language generally opt for continuing this tradition with successive generations, while other religious groups who don't share such strong bonds with France send their children to English-medium schools ("Political and Socio-Cultural Factors" 183-184).

Needless to say, language learning is a fundamental component in the Lebanese educational system and is most likely to remain so with both public and private schools being subject to regular evaluations and inspections on foreign language instruction by trained governmental representatives (BouJaoude and Ghaith 194). Special attention to foreign language education naturally necessitated that the new curriculum in Lebanon be also characterized by its promotion of basic translation skills among young Lebanese learners even as early as secondary school due to emerging forms of linguistic diversity and dynamic language use in Lebanese society that require the possession of such skills when negotiating one's way through differences among and across the multiplicity of languages and language practices. Translation courses that meet for two hours weekly are introduced in the secondary cycle to students specializing in Humanities and Sciences in Grade 11 and to those in Humanities and Social Studies in Grade 12. The following 
excerpt is drawn from the educational plan of the new Lebanese curriculum issued in 1997:

In line with the principles and guidelines set by NCERD ${ }^{25}$ for teaching translation in Lebanese schools and stated in the New Framework for Education in Lebanon (1995), the Committee recommends adoption of the following goals for the teaching of translation in the secondary cycle.

1) Developing the learners' awareness that translation is an intercultural process and meaningful contact between cultures and languages.

2) Drawing on social, psychological, and cultural perimeters of target and source languages to help students understand texts, content, and style.

3) Developing learners' relevant linguistic and communicative skills in the source language and target language(s).

Clearly, in order to help students more critically translate texts of various genres, themes, and styles, the teaching of translation at those levels mainly addresses the goals of developing awareness of translation as "an intercultural process and meaningful contact between cultures and languages" and as emerging in response to social, psychological, and cultural parameters. Though translation at the secondary levels is officially viewed as a process of meaningful interaction between the micro and the macro, as indicated in the educational plan, it remains taught as a bi-relational process between "target and source languages" and not a multi-relation across the multiplicity of languages, discourses, genres, and meanings as a direct reflection of local lived experiences. Alongside the official recognition of the central role of foreign language education at the primary and secondary level and of translation at secondary levels, there is a strong curricular focus on translation in higher education. The establishment of a National Translation Center for the Lebanese University, the only government-sponsored

\footnotetext{
${ }^{25}$ National Center for Education Research and Development (NCERD), a specialized center within the Ministry of Education entrusted with curricular design and reform, textbook publication, teacher training and preparation, and quality assurance
} 
institution, by the Ministry of Education and Higher Education that offers rigorous translation training programs has further strengthened the balance among the three languages closely operating in the country (Shaaban and Ghaith, "Lebanon's Languagein-education Policies" 13). English departments in private American-style institutions, like the American University of Beirut, offer joint translation programs in conjunction with the department of Arabic and near Eastern languages and the department of foreign languages. Such programs offer both undergraduate and graduate-level translation courses about the theory, methodology, and practice of translation and the politics of translation and oral interpretation across ideologies, languages, and cultures. With the dissemination of translation as supported by the Lebanese national curriculum, it is therefore no surprise that Lebanon is characterized by its thriving translation activity. The provision of language and translation services is a booming industry in the country with translingual skills being represented as highly marketable in the business domain and an investment in cultural capital that retains high exchange value in the labor market. Lebanon's strategic geographic location and its strong dependence on trade and commerce have strongly motivated the endorsement of translingual work through translation in its national curricula and the institutionalization of translation at AUB. ${ }^{26}$ Though cross-language work in Lebanon has diverged over the past decade or so from the official government's primary educational intentions and is heading towards commodification, it is the official recognition of the central role of foreign language education and of translation in local educational and language policies that is worthy of

\footnotetext{
${ }^{26}$ See Bou Ayash "U.S. Translingualism" for more on the local specificity of economic and geopolitical relations in Lebanon and how negotiations of conflicting language ideologies are mainly driven by geopolitical relations and economic considerations.
} 
the attention of writing administrators, scholars, and teachers wishing to labor along translingual lines.

\section{The Study: Research Design and Methodology}

\section{Research Questions}

The following research questions will be addressed in this study:

1. What ideologies of language are enacted in language policies, curriculum design, and teaching and assessment practices in undergraduate composition courses and courses on the theory and practice of translation in this particular multilingual context?

2. To what degree and in what ways do both college writing/language instructors and student writers handle and negotiate tensions between the management of multilingualism in language policies and educational practices on one hand and the actual translingualism in sociolinguistic landscapes on another?

3. How exactly can models of translation and theories of the trafficking of meaning inform the teaching and learning of writing?

4. What insights can U.S. compositionists gain from the promises and struggles of the Lebanese context where translation and cross-language relations are a way of life, and most particularly as they plan the future directions of institutionalizing translingual approaches to reading and writing instruction in U.S. writing programs and courses? 
The Research Site and its Writing Program: Historical and Contemporary Language Policies

My study takes place at the American University of Beirut campus, Beirut, Lebanon. The American University of Beirut (AUB), founded in 1866 by American Protestant missionaries from New England and formerly named the Syrian Protestant College, bases its educational philosophy, standards, and practices on the American liberal arts model of higher education. As a teaching-centered research university, AUB has around 700 faculty members and a student body of around 8,000 students. The student faculty ratio is 13 to 1 . AUB students are drawn from all strata and areas of Lebanese society, but with a predominance of middle to upper socioeconomic classes. Based on enrollment figures for the academic year of 2011-2012, the university student population (6,400 undergraduate students and 1,500 graduates) is $51 \%$ male and $49 \%$ female from 73 different countries. 26.1\% of AUB students enrolled by Fall 2011-2012 are international students, especially from the Middle East region (e.g. Jordanians, Palestinians, Syrians, Saudi Arabians, and from the Persian Gulf states). Though students are predominantly Lebanese, it is very common for local students to have dual citizenships, having been born and raised in countries where their parents had emigrated (especially America, Canada, Australia, Venezuela, Brazil, UK, France, etc.) due to political and economic conditions. ${ }^{27}$ With growing numbers of international students and dual-nationality students of Lebanese origin coming back from the U.S. and other English-speaking nations being dispersed among the multilingual Lebanese majority, there is an increasing need for rhetoric and composition specialists among English

\footnotetext{
${ }^{27}$ For more details about enrollment figures at the undergraduate and graduate level by faculties, gender, and residency, refer to the following report developed by the Office of Institutional Research and Assessment $<$ http://www.aub.edu.lb/oira/institutional research/Documents/FB201112.pdf $>$.
} 
department faculty to address this diversity in language and writing practices given the overwhelmingly vast enrollments in writing courses.

Under its admission policies and requirements, AUB requires all entering students to take Academic English classes, and they are placed in them based on their scores on one of a number of different language tests-TOEFL, SAT, or the university- administered English Equivalency Exam (AUB Undergraduate Catalogue 2011-2012, 34-35). Upon admission to any faculty at AUB, Arabic-speaking students ${ }^{28}$ are also required to demonstrate a thorough knowledge of their own native language through sitting for an Arabic Placement Test (APT). If their test scores are low, they will have to register for an introductory Arabic course (ARAB 201A: Basic Arabic Grammar and Syntax), which trains them in basic grammar and oral and writing skills. Those who get higher scores or who do not sit for the test can choose between various courses, namely ARAB 201B, that encourages a close textual and analytical study of a wide variety of reading selections from classical and modern Arabic literature, ARAB 211/212, that is a survey course of Arabic morphology and grammar, or any other advanced Arabic course (above ARAB 221: Arabic Stylistics and Metrics). AUB also provides students and academics interested in developing their Arabic language skills with a unique opportunity to take part in an intensive six week summer program offered by the Center for Arab and Middle Eastern Studies (CAMES), which offers insight into Arabic language and culture and focuses on the instruction in Modern Standard Arabic.

The language of instruction for all courses at AUB is English, except for: courses offered by the Department of Arabic and Near Eastern Languages in Arabic language and literature and introductory courses in Syriac, biblical Hebrew, and Persian; and foreign

\footnotetext{
${ }^{28}$ Non-Arabic speaking students are exempt from the Arabic requirement
} 
language courses offered by the Civilization Sequence Program that provide students with basic to intermediate working knowledge of Chinese (Mandarin) and French. It is worth mentioning, however, that when the Syrian Protestant College was first established, Arabic was the sole language of instruction, and English and French were simply taught as foreign languages. Courses in all disciplines from medicine, pharmacy, biology, physics, mathematics, to philosophy were taught in Arabic (Jeha 106). In enacting and pursuing this policy, the American missionaries were obliged to learn the reading and writing of Arabic texts with the help of native Arabic linguists in order to communicate with students. With regard to the local reception of this Arabic-Only policy, Jeha explains:

[r]ecognition of the Arabic language as the official language of the College was welcomed in the Arab society. It was considered as a positive, a sympathetic gesture and a true contribution to the revival of Arab culture and civilization (109).

The shift from a policy concerning the predominant use of the Arabic language into an English-Only policy under which all departments adopted English as the teaching language occurred gradually over a ten year period from 1873-1883. Political, ideological, as well as practical realities and considerations both locally and regionally have influenced such changes in language policy. Language policies at AUB have throughout history been closely tied up with both the political realities of the region ${ }^{29}$ and the heterogeneity of languages already used by the diverse student population. As indicated in the annual report of AUB President Daniel Bliss for the academic year 18771878 , the contemplated change in language policy from Arabic, "the best means of

\footnotetext{
${ }^{29}$ Prior to World War I, for example, AUB had to abide by the rules and regulations of the Ottoman Empire.
} 
Christianizing and civilizing the East," to English was enacted as a way to increase the number of students from the most enterprising youths of Syria, Egypt, parts of Asia, Mesopotamia, Russia, and Cyprus (Burns). ${ }^{30}$ Based on extensive archival research, Shafik Jiha argues in his historical account of this shift that the American missionaries realized that learning foreign languages, such as English, French, and Italian, came to be essential to the young natives in a commercial seaport like Beirut. With the realization that the mastery of English could give students greater work opportunities in foreign and local commercial companies in light of what President Bliss described as "the manifest demands of the time" (qtd. in Jeha 113), official decisions concerning establishing English as the obligatory teaching language became effective as of Fall 1875. Reflecting back on what he described as "the most important step" "[i]n the intellectual development of the College," i.e. the change of the language of instruction from Arabic to English, AUB's president explicates that "when Arabic was the medium of instruction, Armenians, Greeks, Persians, and others were unable to enter the College" (1902 President's Report). Two decades after the implementation of the new language policy, President Bliss commented that: ... the results have justified the step, especially in these later years, when the instruction in English has become really efficient. Our students are now familiar with one of the greatest languages of modern times, and direct access to the wealth of literary, scientific and philosophical works found in it; and having access to this great wealth of learning, they are by far the better able to keep abreast with the scholarship of other and more favored lands. Moreover, the problem of securing a constant supply of high-class teachers is much facilitated by the change. But we do not forget that we are [sic] within the borders of the great Arabic-speaking world, and therefore we have thorough courses in Arabic required of all Arabic-speaking students. Although the time given to these courses is

\footnotetext{
${ }^{30}$ Also due to the serious difficulties that faculty members in the sciences were facing with the problematic unavailability of Arabic textbooks in the first three years of study in their disciplines, as President Bliss mentioned in his report to the Board of Managers on 15 January 1869 (Jeha 110).
} 
restricted, the instruction is so efficient that our graduates average higher in ability to use the tongue acceptably than those of any other missionary institution in the Arabic-speaking world. And this efficiency is increasing in late years, not decreasing; our higher standing is not obtained at the expense of the Arabic, but the two are advancing together. The thorough Arabic instruction supplies the channel through which our graduates can communicate to their peoples the thought of modern learning; the English equipment supplies thought worthy to be communicated (qtd. in Burns; emphasis added).

The importance of English as a tool for critical "thought worthy to be communicated" that "is not obtained at the expense of the Arabic" is acknowledged rhetorically at the level of policies, but not in practice and currïcula, at least in the writing classroom, as I show in the following sections. As AUB continues its endeavor to keep its local students accomplished in their native Arabic tongue, there is a common consensus among its faculty members that "it is equally if not more important to give them [AUB students] a practical knowledge of the English Language” (AUB Faculty Memorandum to the Board of Managers in 1875, qtd. in Jeha 111). Almost a century after President Bliss's annual academic report, though both languages continue to be "advancing together" they do so in separate trajectories, with the exception of courses on the theory and practice of translation, in separate courses offered by separate departments, namely the English Department and the Department of Arabic and Near Eastern Languages, and their natural interaction and intermingling remains exclusive to Lebanese sociolinguistic landscapes (refer to later sections for a more detailed discussion of cross-language relations and translation instruction).

Though the label of an American-style institution of higher education in Lebanon inherently carries with it a "baggage of linguistic and cultural imperialism" (Schaub 89), writing instruction and writing research at AUB have to some extent managed to 
maintain uniqueness and locality. Though course curricula are modeled on American higher education and larger infrastructures of North American writing programs, AUB's writing program, as is the case of other American-style institutions across the country, operates under the name of a Communication Skills program originally established, designed, and directed in the past by applied linguists and specialists in the teaching of English as a foreign language. Alongside the acknowledgement of the primacy of writing in education at AUB through the establishment and development of a dynamic writing center in 2003 , constant revision of compulsory freshman composition course curricula, and the introduction of WAC/WID courses in 2009 , attention to oral communication skills, considered among the significant marketable skills in professional settings across the country, still persists. Other efforts at AUB to embrace the resourcefulness of the linguistic differences in Lebanese society involve moving away from uncritical exportations of Anglo-American textbooks and writing handbooks. There have been departmental efforts directed towards the localization of textual materials in composition classrooms that not only reflect contemporary life in Lebanon and the Middle East but also the multilinguality, multiliteracies, and multimodalities present in the composing practices of its young writers through custom publishing its own first year composition reader, When Silence Speaks, in 2007 with a revised edition entitled Shades of Grey in 2009 and Afterwords in 2012 (for courses equivalent to Eng 101) as a collaborative project between its FYC teachers and student writers whose diverse voices are in conversation with the texts. Furthermore, the university's writing center has started cultivating the linguistic resources among its tutors through introducing foreign language tutoring services in Arabic, French, and Armenian in 2008. 
The Communication Skills Program offers two core writing courses, Academic English (ENGL 203) and Advanced Academic English (ENGL 204), both of which can be described as text-based rhetoric courses. The pedagogical approach is closest to English for Academic Purposes in the sense that the courses are focused on providing for the practical needs of the students in the university. Students read and discuss texts grouped around particular themes, are introduced to composing strategies (such as drafting, peer review, and editing), learn to search library databases, and are expected to write using sources. Students who are admitted to the university but whose English test scores indicate that their proficiency is not strong enough for them to participate in general coursework may be placed into the Intensive English Course (ENGL 100A or 100B) specifically designed to prepare students for successful performance in the regular university program or the Enrichment Course in English (ENGL 102), which continues to develop students' English language vocabulary, speaking, listening and writing skills. The program also offers two advanced discipline-based writing courses: a business communication course for Business majors and a technical communication course for Engineering and Architecture majors. The writing teachers in this program, usually AUB graduates, were for a long time almost all Lebanese, though recently about 10 instructors have been hired from abroad to staff academic English classes.

\section{Participants and Recruitment Procedures}

The research represented in this dissertation was conducted from April till August 2012. My ethnographic study aimed to combine perspectives from both faculty and students of academic writing courses and courses on the theory and practice of 
translation. I invited teacher participants to participate in the study through contacting individual teachers of ENGL 203 (Academic English), ENGL 204 (Advanced Academic English), and ENGL 233 (Introduction to Translation) offered in Spring and Summer 2012 via email. ${ }^{31}$ Through my email correspondence, I scheduled interview appointments with interested potential teacher participants, who were encouraged to voluntarily initiate contact with me (see Appendix A for sample recruitment email). I also arranged with all the teachers of the aforementioned courses for brief class visits (3-6 minutes) for making a short announcement and presentation about the study, its purposes, and methods. After introducing the ethnographic study to the students of all the English classes of interest to this research and addressing their questions and concerns, I asked interested students to sign up for face-to-face interviews by supplying their contact information (preferably email address) and three possible times for interview appointments, and I arranged for the interviews by contacting each potential student participant individually.

I collected interviews from a total of 55 participants (14 faculty members and 41 undergraduate students). The faculty members included 12 writing teachers, 1 translation instructor, and a foreign language instructor of French courses in the civilization sequence program. I had originally planned to interview only academic writing and translation instructors; however, I had to change my initial research goals as several student participants referred in their interviews to the unique pedagogical approaches adopted in beginning and intermediate level French courses that enabled cross-language relations between English, French, and Arabic in both written and oral communication.

\footnotetext{
${ }^{31}$ Potential teacher participants were identified as instructors of English 203, 204, and 233 through online course listings for those particular semesters. Email addresses of teacher participants were obtained from the English Department website.
} 
It, therefore, became very important for me to include in my research the voice of a teacher of other modern languages in order to better identify shared concerns and differences in language perceptions and pedagogy. The fact that women represented a significant majority of my teaching participants reflects a common trend in the communication skills program in particular, which is predominantly staffed by female instructors, and the teaching profession in general. As for the 41 undergraduate students recruited for this study, they represented a diversity of disciplines, educational, linguistic, and cultural backgrounds, gender, ethnicities, and religions. While the overwhelming majority of the student participants were Lebanese, one student was Syrian, one was half Italian, one was Tunisian, another was half Cypriot, 2 had a dual Lebanese-Canadian citizenship, and 3 others had a Lebanese-American dual nationality. A total of 16 student participants were enrolled in various sections of the translation course, 6 in the academic writing course, and 19 in the advanced academic writing course. See Appendix A and B for additional demographics information for both teacher and student participants.

\section{Data Collection and Analysis}

Data for this project was collected from a range of sources, such as official institutional documents, individual instructional materials, classroom observations, structured interviews, and a method of "talk around texts." At the heart of my research project was my intention to complement "textual" analysis that chiefly predominates research in our discipline with empirical data that sheds light on meaningful and coherent instances of spoken and written language use (see Broad 198-200). Of particular interest to me in this project was examining how language perceptions and claims about language 
policy and practice compare to the actual workings of these by both teachers and students in the writing program and classroom. In order to explore what ideologies of language are being played out in post-secondary language and writing instruction, I collected and examined institutional documents, such as course descriptions, program policies and guidelines, and mission statements. During the interviews with teacher participants, I gathered various instructional course documents from both communication skills and translation courses, such as course syllabi, writing assignment prompts, lesson plans, handouts, and, worksheets. As Anis Bawarshi argues in "The Genre Function," each of these genres "constructs a different sociosemantic dynamic" that heavily shapes teachers' as well as students' "identities, activities, and relations within the situation type" (352). I conducted a rhetorical analysis of all official institutional documents and individual instructional materials in order to examine what language ideologies get played out, how language standards are perceived, articulated, and reinforced, and whether or not language diversity is acknowledged and promoted and how. I also collected descriptive field notes based on my observation of three different sections of introductory courses to translation in order to explore how monolingualist notions compete with translingual realities in the teaching of translation and how students make sense of conflicting approaches to translation.

I conducted thirty-minute structured interviews with teacher participants to inquire in more depth about the nature of language relations emerging in their course materials and official institutional documents and to discuss the underpinning assumptions about English, other languages on the ground, and their corresponding speakers (Refer to Appendix C for sample interview questions). During these interviews, 
I also worked with selected interested teachers on the design of writing assignments of their own choice and how they think they might rework these in ideal translingual teaching situations and also on how they would respond to alternatives to conventional academic forms in writing samples I had provided. In some cases, teacher participants offered additional data sources that I mainly used in supplementing the interviews, such as invitations for visits to their own classrooms, sample textbooks, and oral discussions of student texts and writing assignment prompts.

Additionally, I conducted twenty-minute audio-taped interviews with participating student informants to inquire about the nature of their translingual language practices both inside and outside the classroom for a better understanding of how they were shaping language and to what specific ends, and how well they thought their teachers actually respond to alternatives to conventional academic forms in their college writing and language use. I began by asking participants to describe their academic history in order to get a brief idea about their past and present literacy practices. In designing my interview questions, I was attentive to moving beyond simply conducting an "enumeration" of languages used by student participants through asking them to identify their home language(s), dominant language(s), and contexts in which they used each separately (e.g. How many non-English languages/ English varieties do you use?; What is your first language? Second? Third? Fourth?; Which language(s) do you speak at home? with friends? at school?; What language(s) do you think in? write in? speak in?). Questions like these, I believe, echo residual monolingual directions towards the quantification of language and the compartmentalization of language practices into disparate spheres that an emerging ideology of translingualism contests. They continue 
to revive the problematic ideology of "countability" and "singularity" of language under which languages are perceived as "separate entities" and identifiable objects that can be assigned to and located in specific territories and not others (Pennycook 82). As Pennycook argues,

[t]o render diversity contingent on the numerical representation of languages is to focus on languages as entities rather than on linguistic resources, on the quantitative strategy of language enumeration rather than the qualitative understanding of the traffic of meaning (68).

In contrast with common tendencies to assume that the "diversity of languages" is the central way of understanding language diversity (see Pennycook 97-100), my interview questions focused on students' perceptions of and attitudes towards local language practices, how they are shaping language and to what specific ends, and their experiences with and concerns about working with English in the writing classroom (see Appendix C).

I also conducted a second, third, and sometimes fourth round of one-hour long interviews with 8 interested students for a more focused discussion about the relation between their local language practices and diversity of meanings in their relations and interactions (also see Appendix C). I adopted a method of "talk around texts" developed by Roz Ivanič in Writing and Identity and also adopted by Theresa Lillis and Mary Jane Curry in their recent work Academic Writing in a Global Context. This method is a powerful tool for generating more discussion with student writers about wide ranging "contextual as well as text-specific issues" (Lillis 176). It involves talk between the researcher and participant on some form of text that the participant is writing or has written, and this kind of talk not only helps focus attention on certain linguistic features 
in the text but also helps the researcher tease out the sociocultural and sociohistorical contexts behind such linguistic choices and how they relate to specific moments in the participants' life and literacy histories (Lillis 176). During those extended conversations, I conducted with the help of students a close reading of various writing assignments of their own choice (e.g. multiple drafts of essays, research paper drafts, peer review forms, writing projects, classroom assignments, reading responses, and reflective journals) and a discussion of their current revision plans and strategies and of their preferred method of revision in ideal translingual teaching situations. As I combined perspectives from the multiple rounds of interviews about writers' intentions, I conducted a close textual analysis of the rhetorical moves individual student writers made in their own writing in order to explore the specific purpose behind these and how exactly they connect to their identities and life worlds.

After collecting detail-rich interview data, I began my data analysis with reading interview transcripts and allowing categories, themes, and relationships among these to emerge from participant responses. ${ }^{32}$ In order to help me in organizing, describing, and theorizing from the data, I used my own research questions and the research literature in generating my code scheme. As I wrote analytic reflection notes and compared them within and among interviews, I paid close attention to the participants' use of language and the emergent meanings in their own narration of personal experiences. I looked not only for patterns among the data but also for the distinctive qualities in each participant's responses, thereby working towards a realistic representation of the participants' perceptions and experiences. My analysis of the interview data revealed some patterns

\footnotetext{
${ }^{32}$ While also keeping in mind that one confounding property of categorical and thematic construction in qualitative inquiry is that data cannot always be precisely and discretely bounded as they are at best, operating within fuzzy boundaries.
} 
and major recurrent themes related to language perceptions and actual language practices while at the same time indicating the uniqueness of each participant's perceptions and experiences. As I compared interview transcripts and field notes, I looked closely at instances of repetition in the participants' responses that might indicate certain issues of concern and importance to them as well as repetitions in my responses to their comments. In my analysis of the interview or textual data, I use pseudonyms when referring to participants unless they had requested that I use their real first names.

I analyzed the transcriptions of interview-related data following the principles of Alastair Pennycook's framework in Language as a Local Practice that views language as a local practice and as always emergent and located in the everyday doing of language over time and across space. Under this theoretical framework, Pennycook examines how social and power relations, identities, and knowledge are constructed through written and spoken texts in various social and cultural settings. More particularly, Pennycook's project takes up the challenge of providing tools for understanding language, literacy, discourse, genre, and style as social practices with ideological underpinnings and intricately linked to broader social and political concerns. With a critical lens towards the larger socio-political and socio-cultural ideologically shaping linguistic-discursive practices and texts, this approach to language has helped me investigate how multilingual writing students produce and negotiate meanings across difference and how their language practices are shaped by asymmetrical relations of power and the wider social and cultural structures in the institution of which they are part and in the wider multilingual society within which they live. 


\section{Politics of Location and Researcher Positionality}

Kirsch and Ritchie in "Beyond the Personal: Theorizing a Politics of Location in Composition Research" propose that a "politics of location" enables a collaborative, reciprocal, equitable, dialogic, and mutually beneficial relation to both participants and researchers. As composition researchers, Kirsch and Ritchie argue that we need to critically examine how our own gendered, cultural, linguistic, professional, ethnic, racial, and personal histories influence the way we shape our research. Following Kirsch and Ritchie's recommendations, I discuss in this section how my own observations and representations are filtered and mediated through my own cultural, educational, ideological, theoretical, and pedagogical histories and positioning. Questioning the situatedness of my work and my own subject position, I realized that my insider status to the Lebanese and more particularly the AUB community helped me avoid some of the challenges that foreign researchers might face in lacking sufficient background information and therefore, more easily situate my findings within the larger historical, economic, geopolitical, political, and sociocultural forces. This also assisted me in overcoming some of the power differentials that foreign researchers might encounter in coming from a colonial community and gave me the opportunity to deepen my understanding of the contexts in which my research participants lived and worked. My identity of an academic researcher who is also an insider most likely played a role in participants' perceptions of me as familiar, non-threatening, and possessing a common background and information about the program and the institution, all of which facilitated the progress of the interviews. 
However, when thinking about my positioning as a researcher who was part of the AUB community but is currently an outsider, this hybrid position also interfered with my own objectivity in representing my research participants, particularly writing instructors. The most challenging task I faced in this study was balancing out conflicting past and present allegiances and fairly making spaces for discordant voices and for alternative perceptions about language relations in composition pedagogy, especially those voices that complicated and challenged my own translingual dispositions towards language use and its instruction. I was faced with the ethical decisions involved in qualitative research, specifically interview-based research, of thinking about ways in which I can portray contested monolingualist dispositions towards language use without accidentally "betray[ing]" my teaching participants, particularly those to whom this research could result in "bad news" (Newkirk 4; see Thomas Newkirk's discussion of the ethical dilemma of seduction and betrayal in qualitative research). Though I ended up showcasing some of my teaching participants in a negative light, I recognize that most literacy laborers in my study are working under institutional hierarchies and structures and socio-economic, political, and ideological conditions (for a more thorough discussion see Chapter Five). Adopting a detached, defamiliarized, and objective perspective while representing the nature of language policies and pedagogical and assessment practices in writing classrooms that did not show deepened sensitivity, acceptance, and tolerance towards language and language difference was a near impossible task. This was particularly difficult after listening to my student participants voicing their dissatisfaction with their teacher's responses to language difference in their own writing and sharing stories of their struggles and frustration as they negotiated dominant polities and 
pedagogies. In my attempts to negotiate my own subject position, the way I represented and interpreted my teacher participants' treatment of language diversity was also influenced by my own experiences as someone who is also constantly: thinking, living, and composing in translation; negotiating cultural, linguistic, and even disciplinary differences; and working through points of friction between my own dispositions towards language use and those of my various professors and colleagues. After all, as Lulu Sun argues in "Presenting and Mispresenting Students: Constructing an Ethic of Representation in Composition Studies," representation is not only the art of "construing" but the art of "constructing" and "composing" experiences in light of the specificity and complexity of personal, material, economic, and political conditions (see also Sullivan).

Though most of the teaching participants in this study were my previous colleagues, close friends, and sometimes even teachers and though I was presented to all potential student participants by most teachers of writing courses as a local, an insider, and a previous AUB colleague, power differentials were inescapable in my research. Both teacher and student participants perceived me as a multilingual writing specialist who had received her training in a renowned American institution, and this potentially influenced my work with them and the responses of my participants. For instance, my perceived position affected my interactions with students like Nathalie, Maria, Naser, Christophe, and many others who voluntarily came to me with a pile of writing samples asking for my advice on how to address their language difficulties. Also, some teachers who complained about not receiving appropriate support and training on how to best deal with issues of language diversity and difference in the academic writing classroom directly asked for my professional advice on redesigning some writing assignment 
prompts under ideal translingual teaching situations. Such power differentials hindered my attempts to elicit responses from my researcher participants about the actual nature of their negotiation strategies in light of constant tensions between monolingualist ideologies and translingual realities in their own labor with literacy. Most of my research participants kept asking about my own views as a researcher and a specialist working on issues of language use and language difference in writing.

In order to ensure the accuracy of my representations and interpretations, I incorporated a range of sources of data from field notes, structured interviews with teachers and students, and textual analysis of written materials (student essays, instructional materials and assignment prompts, and official institutional and programmatic documents). A number of student and teacher participants showed great interest in reading sections of this study, which included my representation of their language perceptions and practices, and summaries of my own conclusions, and offered to provide their own review and responses to various drafts of my work. Though I did not invite the interpretive initiative of my own research participants in order to verify my analyses and theorizations, the "talk around texts" technique helped me bring student writers' voices to the center of my explorations of what's involved and what's at stake when negotiating language difference in academic writing. In other words, it enabled me to pay special attention to their own perspectives and what is authentic and meaningful to them. It also helped add a sense of commitment to collaboration in the research process through working with student writers and not on them, and instead of speaking "for" or "about" them, they speak for themselves. I was able to provide spaces for multivocality that directs research away from becoming a monologue through including excerpts and 
direct quotations from my informants' actual stories in their own voice but also drawing analytical comparisons between different informants' literacy experiences to illustrate how conflicting language practices and ideologies operate under varying economic, social, cultural, historical, and political conditions, vocational aspirations, and linguistic affiliations. 


\section{CHAPTER FOUR}

\section{REPRESENTATIONS OF LANGUAGE IDEOLOGIES: LANGUAGE POLICIES, PERCEPTIONS, WRITING PEDAGOGIES, AND CURRICULUM DESIGN}

In this chapter, explorations of the $\operatorname{local}^{33}$ at the American University of Beirut afford us a way of looking at how policy statements, language perceptions, and pedagogical practices are closely intertwined and are constantly informing and informed by one another. Certainly, however, the dynamic and interactive way in which language policies that are imposed from the top down interact with the way they are interpreted, negotiated, and enacted (or even resisted and appropriated) from the bottom-up makes it sometimes impossible to neatly differentiate between one level and the other (see Garcia, "Bilingual Education"85). As I argue in the next chapter, an eye towards local language relations emerging on the ground, in policies, and in teaching practices offers a pressing tripartite lens that lies at the core of rethinking language policies, beliefs about language and language use, and current composition pedagogies along translingual lines. My analysis in this study of the ways in which local language policies and individual course materials reinforce monolingual dispositions toward language and language difference leads me to locate current work in composition in a "post-monolingual" condition in the

\footnotetext{
${ }^{33}$ The notion of local in this project refers to the temporal and spatial contexts of student work, the diversity of their past, present, future life as well as the social contexts of their lived experiences in and outside school.
} 
sense that both writing students and teachers are constantly navigating between policies and practices aligned with monolingualism and translingual orientations.

\section{Language Policy Statements at AUB through a Local Lens}

In its mission statement, the American University of Beirut deeply proclaims adherence to a liberal philosophy that "seeks to foster tolerance and respect for diversity and dialogue" (http://www.aub.edu.lb/main/about/Pages/mission.aspx). However, when it comes to demonstrating actual commitment to language diversity, AUB is typical for lacking explicitly stated language policies that position English in relation to existing linguistic resources or any official statements regarding language and language use, ${ }^{34}$ aside from a single statement on its official webpage that declares English as the sole language of instruction except for courses in the Arabic Department and other language courses (http://www.aub.edu.lb/main/about/Pages/index.aspx). Of the few policies is the English language proficiency requirement that requires all undergraduate students prior to enrollment at the university to "demonstrate a level of English proficiency consistent with the demands of a program carried out almost exclusively in the English language" (AUB Undergraduate Catalogue 2011-2012, 34-35). Interview responses from the overwhelming majority of teachers do actually suggest the absence of explicit policy statements. Or as one of the teacher participants noted, "if it actually exists, it is not made powerfully visible." Failure to articulate an official position regarding the presence and active use of local language practices alongside English(es) among AUB's students, faculty, staff, and alumni contributes to the invisibility of linguistic heterogeneity on its

\footnotetext{
${ }^{34}$ Personal communication with Dr. Lina Choueiri, Assistant Chair and Associate Professor of English Language
} 
campus and may run the risk of linking the value of intellectual work to English

monolingualism. In my interviews with students, several students referred to a statement of correct language usage in the undergraduate university catalogue of the academic year 2011-2012, that warns against "substandard" forms in students' written communication:

\section{Correct Use of Language}

Facility in clear, correct, and responsible use of language is a basic requirement for graduation.

Papers (term papers, essays, or examinations) that are ill-written, no matter what the course, may receive a lower grade for the quality of the writing alone.

The final grade in any course may be lowered for consistently substandard written or oral expression; in extreme cases a failing grade may be given for this reason alone.

(AUB Undergraduate Catalogue 2011-2012, 49)

"Your bad English can make you fail a course," as one Biology, pre-med student stated. I was later informed of administrative decisions to remove this statement from the new catalogue for the academic year 2012-2013 as it was taken for granted that students must have already demonstrated mastery of SWE rules and conventions at the end of their academic career or else they wouldn't have made it that far. The absence of explicit institutional or programmatic language policies combined with the presence of similar guidelines that dictate "correct" forms of language use has not only propagated among students a normalized assumption that academic writing following monolingual English native-speaker norms is self-evidently desirable but also resembles unintended efforts towards the containment of significant forms of language difference in writing. 


\section{Multilingual Students' Language Perceptions: Representations of English}

A close description of the working of language practices locally necessitates an understanding of the language ideologies lurking behind particular understandings and perceptions of language, and particular ways of orienting towards language (see Pennycook; Tardy). As I asked student participants for permission to record their interviews, 4 students made apologetic comments for their "catastrophic" English, as one nursing student put it, thereby showing a great deal of concern about their fluency and nonnative-like pronunciation and lack of confidence in their language abilities. The fact that they said this when speaking to someone, like myself, who had no claim to a "native" English speaker status is a clear indication of the depth of the ideology of monolingualism in ways more forceful than if such comments had been made to a foreign researcher perceived as a "native" English speaker.

At the onset of the interviews, 6 different students asked the same type of questions, "Does this interview have to be in English?", "Is it all going to be in English?", or "Do I have to speak in English?", "Is it ok to respond using the Lebanese way, you know like mix English with French and Arabic?" Such questions carry a great deal of significance as they indicate that student participants may have felt more comfortable talking to me about their ambivalence toward English, as well as talking in other languages as opposed to an English monolingual researcher. Clearly, this further supports Canagarajah's call for more multilingual scholars in conducting research on the composing practices and negotiation strategies of multilingual writers as they "shuttle 
between one language/context/discourse and another" ("Writing Pedagogy of Shuttling" 591).

As student participants described how they operated under exponential pressure by a variety of material conditions to properly function in English-dominated classrooms, they expressed emotional and visceral reactions of ambivalence towards English. We can see these in some of the images they used to describe English: "A rock that you are forced to swallow," "I hate English," "I don't like English," "I feel blocked by English," "I have really narrow spaces with English," "I'm writing in English about things that don't happen in English in our society," "I feel tortured when writing in English," "I feel trapped when I try to speak in English," "I'm always suffocating when using English" were among the images that students used to express their struggles as they worked their way through academic English work. These emotional, psychological, physical, and visceral reactions are not surprising as students are under exponential pressure by a variety of material conditions to properly function in an English-dominated world. Projected as an obstacle resulting either in choking, abhorrence, blockage, confinement, detachment, torture, entrapment, and suffocation, "English has been declared 'guilty"' by these multilingual writers (Kapp 608). They perceive English as generating barriers rather than a neutral medium for direct access to and transmission of knowledge, as claimed in the university policy statement. To better represent the array of student perspectives toward English monolingualism at AUB, I will now share the experiences of my student participants.

Nathalie was enrolled in a French-medium school for her primary and secondary education. Currently pursuing her degree in Computer Communications Engineering and 
two minor degrees in Math and Business, she had to cope with the unfamiliar academic expectations of an American university. Nathalie's sense of her relation with English is heavily weighed down by the story of her younger sister being pressured by their father not to get enrolled in a French-medium university that is in the vicinity of their residence area because, as he has put it, "the whole future is in English." Under the pressure of linguistic necessity and expediency, Nathalie described how her sister was forced to give up her passion for French literature and her dream of becoming a journalist one day and had to reinvent a new fondness for Business, since AUB did not offer degrees in French literature or journalism. Because as her father put it, "English is the language of technology, science, and business," both Nathalie and her sister, who reside in Zalka, a northeast section of Beirut, are now forced to grapple with the expenses and the mental and physical strain of commuting for four hours by bus back and forth to AUB every day.

On top of these strenuous conditions, Nathalie expressed feelings of frustration and anger that her teachers did not attend to or effectively respond to her immediate writing and language concerns. She faced difficulties developing her ideas as her sentences always turned out to be deviant from the syntactic conventions of SWE. As Natalie explained, "I always feel I' $m$ hitting a wall when I have an idea and I can't write it in a good way that is satisfying to my English teacher." As she described her experiences, she voluntarily presented me with a bunch of her graded writing assignments from current and previous English courses, asking for my advice:

Everyone keeps saying "read, read, read." I know I should read more in English but it's not fast enough for my language to improve and I honestly don't have that much time. I want a fast solution.... . I get frustrated when I read "Visit the writing center. It will help you a lot," or "Avoid language mistakes," or "Revise language use." I feel trapped because I don't know what to do. I want to be a better writer. 
Obliged to come to terms with university writing practices by following her teachers' suggestions, Nathalie described having to utilize all conceivable means and to exert extraordinary efforts to meet the academic writing expectations. In an increasingly multilingual age in which the changing realities of popular culture and the booming entertainment industry are promoting multilingualism, Nathalie and her sister's moviewatching experiences transformed into remedial English lessons involving reading aloud activities, looking up new terminologies, and keeping vocabulary word lists. While growing engagement with globally consumed movies with closed captioning and subtitling services are allowing for new multilingual experiences, Nathalie and her sister spend their spare time watching English language broadcasts on cable TV with the hopes that these approaches might improve their American English fluency and pronunciation ${ }^{35}$ :

We made it a point to only get movies with English subtitles and started reading romantic novels [made into movies], like The Notebook and Dear John. And sometimes we read the novel and then watch the corresponding movie.

Directing all her energy towards the attainment of diction, pronunciation, and grammar meeting idealized native-English speaker norms, Nathalie expressed her aspiration to join professional circles, efforts that she saw as largely contingent on her mastery of standardized English usages:

I love to go abroad for new engineering projects and meet new people in my field. I want to attend conferences and discuss my ideas in the U.S. and Canada and be a link with my Arabic world. And I don't want my language to be the barrier.

\footnotetext{
${ }^{35}$ Also compare to Prendergast's account in her critical ethnography of Slovakians' efforts at learning and maintaining English fluency at home.
} 
Nathalie's allegiance to a monolingualist view of successful communication in English as the mechanical reproduction of standardized American English usages creates problematic pressures on her literacy learning and development. In an increasingly globalized world where as Nathalie states, "the more languages you know today, the better," her linguistic and cultural resources are being confined by monolingualist obsession with native-like fluency. As Nathalie explains:

I'm starting to forget the French language at AUB. I'm trying to recover what I've lost and maintain my proficiency level by reading more French books. When I first came to AUB, I thought I would be gaining another language. But now, I am losing one to another. French keeps getting far. I've realized recently that I'm losing this connection with French. But I don't want to lose it. It represents my childhood, a phase in my life when I was at school.

Here lies the dilemma experienced by language and literacy learners attempting to amplify their presumed Englishness for the promise of improved academic and career prospects. Nathalie's comments echoes monolingualist ideologies that propagate the myth that language learners can recover expertise in other languages after working with English, a near impossible task bound to generate even more frustration and anger. With a reductive view of languages as separate entities to be locked in and picked up again at different times and in different spaces of one's life, Nathalie's language perceptions rest on monolingualist assumptions that the learning of one language has no effect on one's engagement with other languages. The possibility of actively reworking their current and emerging relation with English in light of strong, continual relations with French or Arabic is never acknowledged nor legitimized in curriculum design and thereby, in their own imagination. 
Along the same lines, another student participant, Maria, an Education major, describes her linguistic struggles as her parents made her switch from a French-medium school into an English-medium school in Grade 4. According to Maria, though she still views this abrupt decision as a "form of punishment" for she had to adjust to relearning all scientific and mathematical concepts in a new language, her parents take pride in discovering that "English is an international language" early on before it was too late for their only daughter to acquire what they had perceived as a language "gem." These individual accounts demonstrate the extreme measures some parents are willing to take just because English is the global language, such as either forcing their children to switch from a French to English educational system sometimes even as late as middle school or changing their children's career paths from journalism, translation, law, or French literature into any of the degrees offered at English-medium institutions like AUB. ${ }^{36}$

Just like the parents of Nathalie and Maria, to whom English is a lifetime investment and a "life insurance policy" (Lu, "Living-English" 48), Christophe perceived access to English as a tool for educational and professional opportunities and guaranteed future economic development and success. Born and raised in the heart of Ashrafieh, one of the oldest Christian cities of East Beirut, and a graduate of Grand Lycée FrancoLibanais, one of the prestigious French lycées in Lebanon, Christophe described the complexity and diversity of his past and present language relations in light of the hegemony of English in educational landscapes and the global business world:

I define myself by French. I write in French. I compose plays in French. I read in French. I think in French. I live in French. I don't know how to be honest but in French. I am sad and happy in French. We tend to forget that English in Lebanon

\footnotetext{
${ }^{36}$ For an illustration of the domination of English Only assumptions in popular representations of English and ideal English users, also see Lu's account of the popularity of surgical fixes in China and South Korea under the exponential pressure to use English in an "accent-free" way (601).
} 
came after French. I despise the fact that we're trying to eliminate this part of our national identity and I blame it on English. (emphasis in transcript)

Continuing to question the ways in which those in powerful positions to grant or withhold educational and employment opportunities have come to think about English within colonialism, post-colonialism, and modernity in Lebanon, multilingual students at AUB like Christophe are forced to negotiate tensions relating to maintaining the symbolic capital associated with the possession of standardized English usages on one hand while remaining true to one's interpretation of self and the world on another. Explicit reactions against the effects of a longstanding English Only ideology in various pockets of the educational and professional realm that clash with lived realities and the translingual nature of language relations on the ground are most visible in Christophe's comments:

We're living this relationship between languages every day so why not talk about it, discuss it, take advantage of it, incorporate it. We have three main languages in one small country. It's a force. But we are forgetting it.

In addition to invoking the cultural and historical specificity of visions of language in that specific location, Christophe not only declared English guilty but also pointed towards the policies and educational practices of linguistic expedience that have distorted existing language relations in ways that propagate forgetfulness about the specific history and linguistic realities in the territories of pre-colonialism, colonialism, and post-colonialism in Lebanon. Christophe admitted taking what he describes as a "Machiavellian" stance towards English, thereby suggestive of linguistic necessity and expediency. As a Chemistry student with a dream of pursuing his medical studies in the U.S., Christophe explained that: 
the choice of enrolling in an American institution is hardly a choice at all; thinking of opportunities in the future, it was the obvious choice though it meant sacrificing my own comfort. After all, the U.S. is the number one country in research and medicine and is the center of mostly everything in the world.

Just like Christophe, Nathalie, and Maria, many students I've interviewed from across the disciplines have expressed their aspiration to join their dream professions in a capitalist global market and enhance their career prospects, efforts that they see as largely contingent on their mastery of standardized English usages. To these students, English is treated as an "unavoidable" and imperative commodity to "buy into," as Catherine Pendergast puts it, both materially and psychologically (8). Multilingual students in this study projected English as something to use and heavily invest their time and money in without entertaining the possibility of continuously reworking English. Another students' construction of language speaks to this representation of English as fixed rather than fluid English, one discrete from rather than inevitably intermixing and intermingling with other languages, discourses, and language practices on the ground. For instance, Ayla, a Biology pre-med student, explained that she might use the Arabic $w$ or the French $e t$ instead of 'and' in ungraded freewriting pieces, "but when it comes to writing essays, you can't use it. This is not 'real English'. You need to separate and isolate yourself when using academic English."

As students like Nathalie and Christophe, who pride themselves in being Francophiles, narrated their present struggles as they grappled with the pressures of demonstrating fluency in a standardizing global English deemed the only acceptable way of using English in the eyes of those in power, they were very adamant about refusing to be labeled as failures or having any signs of linguistic imperfection: 
I consider it a personal failure if I don't speak English well.

(Christophe)

My English-educated friends make fun of an Engineering professor who mixed up between "button" and "bottom" in his pronunciation and misspelled it in the final project. I don't want to become like him. I feel ashamed when I make language mistakes when speaking in English. I won't be satisfied with myself. I'm always concerned about sounding correct. Correctness in my opinion is the only way to get my ideas delivered the way I want them to. At AUB, and in the future, if your language presentation is weak, people won't take you seriously. El Anglais bta3ti wahra w byi7termooni aktar ['Correct English grants its users the veneration and respect of others'].

(Nathalie)

Also pertaining to my investigation of the politics of language in writing instruction at AUB, a sophomore Graphic Design student from Haret-Hreik, a mixed Shiite and Maronite Christian town in the southern suburbs of Beirut, also faced similar experiences of difficulty in the negotiation of difference between language relations within and outside academic writing contexts. Naser was exposed to the intricacies of the Arabic language at a very early age by his father, who is a professor of Arabic Literature. He described being engaged at home in advanced reading and writing of various forms of Arabic poetry and prose: "I define myself by Arabic. I write in Arabic. I read literature in Arabic. I think, live in Arabic." Naser presented two competing definitions of academic writing based on differences in linguistic medium. He viewed writing as "a reflection of the self and others, the discovery of meaning and value, and a form of interaction and creating unique relationship not only with the self but the world." He complained to me about the difficulty of writing this way in the college writing classroom about "things that don't happen in English" in Lebanese society. His view of academic English writing 
resembled, as he put it, "a set of skills we have to learn for the use of it." As Naser illustrated,

through English, we can't go back to my previous definition of writing as autobiography, reflection, creativity and authenticity. You have a set of standards and rules for writing and you have to choose from them as they are when writing your English papers not because you really care or have a voice to express but because they are the few right things. You need to separate and isolate yourself when using academic English.

Clearly, we get a sense through Naser's responses of the politics of language involved in identifying specific kinds of writing as academic and others as nonacademic ${ }^{37}$.

Naser showed concern that there appears to be no room in the academic writing classroom for his Arabic linguistic and literary expertise that is critical not only to his sense of self but more importantly to his career prospects. Combining his passion for graphic communication arts and design with his expertise in Arabic, Naser constantly worked with Arabic calligraphy and typography. He explained how he always needs to "read and write in Arabic, especially when designing book covers and posters, working with packaging and label designs for new products." Nasser described how much he enjoyed working on two different projects in a Graphic design course in which his professor created spaces for students to mobilize their expertise and motives in languages and genres distinct from the language of instruction and dominant disciplinary genres. Nasser chose to compose in Arabic a travel narrative describing creative designs in the cityscapes of Beirut and an autobiography about his experiences in the department and his growth as a professional. The kind of writing that Nasser experienced in graphic design sharply contrasted with the more strict policies of language use in academic

\footnotetext{
${ }^{37}$ also see the next section on teachers' language perceptions for more on this issue of competing definitions of academic writing in relation to language difference
} 
writing courses. Making explicit comments against the effects of English

monolingualism that dominates writing instruction in ways that clash with students' lived realities and professional aspirations, Naser explains:

You can't detach us from our native language like this in the English writing course when we're daily exploring the world through Arabic. I'm writing in English about things that don't happen in English in our society. Arabic provides a larger context I can work with even in graphic design and not like English where I have really narrow spaces.

Like Nathalie and her sister, Naser's academic writing experiences lead to his construction of English as a "narrow space" that isolates meaningful and authentic aspects of his relation to self, others, and the world.

The comments of several students about how guilty and disappointed they were that they were "growing apart from" their own native Arabic language or French demonstrate the importance of the preservation of these linguistic affiliations and attachments to AUB students' emotional, personal, social, and intellectual development. Though the primacy and promise of Standard English looms large for these multilingual students, its ostensible neutrality and inevitability is strongly problematized. The students I've worked with in this study, the like of Christophe, Maria, Nathalie, and Naser, expressed their frustration with dominant polities and pedagogies that announce what English can do for them and that assign agency to "English itself" without acknowledging the agency of language users and writers in shaping and reshaping English. In other words, they are struggling with an ideology of monolingualism that depicts learning and writing in English as independent of rather than interdependent with their relation and affiliation with other vibrant languages. 
Another multilingual student showing a drastically different sense of authority when using English wishes to be called Diva. Diva has lived her whole life in Greece, and recently moved to her dad's home country, Lebanon, to pursue her education at AUB. Born into a family with a Greek non-Arabic speaking mother and a Lebanese nonGreek speaking father, English is the link language that, as Diva describes, "binds the family together and brings everyone closer." The Greek language gives Diva a sense of uniqueness and "privacy with her sister and mother," that English cannot give as "almost everyone nowadays knows English.” Arabic strongly links Diva to where she resides now, to her father, her relatives, and the people she knows in Beirut and represents "the Arab in me." "There are these two sides in me, Arabic and Greek, and English is in the middle; and it's just what keeps me and my family together." Despite possessing closer affiliations and greater expertise with English than students like Nathalie and Naser, Diva still joined her peers in refusing monolingualist assumptions that reinforce the very "oneness of English" (Pennycook 80; emphasis added). As Diva explained,

our English is different from the English that other universities in other countries in the world teach. We have different ideas, we come from different worlds, we live in different language worlds.

Diva's sense of empowerment when communicating in English is contingent on a translingual approach to all three languages that matter to her identity and life world in ways that mesh them all together. As she explains,

I cannot communicate in English only. Nor can I communicate in Greek and Arabic alone. My sentences don't make sense to me at least. Right now, I live, think, and write in all: Greek, Arabic and English

In one of the response papers Diva composed for her academic writing course, she showed a strong allegiance to maintaining the nature of cross-language relations 
emerging in her life worlds. In the opening paragraph to her paper on negotiating various language and cultural worlds, Diva used the Lebanese Arabic kalimet, which is the Anglicized version of the Classical Arabic term 'كلمات' meaning 'words' and the Greek phrase les kai followed by its English translation "as if":

I do not have to translate in order for me to write about my childhood, nor do I have to translate now to speak about my present. What goes in my mind is a mixture of words, kalimet - words that make me think in a certain way so that I'm able to express myself les $k a i-$ as if it is all some universal language.

In response to my question about whether or not she thought the use of the term English 'words' and its literal Arabic translation kalimet in "a mixture of words, kalimet" would be marked out as instances of redundancy by a stickler for correctness in writing, she firmly stated that they are not in fact interchangeable in her own writing. As Diva explained, "the English term 'words' is just so plain; it's just words." "But when I think of the Arabic kalimet, I think of the authentic Lebanese jaw with its defiantly frivolous ambiánce even during the worst of times. The Arabic kalimet, is so m'ajja'a [crowded with meanings], you can feel the life inside of it."

While Diva showed signs of actively accommodating her readers' lack of knowledge of Arabic or Greek and assisting their co-construction of meaning in her opening sentences, she chose not to negotiate a footing with her readers in her final statement:

What goes on in my head when thinking, or when I'm speaking to someone is just a list of words. Three languages, one meaning- what they mean to me. I could feel detached, ma ile jledit hadan, kai den thelo na kano tipota. For I don't want to do anything. 
By using non-English codes (e.g. Lebanese Arabic ma ile jledit hadan 'I'm not in the mood for anything' and Greek kai den thelo na kano tipota ( $\kappa \alpha l \quad \delta \varepsilon v \theta \varepsilon \lambda \omega$ va $\kappa \alpha v \omega$

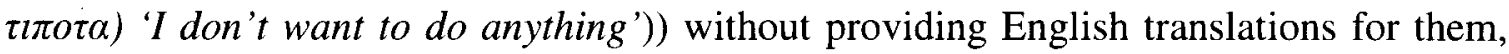
Diva insisted on challenging her readers to grapple with her translingual writing practices because, as she stated, it is only this way of using English that keeps her together. Suresh Canagarajah in his study of translanguaging strategies argues that by refusing to translate, multilingual student writers strategically choose to realign their relationship with their readers and challenge them to work harder for the construction of meaning ("Codemeshing"409). A policy of English-Only dominating academic writing practices, according to Diva, is at odds with the heterogeneity of her linguistic realities and lived experiences:

It's really important to write in this style. We shouldn't be limited by what we should say and how we should say it. We're in an American university but it's all based in Lebanon. yi'ni [the fact is that] we've based our knowledge in Arabic. This is how we live; in both languages, English and Arabic. (emphasis in transcript)

Another example of the active engagement with cross-language work in acts of reading and writing is that of KAPPA, a nontraditional sophomore student in Landscape Design. Before he decided to move to Beirut, KAPPA lived and studied in his hometown Trieste, a city in northeastern Italy. KAPPA's mother piqued his interest in the works of Lebanese writers like Amin Maalouf in French and of Khalil Gibran in English, while his father, who is Italian, exposed him to literary masterpieces by Dante and Sicilian novelist Leonardo Sciascia. 
In the academic writing classroom, KAPPA constantly negotiates English through what he likes to call the Triestino moda de dire or "way of saying and communicating things," which is generally discredited by Standard English usages. In Kappa's words, I feel my English is enclosed in rigid structures and sometimes it's nice to break the structure through this moda de dire. I'm not always able to say what I want exactly in English so I use this moda de dire and I sometimes translate directly from it. It's more me than formal English sometimes.

In a research-based writing classroom, Kappa finds no welcoming room for his moda de dire, which seems to be critical to his sense of self and cultural conditions. However, he still manages to remain faithful to his moda de dire and makes room for cross-language relations through incorporating scholarly work in Italian into his academic English writings. Before doing so, he made sure to get permission from his English instructor to use non-English sources: "It is not something we usually do at AUB. We assume that in an English course, all sources have to be in English." For an argumentative research paper, he was working on the topic of the mafia and its culture of Omerta, or code of silence, and used one Italian book as his primary source, an English translation of another Italian book, in addition to an Italian documentary film. When I asked Kappa about the motivation behind choosing to work with non-English sources given all the challenges the process of working across languages entails, he explained, "I feel original and authentic when I make connections to Italian and Italian scholarly sources; it also enriches my writing in English." When I tried to prompt him to think about how these non-English sources might have contributed to advancing or complicating his arguments compared to an English source on the same topic, he explained that Italian sources helped him, as he put it "get the inside eye of the problem": 
You're getting opinions from the locals and not from Americans about how ordinary people actually think. No other source in any other language can give a better inside view.

Though working with Italian sources would add needed intellectual depth into his writing, KAPPA still felt constrained by the lack of exposure in his academic writing course to the proper methods of effectively incorporating and citing foreign language sources. As KAPPA complained, "I'm not sure how I should cite an Italian source. I am not sure if it's okay to include sentences in Italian in my English writing as my teacher and the students in class don't speak Italian." Kappa showed concern that his readers' lack of knowledge of Italian might "disrupt the rhythm and reading flow" as they might decide to skip non-English excerpts. "They don't talk about my problem in class," he stated. "How do I work with these sources properly? It's strange that they don't do that here when most students know more than one language." While KAPPA persisted in the task of using Italian scholarly sources in his academic work, the fact that he still felt he couldn't do so very confidently and comfortably in the writing classroom is a clear indication of how monolingualism operates at the level of immediate writing practices as a set of powerful dispositions about language use in writing.

Through my conversations with other student participants, some described that maintaining and further developing cross-language relations in written communication is critical not only to their sense of self but in some cases even to their career prospects:

As a Nursing student, I find it very important to use both oral and written Arabic when communicating with patients and explaining important information to them.

Ryan, an electrical engineer from Syria mainly specializing in power and who wants to join his dad's firm in Iraq, regrets not being taught in the technical writing classroom the 
Arabic equivalents for the English technical terms and how to compose various forms of workplace correspondence. As he put it,

I know I will face a lot of difficulties in my job later on in communicating with other engineers, foremen, and workers from Syrian, Jordanian, and Saudi origins.

While the indoctrination of SE rules and requirements is predominantly justified by educators through invoking the demands of the globalized business world, these students seemed to be invoking the need for increased pedagogical spaces for crosslanguage relations based on the demands of the local or regional market. Another pattern that emerged in students' responses is related to differences in language use across disciplines:

In Engineering, they just want you to give the idea. You say it in Arabic; you say it in English as long as people can understand it. A lot of times we're speaking in English, and then someone asks the question in Arabic. We have professors who only speak in Arabic. But in writing, there's no way you can use Arabic. You have to stick to English. Bas [But] maybe in the middle of the sentence.

In business, it depends on the teacher. You go to some class and the teacher might teach you in French, another in Arabic, sometimes in English. It depends on the body of students.

(Emile)

I've been to a class where the teacher could not even speak English but it's mostly Math so we were able to comprehend it. And in class on business ethics and business law, we've reached the section on the Lebanese law, so this section requires teaching in Arabic. We had to master English for the first twenty chapters on the American law and then Arabic for chapters on the Lebanese law. We're lucky to have a professor who practices law in majlis al nouweb [Parliament House] and is fluent in both languages.

(Nadim) 
The kind of linguistic flexibility that these students have experienced when writing and communicating in various disciplines across the university sharply contrasted with the more strict policies of language use in courses housed in the English department.

The perspectives gleaned in this section from all these multilingual students foreground the following observations, all of which suggest the exigence for a translingual approach to writing. First, except for students like Diva and Kappa, multilingual students' perception of their relation with English suggests a deep infiltration of monolingualist assumptions, for instance: (a) seeing English, Arabic, and French as discrete and fixed entities appropriate for distinct social spheres; (b) showing allegiance to a skill-oriented approach to learning writing and fixation on the acquisition of native-like English proficiency and fluency; and (c) treating relations to individual languages as arbitrarily picked up or eliminated as language learners move between discrete contexts and stages of life. Secondly, though their perception of their relation with English is heavily influenced by monolingualist assumptions, multilingual students are frustrated that insistence on English Only instruction does not seem to allow them to sustain complex relations with diverse languages and ways of using English critical to their experiences both within as well as outside the writing classroom. For instance, Nathalie and Christophe's desire to sustain their attachment to French while learning English and pursuing their professional goals; Nasser's need to compose in Arabic for exercising intertexuality in his graphic designs; Diva's strategic reworking of English; and Kappa's intellectual engagement with Italian scholarly work. And finally, multilingual students seek classroom spaces where their sense of the need to address their relation with multiple languages and disciplinary discourses are openly acknowledged 
and actively mobilized. For instance, we see KAPPA requesting guidance in how to incorporate and reference non-English medium writing against the limitations that English Only monolingualism imposes on academic writing, and Diva wants academic work that can help her continue reworking English in light of her ample experience using English as a link language across users of diverse languages.

As they wrestle with monolingual English-Only ideologies dominating curriculum design and writing pedagogies, these four students of diverse linguistic and cultural profiles are differently handling the mismatch between translingualism in their lived realities and the academic curricular insistence on cultivating English as the universal predetermined linguistic medium in educational sites. While Diva boldly experiments with English and constantly puts it to work as a "living" language, the primacy and promise of Standard English looms large for students like Nathalie as well as her sister, even Christophe and Maria. Viewing English as a link language between her different family members as well as her home and school discourses, Diva claims a sense of ownership and authority over English and other languages as she possesses expertise in negotiating English in multilingual situations. There seems to be a resemblance between Diva and KAPPA for whom Italian closely connects different parts of his life worlds. In contrast, students like Nathalie, Christophe, Nasser, and Maria are frustrated and disappointed by the domination of monolingualist assumptions that the goal of language and literacy learning is the possession of native sounding English and the fluent mastery of standardized English usages. These students' struggles illustrate the most damaging effects that monolingualist ideologies can have on students' life and literacy learning experiences. Just like Nathalie and Christophe who possess expertise in and attachment 
to French, Naser has ample Arabic expertise deemed irrelevant in academic English writing classrooms. We see students like Nathalie, her sister, Christophe, Maria and Naser struggling with an ideology of monolingualism that depicts learning and writing in English as independent of rather than interdependent with learning and writing in other vibrant languages like French or Arabic. This illustrates that the problem lies in the treatment of English in the writing classroom as well as in various pockets of education as a reified, stable, and discrete entity and in never entertaining the possibility of reinventing and modifying it for each occasion of reading and writing. It is such reductive notions of English as existing in a monolithic, static form discrete from other languages and discourses that have certainly masked these students' experiences with the actual fluidity and permeability of language boundaries.

\section{Writing Teachers' Perceptions of "Living-English” Writers and their Writings}

Through a process of self-reflection, the teaching participants in this study focused on their meaningful teaching experiences while giving examples of particular instances of student struggle from past and/or present moments in their teaching career, but also with emphasis in some cases on their future plans. Widely conflicting language ideologies and beliefs about language and language use in writing emerged in my interviews with teachers. In this section, I particularly examine how varying ideological stances show up as writing teachers talk about their students and their writing abilities, and describe their own decision-making in the writing classroom in terms of curriculum design, teaching practices, and assessment. In order to attend to the underlying language ideologies, I address the overarching question of: In what ways do writing teachers' 
discourses reproduce, reinforce and/or confront/counter a longstanding monolingual ideology within which they predominantly operate? My interpretation of instructor's responses and conflicting discourses about academic writing in relation to language difference are based on the following: different ways of conceptualizing and addressing language error in student writing; different ways of thinking about and reinforcing standards of language and written English; degree of tolerance towards the range and functions of cross-language activities; and the place of translation and the trafficking of meaning and language in writing. Based on the results of individual interviews, I was able to identify four different levels of commitment to and engagement with translingualism that emerged from teachers' responses:

\section{Immunity against Translingualism}

One group of teachers ( 2 out of 14 ), have relatively strong positions towards diverse forms of shaping language in ways that can best be characterized by total forgetfulness about language diversity or even denial of its influences on student writing. One of the instructors is a local and a holder of a Certificate in Teaching English to Speakers of Other Languages (CELTA), which is an internationally recognized ESL teaching qualification offered by the University of Cambridge. The other instructor is an American with a graduate degree in Rhetoric and Composition and has received no special training in second language writing issues and working with English language learners.

Voicing strong adherence to the hegemony of a monolingual English-Only paradigm, one of the teaching participants declared that "Standard English is immune 
from all those language changes" (emphasis in transcript) and the types of active multilingualism that are circulating widely in sociolinguistic landscapes. As Horner et al. remind us, similar myths about "unchanging, universal" standards for language that have widely propagated among literacy laborers and educators serve the sole purpose of "simplify[ing] the teaching and learning of language" ("Language" 305). Under perceptions of "static" or "uniform" language standards, what such views of language standards do not account for is the important consideration that what constitutes conventions and norms in written communication varies tremendously from one genre to another and from discipline to discipline and over time. Appeals for awareness of such considerations across disciplinary discourse are clearly reflected in the following unsolicited student comment as it emerged in one of the individual interviews with students:

Unfortunately, I am cursed this semester with a teacher who only corrects English grammar. She would go on and on about saying that I should not have long sentences whereas in Sociology, for example, if you read Weber who is infamous for his extremely long and complicated sentences that's all you read. He speaks gold. He's one of the fathers of Sociology; He is the worst of the worst when it comes to that [correct language usage] and it's not incorrect; it's style. And she has the audacity to correct my English when I have a minor in English. I've been really angry about this for months. You don't correct my English when I got a significant academic qualification. For her to tell me that my sentences need to be short so short to the extent that I can't be stylistically eloquent is academic genocide if you want.

With extensive reference to the writing style of German sociologist Max Weber, who profoundly influenced social research, this student seems to be invoking different underlying disciplinary values that are embodied in stylistic variation and rhetorical practices, value systems that writing pedagogies built around monolingual language ideologies do not attend to. By portraying language standards as fixed and unchanging 
rather than fluid, ideological, and rhetorical, this ideology of language standardization prominent among some literacy laborers fails to account for porous, permeable boundaries among languages, discourses, genres, media, and disciplines as these are in constant interaction and intermingling across time and space.

Deep loyalty to the expected norms of Edited American English is strongly justified by this group of teachers with a concern that students can be "hurt by society" as English is the language of choice, especially in global business, as illustrated by the following comments:

It's not all rosy in the outside world; you need to have your good language skills to make it.

My approach is to teach them the standard and not necessarily accept the nonstandard or broken English. We're resistant to tolerating it in writing because that's what they're going to face in the outside business world unless the world changes.

In light of the workings of a monolingual paradigm, rarely is the value of English monolingualism for success and economic prosperity ever questioned and problematized despite research evidence to the contrary (see Garcia). ${ }^{38}$

As they operated under institutional hierarchies and structuring conditions, writing instructors, most notably the local instructors at AUB, regarded the notion of the "native speaker" as an idealized figure. This is clearly depicted in some of their comments about their characterization of good writing: "their [students'] writing should be something a native speaker can understand;" "I expect SE requirements to be met and

\footnotetext{
${ }^{38}$ Ofelia Garcia in "Spanish language loss...: Implications for Language Policy in Schools" provides qualitative evidence from language minority groups that refutes this sociolinguistic myth. Garcia, for instance, argues that despite the high rates of linguistic assimilation by African Americans and by most Latinos in the United States, they have had little economic success. She also gives the example of CubanAmericans that have had the greatest economic success in the U.S. despite the low rates of linguistic assimilation achieved by this Latino group, thereby challenging "the mythical nature" of the proposition that English-Only monolingualism leads to economic growth and greater social mobility (147).
} 
correct English grammar to be used in writing." When responding to instances of language difference in student writings, these instructors indicated that they do so through marking up students' essays for various language errors (collective nouns, subject verb agreement, run-ons, comma splices, fragments, punctuation, etc.); or sometimes even providing extensive explanations of the 'broken' grammar rule both in written comments and one-on-one conferences; asking students to prepare mini presentations on various grammar concepts and themes throughout the semester; as well as referring students to the writing center to get help in fixing their language errors. Some writing instructors acknowledged the cultural appropriateness of local language practices, but they stopped short of using these forms in the writing classroom as this comment by a local instructor indicates:

I myself avoid using languages other than English in the classroom. It doesn't give the student the impression that you're actually teaching the language.

Certainly, such responses point towards common views of language and language difference that teachers seem to be laboring under, understandings that an "English-Only environment is most conducive to language learning" (Tardy 648). One of the driving forces behind such monolingual orientations is the perception that exposure to languages other than English in the writing classroom can be very harmful to the attainment of Standard English and can thereby contribute to eroding language standards. Similar perceptions about the centrality of Standard English in the writing classroom persist despite burgeoning scholarship that calls for reshaping existing language constellations and relations in ways that resituate SE from an unrealistic central position into the starting point for more critical engagements emerging in transnational and translingual 
contact situations (Canagarajah, "Lingua Franca;" Trimbur, "Linguistic Memory;" Lu, "Living-English"). Such responses to language diversity heavily driven by monolingualist ideologies are the most likely to propagate monolingualist assumptions about the reification and stability of language and cause the kinds of frustration documented in student participants' accounts of their relations and experiences with English as described in the previous section.

2. Preventive Measures against Translingualism

This pedagogical response to translingualism still operates under the hegemony of monolingual ideologies, but shows a lot more tolerance than their previous counterparts in acknowledging the existence of cultural and linguistic difference in student writing. The way language errors in student writing are approached under this model is more flexible as teachers claimed being very strict with basic sentence structure errors and awkward syntax and less strict with minor errors that don't cause any kind of misunderstanding or damage to their intended message and clarity of ideas as those can be revised in the final drafts. Despite these significant differences between both types of responses to language difference in writing, this approach still echoes monolingual directions, especially in its limited degree of acceptance of heterogeneity in language practices. The main distinction between this group of teachers ( 4 out of 14) from the first group is that they do acknowledge students' knowledge of and expertise in another language but view linguistic resources as the arch enemy of the mastery of rules and conventions of SWE. While the first group treats students as blank slates this group views teaching in the writing classroom as combating student resistance to the 
homogeneity of writing in English.

Reinforcing a tacit politics of English Only, when responding to language difference in student writing that is mostly viewed as problematic and interferring with communication, three of the most common comments teachers made in order to prevent translingual writing practices were variations of "This is not English," "This is not how we write in English," "Think in English," "Stop thinking in Arabic or in French." Regardless of the effectiveness of these reproduced comments, that allegedly serve as "wake up calls" for writing development as some teachers claimed, such comments echo dominant monolingual English-Only ideologies as they constitute one way of suppressing language difference in the writing classroom. Through stifling the actual expression of constellations that involve languages other than English, there is a common tendency among supporters of this pedagogy to reinforce the use of only the "target" English language in the writing classroom and forbid the use of all other languages or language varieties. Described as a "number one enemy," as one of the instructors puts it, these teachers seem to prohibit the remaining traces of non-English languages and language practices in English syntax, semantics, or lexicon. As the following complaints illustrate, most teachers expressed annoyance with traces of literal translation from Arabic or French into English written texts:

The translation [in student writing] kills me. You could hear the French and Arabic throughout.

They [students] don't write in English but in Anglicized Arabic or French or if they do write in English, it is usually internet slang English.

Another pedagogical practice adopted in order to further "contain" traces of difference in student writing is the general trend of identifying students transitioning from 
French-medium secondary schools, or commonly labeled as "French-educated" students, and distinguishing them from their "English-educated" counterparts. This group of students (as the excerpts in student interviews in the above section have shown) face a lot of challenges and difficulties as they come to terms with the demands of American educational systems and American academic writing conventions given minimal preparation for these by the national educational system. The overwhelming majority of teachers acknowledged the rich resources "French-educated" students had in the writing classroom as they have extensive training under the French baccalaureate system in genres like le commentaire composé and la dissertation that require in-depth analysis and critical engagement with academic texts. However, compared to their "Englisheducated" counterparts, teachers complained not just about students' not attaining near native fluency and pronunciation but also some of the typical unconventional moves that "French-educated" students made in their writing, like starting argumentative texts with an antithesis, or concluding essays with new topics and introducing new information, or extensively using the verb "ameliorate" (perhaps in some teachers' imagination, such uses are modeled after the French améliorer). One way of addressing what this group of teachers seem to perceive as signs of negative interference from French into academic English writing is through presenting short modules that address the most frequently made errors and talking about them in the open usually through humor and anecdotes of teachers' similar experiences with limited knowledge of a foreign language. Such practices echo monolingual orientations that have propagated in the academy and society at large through reinforcing the stratification of writers into labels, such as Englisheducated vs. French-educated and their written productions into "deficient," "non- 
English" and binaries of standard/nonconventional. As Vivian Zamel in "Toward a Model of Transculturation" argues, such dichotomies based on a "deterministic stance and deficit orientation" (341) towards what writing students "can and cannot do" based on their differential language background (346) support a reified view of student identities and the languages that they represent.

\section{Conditioned or Circumstantial Translingualism}

Showing stances of tolerance and accommodation toward language difference, this group of teachers (6 out of 14) view language heterogeneity as a right. "It's pointless to resist it; it's happening," as one teacher commented. Radically at odds with dominant pedagogical approaches mainly driven by orientations towards the transmission of knowledge about SWE in acts of reading and writing, these instructors have criticized the degree to which some English teachers are willing to go to enforce SE norms as they themselves have once been victims of such traditional approaches. Some of them shared their personal stories about childhood experiences of undergoing severe punishment by educators for not using proper SE in academic work. One instructor described the psychological impact of being forced to eat soap upon starting her sentences with 'and'.

While English is the sole language of writing instruction, these teachers' pedagogies are built on an awareness that the linguistic repertoires students bring to the writing class are worth listening to, respecting, and exploring further. Some teachers have made efforts to assign readings that are not normally thought of as embodying SWE conventions. These readings, such as "Volar" or "May he be Bilingual" by Puerto Rican writer Judith Ortiz Cofer and "Lingua Franca" by Luc Sante are characterized by their 
inclusion of a meshing of languages and varieties of language, like Spanish and French, in ways that differ significantly from the norms of SWE. However, despite assigning readings by unconventional writers like Cofer and Santa whose textual productions are characterized by hybridity, these teachers had certain reservations against encouraging such rhetorical and linguistic practices in their own students' writing, as evident in the following responses:

I don't do it [allow students to translanguage in their own writing] as I'm concerned. Is it the right thing to do or not? I don't know to what extent that is accepted by the language police like grammarians, textbook authors. I don't feel I have the authority.

I would have a problem if those language practices show up in the final draft but not in the first draft.

Translingual language practices in writing are only tolerated in the learning process, but not in the end product (see Elbow; Bean et al.). It is only when students have proven their ability to produce correct and polished written text, or if they become published or publishing "writers," can they display creativity with language use in writing. Such comments seem to indicate a distinction between what students can do after they master English and what they must do while acquiring it.

Two instructors mentioned examples of students who are voluntarily incorporating non-English academic sources into the research paper and engaging in the translation of these sources written in one language into English. The instructors felt it was a shortcoming for them as they could not figure out whether or not students' translations were accurate. By default, as students operated from a non-English source in an English paper, they were asked to provide their own translations for excerpts in a foreign language (more on the politics of working with academic sources outside English 
in the next section). Another instructor described a writing assignment prompt that introduced students to the graffiti culture through asking them to walk around the city of Beirut, observe the specificity of linguistic cityscapes, and record their own exploration of the intertexuality of graffscapes. This assignment integrated the genre of graffiti writing into the academic writing classroom as a way to prompt students to critically consider issues of equity, art, vandalism, social class, language, and privilege. When I asked her about how students negotiated differences in the writing systems of Latin letters and Arabic script with its right to left orientation, she expressed her concern about students' academic writing including a lot of non-English script. In handling this unique situation, the teacher specifically asked students to translate all languages and language varieties into English and transliterate (i.e. Anglicize the Arabic text) the untranslatable Arabic text as that "makes it less foreign and exotic than the pure Arabic script."

Obviously, merely allowing students to use non-English academic sources or introducing nontraditional texts like these in the writing classroom is simply not enough for contesting monolingualist dispositions in the writing classroom. Continued usage of Standard English as the linguistic norm for such sources in the written text does not really constitute a process of combating monolingualism. It further separates content from form, while treating English as a neutral linguistic form for direct transportation of contents intricately woven in Arabic. Semiodiversity or the "diversity within language," i.e. the multiplicity of meanings, in this case is seen as separate from glossodiversity or the "diversity of languages" (Pennycook, Language 100). ${ }^{39}$ Despite their increased tolerance for language difference in writing, such pedagogical practices still operate according to the central assumptions of English-Only monolingualism. The pressures of

\footnotetext{
${ }^{39}$ Also refer to Bou Ayash for a discussion on the creation of semio-diversity on top of glosso-diversity
} 
monolingual English-Only ideologies in language and writing instruction have forced teachers to intervene with and control translingual language practices in various ways:

- No traces of translingual writing practices in substantial polished drafts

- No non-English excerpts without an English equivalent when working with academic sources published in a foreign language

- No non-Latin script even when exploring and writing about translingual language practices on the ground

As it is evident that these instructors are dealing with various tensions, while some voiced concern about to what extent translingual work would be accepted by the academy, others expressed that they lacked the appropriate training and preparation for engaging with the messiness of cross-language explorations in the writing classroom. "I don't think I have the right training for it and I'm not sure how to handle its outcomes," as one instructor stated. Except for one instructor who stated having experience working in ESL and multicultural centers in Vancouver, the overwhelming majority of the teachers participating in my study indicated having very little to no training for working with multilingual writers and their texts and for understanding and dealing with their unique negotiation strategies. Some instructors could see more of such translingual language relations coming more reasonably into the work of the writing center than the writing program and classroom, others could foresee difficulties in terms of the types of students that differ from one semester to another or lack of student interests in tedious translingual work. "It's doable," as one instructor declared, "but totally circumstantial." Put differently, while writing teachers are aware that decisions on how to negotiate 
differences depend on the specific context of production and reception, they regard circumstantial contexts as irrelevant to the academic or the business. They also feel they are only trained to teach writing for and from a set context, and not for "circumstantial" contexts that vary from one student or written text to another.

Clearly, this group of teachers is grappling with the postmonolingual tensions inflicted by the widespread presence of multilingualism in sociolinguistic landscapes and its forced absence in educational and dominant ideological landscapes. Critical awareness of the sociolinguistics and politics of teaching academic English writing can best be portrayed in comments, such as "we need to find an ideal balance," "Their writing is unique but they also need to be part of a community of minds." Given the institutional nature of monolingualism, its propagation among the academic community remains a major source of tension for this group of teachers, as the reaction of one teacher illustrates:

We don't want everyone to fit into a mold. Who said they have to be very conventional in the way they write. But they also should learn to be selective because this is not a creative writing class but an academic writing class

A dominant perception circulating among some writing scholars and practitioners is that writing in non-dominant or non-English language practices is not fit for academic contexts. Academic work involving English in the presence of other languages, according to these teachers, is not suited for the degree of rigor of academic research writing and argumentation and is, therefore, more fit for the work of creative writing courses as language use in creative writing "can be further out of bounds," as one teacher justified her position. Greater tolerance is given to textual diversity in creative writing as a form of literary multilingualism (also see Canagarajah, "Negotiating the Local" 207; 
Lu's "Professing Multiculturalism"). This gives us an idea about teachers' perceptions of what actually constitutes good academic compositions in relation to nonacademic writing.

Enacting translingual relations under these pedagogical approaches remains both conditional and circumstantial for many of these instructors in that it heavily depends on the topics of writing, the assigned readings, and more importantly on the student make-up and their interest in working with non-English sources. In other words, whether teachers intentionally choose to engage in translingualism or are forced into navigating translingual work by their students' choices, their pedagogical approaches are still driven by the logic of conditioned translingualism as they sensitively negotiate tensions between the constant political pressures of generating the status quo and their ideological orientations towards keeping up with rapid sociolinguistic changes.

4. Advocacy for Translingualism:

Based on what teachers said in single interviews about the beliefs they hold for language and language use, responses by this group of instructors ( 2 out of 14) indicated their strong support for translingualism in their own policies and practices as their courses engage in acts of advocacy that create opportunities for more equitable and pluralist discourses and invite translingual practices by multilingual students. These courses include the translation courses offered by the English Department and beginning and intermediate French courses offered by the Civilization Sequence program. Teachers of these courses have dispositions of tolerance and appreciation for languages other than English. The diverse repertoire of languages and language practices that multilingual 
writers bring into the classroom are viewed as intellectual resources that can contribute to personal and social development. This was especially apparent in the following responses:

Why not use everything in the language classroom: English, Arabic, French, new media, etc.

I admire the students' English ability and I accept the multiplicity of ways in which they use the English language.

I don't want students to feel frustrated and that I am treating them as alien students.

Through translation, they develop a sensibility to the language in its particularity.

One of the foreign language instructors, described her initial teaching experiences following a traditional monolingual approach "as a shallow and undignified way to treat students as a blank slate." Coming to terms with the fact that "there's no traditional or modern textbook or pedagogy as it's all about the teacher" and the teacher's language dispositions, this instructor shows attention to the emic as she claims to have set her mind into "enter[ing] the minds of students" through "awaken[ing] their deeper senses to language." The teaching and learning of a "living" foreign language has to be "alive," according to this teacher. "I've used English and sometimes Arabic to really help them become more French as they now have a direct relation with French," as she argues. In order to help students to grasp the "nuánces" of language, "the little differences that make all the difference," she declared a strong "commitment to translation," that she defined as "not a transfer of meaning" but rather "a creation of meaning." Her writing assignment prompts, exams, and worksheets encouraged translation to and from French and English and in ways that not only "demystify" the foreign language but also engage 
students in a "rationalization of language" use and "a comparison of attitudes, visions, cultures, mentalities, and worldviews." She described her approach to foreign language instruction as a way of working in and out of French and English: "My students and I immerse ourselves in French and always make sure to dive back into English. It makes the class very much fun and interesting. I always come back to English and that releases the tension in the language classroom."

Another instructor who teaches literary translation courses argues that engaging students in translingual work "does not mean shaking the standards or detracting them [i.e. students] from standards." Common perceptions among academic writing instructors, according to this local instructor, that "students should not use Arabic but only English" sound like "a castle in the sand." As students are involved in rigorous translation activities and projects, they are encouraged to consider the "impact of every word, structure, and punctuation device" in their translations and the translations of others, thereby becoming "more mature in their linguistic choices." The bulk of the source texts are literary texts written in classical Arabic, with a smattering of Lebanese, Egyptian, and Palestinian discourse. "Using a second linguistic dimension" to contend with, students who get heavily immersed in translation theory and practice become more "responsible writers" as they are critically engaged in thinking about and weighing "their choice of punctuation, structure, usage, word choice, etc." The interactional spaces created for translation in these courses establishes translingualism as a highly esteemed practice among multilingual students (for a greater attention to translation practice under a translingual framework, refer to the final section in this chapter and also the concluding chapter of this dissertation). 


\section{Translingual Practice: Negotiation Strategies of Multilingual Writers}

As conflicting language ideologies and language relations have been signaled through teachers' perceptions, based on data from multiple rounds of interviews and student writing samples, I analyze in this section the nature of multilingual writers' negotiation strategies as they wrestle with the hegemony of monolingual English-Only ideologies dominating curriculum design and writing pedagogies and assessment practices where local language practices have no legitimate space.

Working from Academic Sources in Languages other than English as a Rhetorical Practice

In a culturally and linguistically diverse setting, where the overwhelming majority of students are at the very least bilingual, the academic sources that some students work with are not always limited to English academic sources. Three students from different sections of English 204 (i.e. Advanced Academic English) who were working on their research papers reported that they first felt the need to get permission and approval from their English instructors before using sources that are not written in English. "It is not something we usually do at AUB. We assume that in an English class, all sources have to be in English," as one student stated. Viola, a Biology pre-med student born and raised in Venezuela, was working on the topic of violence in the audiovisual media by the Venezuelan government and used one Spanish newspaper article. Diva, a Business student born and raised in Greece, chose to work on the issue of rape laws in Lebanon and used one online article in Arabic. Another student, who prefers to be called Kappa, is a nontraditional student born and raised in Italy who was working on the topic of the mafia and its culture of Omerta, i.e. code of silence, and used one Italian book as his 
primary source in addition to an English translation of an Italian book (which he also compared to the original) and an Italian film documentary. Viola commented that "our [also referring to some of her classmates'] work is very country-focused, so we need to use sources in Spanish;" however, all three students indicated that they would also use non-English academic sources in their future academic work in the university even if their research topics had no connection with the specific geographic location associated with that foreign language. When I asked Kappa about the motivation behind choosing to work with non-English sources in light of all the challenges the process of translation entails, he explained, "I feel original when I make connections to Italian and Italian scholarly sources; it enriches my writing." When I prompted him to think about whether or not a non-English source helped move his research and arguments forward compared to an English source written on the same topic, he explained that "an Italian source helps you get the inside eye of the problem. You're getting opinions from the locals and not from Americans about how ordinary people in Italy actually think. No other source in any other language can give a better inside view."

However, because learning how to effectively use or cite foreign language sources or even translated work in English writings is never given any attention in the academic writing courses, these multilingual writing students are forced to make inescapable compromises as they work across language difference. In our second round of interviews, both Kappa and Viola chose not to include the original quotes in Italian or Spanish as they appeared in the source and decided to only provide the English translation in their first drafts. Kappa justified his choices not to include original excerpts from his Italian sources along with the English translation by saying, "I'm not sure how I 
should cite an Italian source. Do I keep the original Italian title, or use a translated English language title? I am not sure whether or not it's okay to include sentences or titles in Italian in my English writing as my teacher and the students in class don't speak Italian." Not only did Kappa show concern that lack of knowledge of Italian on the part of his readers might, as he put it, "disrupt the rhythm and reading flow" as they might decide to skip non-English excerpts, but he was also worried about how his teacher might react upon "seeing Italian in an English paper" and whether or not she would perceive that rhetorical and linguistic choice "as an attempt to fill out pages and add more words to meet the minimum page requirement." Feeling constrained by the lack of exposure to the proper methods of handling foreign texts in classroom discussions on various documentation styles and citation guides, Kappa complained by stating that "they don't talk about my problem in class. How do I do that properly? It's strange that they don't do that here." In the third round of interviews, I offered to show both Viola and Kappa how to properly cite sources published in a language other than English by referring them to MLA handbook $7^{\text {th }}$ edition with explicit guidelines on the citation of foreign-language sources. We looked at several examples of how French, Spanish, and Russian sources are properly cited in the works cited list and inside the text. I also shared some of my own writing samples in which I cite French scholarship in order to provide additional evidence that such practices are totally acceptable in scholarly work and readers can clearly identify scholar's own translation or that of a professional translator from the original and perhaps seek them out on their own. Viola expressed her surprise by saying "I didn't know I can do that in my citations" but later said "No, no, no, no, I don't want any Spanish in my paper." 
Diva, on the other hand, was struggling with a different dilemma. She grappled with instances of untranslatability when working with actual excerpts of Lebanese laws against rape from the Nasawiya website, an official organization for young Arab feminists. As Diva struggled to translate an official statement of the Lebanese laws and penal codes, particularly Article 522, she concluded that the meanings changed with an exact word-for word translation and her attempt at a non-literal translation did not capture the tone and register of the Arabic original because, as she argued, "the Lebanese laws did not seem as barbaric and harsh in the English version." With the accuracy of her translation being vulnerable to criticism, as she could not find any verified English translations from both media and/or governmental (Arabic judiciary) sources, Diva decided to keep the original Arabic script. Interestingly, while both Viola and Kappa limited their use of either Spanish or Italian to the source titles in their in-text citations and bibliography, Diva chose not to provide an English translation and have the Arabic excerpt stand on its own in her research paper. Viola argued that "this is an English course, so you know that you need to translate the quotes into English." In preparation for her oral presentation, Diva showed me images of demonstrations against rape laws in Lebanon that portray banners using Arabic text. She was planning on incorporating those into her research paper and her power point presentation, but she also had a backup plan where she had already researched for English-only images in case the teacher disapproved of the ones portraying Arabic writing ("You never know if the teacher will allow you to use the ad in Arabic"). As the paper is for university-level coursework, “there's no room for taking risks; I'm doing this for my grade," claimed Diva. When discussing what she described as her research paper's "limitations" in front of her 
classmates, Diva made sure to point out that one of her work's problems is that "the majority of the sources were in Arabic," thereby making her research task more daunting and challenging.

A discussion with Kappa about the individualized translation strategies he adopted when working with Italian sources for an English research paper was intentionally steered by Kappa into a brief description of the history of his hometown, Trieste, and the locality of its language use. As Kappa explained, Trieste, a city in northeastern Italy and a prosperous seaport in the Mediterranean region, has been home for a dominant local dialect of Trieste called Triestine (that Kappa pronounces as Triestino) that gradually replaced the former Tergestine dialect (related to Friulian), a phenomena first popularized among fishermen and sailors. The original pre-Roman name of the city, Tergeste, derives from the Venetian prefix terg-(market) and the suffix est- (place), which are etymologically related with Slovenian and Serbo-Croatian tržište meaning "market" and mesto/mjesto meaning "place." This dialect and the official Italian language are spoken in the city, while Slovene is spoken in some of the immediate suburbs with a small numbers of Serbian, Croatian, German, and Hungarian speakers. Kappa felt the need to the establish some background information as a rhetorical trope for illustrating to an outsider like myself to the Italian culture, and more particularly the Triestine dialect, the idiosyncratic way he negotiates English through what he likes to call the Triestino moda de dire or "way of saying and communicating" things, which is generally discredited by Standard Italian usages. In Kappa's words,

this moda de dire makes me smile. I feel my English is enclosed in rigid structures and sometimes it's nice to break the structure through this moda de dire. I'm not always able to say what I feel exactly in English so I use this moda 
de dire and I sometimes translate directly from it. It's more me than formal English sometimes.

Kappa found no welcoming room for his moda de dire in the academic writing classroom, especially when working on a research paper in which reliability and credibility criteria are traced back only to scholarly work and not localized perspectives and worse yet local language practices and usages. For instance, Kappa described how he chose to stick to Robin Wynette Pickering-Iazzi's English translation of Rita Atrai's testimony in Mafia and Outlaw Stories from Italian Life and Literature. Though Kappa's own translated version remained his preferred choice as it is more authentic and faithful to the principles of the Triestino hybrid moda de dire, he still included in his research paper the work of what he described as a "real" translator and editor that can grant his own writing more authority and credibility:

La mafia siamo noi e il nosīro modo sbagliaīo di comportarsi (Original)

We ourselves and our mistaken way of behaving are the Mafia (Pickering-Iazzi's translation 161)

The Mafia is us and our wrong way to behave (Kappa's translation)

Structural changes like the ones Kappa made in his preferred version not only preserved the intonation of "harshness and fierceness of the local moda de dire," according to Kappa. It also helped him better foreground his main argument that "the system of organized criminality is fed, powered and supported by omertà, by silence, by the passive nothingness of our actions in front of injustice." In comparison to the "real" translator's version, contrastive emphasis in Kappa's version invoked through syntactic restructuring 
and intonation patterns is necessary according to Kappa not only be truer to an

"Italianized" Triestino English but also to bring about changes into southern Italy through defeating omertà. As Kappa's response illustrates,

Although this translation was found in a reliable source, I would translate the last sentence differently because it is kind of those moda de dire and the syntax as I put it is more impressive and more faithful to our "moda de dire."

By abandoning an enactment of a moda de dire reading and rewriting of the original, which seems to be more critical to Kappa's sense of self and cultural conditions, Kappa succumbs to what is deemed more acceptable in research-based writing according to monolingual norms.

It is quite clear in all the three cases of Viola, Diva, and Kappa that while some multilingual students negotiated the politics of English when working with foreign language texts whereas others dealt with the problematic of translation differently, the quality and rigor of translingual work was largely constrained by various perceptions about the expectations of an academic audience and the underlying uncertainty revolving around non-dominant rhetorical practices in the English academic writing classroom. These students felt the need to use scholarly research in languages other than English but couldn't do so safely, confidently, and comfortably in their academic writing, a fact that clearly shows how monolingualism operates at the level of immediate writing practice as a set of powerful dispositions about language use in writing. Going through the process of translation when working with foreign sources would impact their sense of themselves, their relations to others and the world, their sense of diverse language relations, and hence the meanings they produce in the composing process in ways that cannot be achieved in an English-Only monolingual classroom. These same processes of the back 
and forth movement of meaning enabled by similar translingual work need to be deliberately built into writing pedagogy.

\section{Negotiating English: Translingual Practices in Multilingual Students' Texts}

A close look in this section at the translingual writing strategies of multilingual students enables us to think through what these language practices actually are, what the specific purpose behind their use is, and how exactly they connect to their writers' life world and sense of self. Throughout the multiple interview rounds I conducted with students about their practices, several students demonstrated practices of resistance in their own writing to the "uncritical" teaching of SE and the strict evaluation of its usage in academic writing. I also demonstrate in this section how the type of feedback from instructors can hinder the complexity of multilingual writers' linguistic choices and their rhetorical effectiveness. While conversations with multilingual students portrayed strategic options and choices in light of intra- and inter-linguistic difference, written comments by instructors are mainly driven by tacit English-Only monolingual ideologies that deny multilingual students' intentionality, positionality, and agency and that approach translingual composing strategies as deficiencies and errors rather than differences and innovative designs.

I report first on the translingual writing practices of a student who wishes to be called Diva. The interpretations I offer here are based on her explanation of the choices she makes in her own writing and on the attitudes and beliefs she portrays towards English and other languages. Born and raised in Greece to a Greek mother and a Lebanese father, Diva assigns a native language status to English while also sharing her strong linguistic affiliations with Greek and Arabic, which tie her to her own roots and 
values. The Greek language, which reminds her of the beach with its ghalajio color, gives Diva a sense of uniqueness and "privacy with her sister and mother" that English cannot give as "almost everyone knows English." Arabic strongly links Diva to where she resides now, to her father, her relatives, and the people she knows in Beirut and represents "the Arab in [her]." In a critical response paper for an English 203 course (Academic Writing), Diva combined Arabic and Greek in what I call a "mix-and-match" strategy throughout her predominantly English essay. In this writing assignment, students were asked to choose to write about their own reaction to the assigned readings as a whole or particular arguments or assertions made by the author that intrigued them the most. Students are specifically asked not to summarize the reading selections or simply describe their own personal feelings about the readings but rather offer a close examination of a single text or a set of texts and the significant questions and issues raised in the text. Diva chose to respond to an essay "Lingua Franca" reprinted in the English 203 reader that was written in a "mix-and-match" style with a combination of English and French. As Diva and I read her essay together, I pointed to particular words, phrases, sentences, and entire sections in her writing and inquired about her perceptions, attitudes, goals, and expectations in order to get a better understanding of her writing practices and negotiation strategies in light of language difference.

Going against forces of globalization and the order of fast capitalism that have assigned English the unmistakably global status of being the world's lingua franca, Diva entitled her essay "My Lingua Francas" and explains that unlike the author to whom English is the sole lingua franca, her "lingua francas are not one" as she has her own "universal language with all [three languages] together": 
I used to think I had no answers to everything, but now I know...things don't change, meanings don't change; everything doesn't change when I'm in English, Arabic and /or Greek. Right now, I live in all: Greek, Arabic and English even though I live here, in an Arabic world

Emphasizing the interconnectedness between her heterogeneous identity and her language affiliations, only this way of using English is "what keeps [Diva] together":

There are these two sides in me [i.e. Arabic and Greek] and my English is in the middle; and it's just what keeps me together.

As I proceeded to unravel Diva's understandings of why she engaged all three languages in her writing the ways she did, it became clearer that among the factors that instigated her refusal to reproduce the hegemonic conventions of SWE was seeing this strategy being skillfully modeled by a "real" professional writer like Luc Sante. Despite differences in power relations, status, writing experience, and levels of expertise, Diva's own translingual practices in writing were empowered by Luc Sante's own.

Usually, we're not allowed to so I was like inno [so] since the author did it and it's in our book, why can't I do that too? Why would the teacher mind if I did the same if she gave us the text to read. You can't just give us a text where the writer expresses how he feels in a new style and we can't express the way we feel in the languages in which we feel. I know it's big risk writing like this in an English class, but you just have to do it sometimes.

Diva's decision also depended on the genre of a response paper, which allowed for more authorial presence and voice and on the topics of the readings and discussions in the classroom which dealt with various issues about culture, identity, and literacy ("Thank god it's a theme on language and identity in 203. I can finally be myself"). However, Diva expresses her ability to "gaug[e] the congeniality" (Canagarajah, "Translanguaging" 404) of the writing situation for translingual writing practices, as illustrated by her 
following explanation about refraining from enacting translingual strategies in other forms of writing:

It's more formal English. I did use some Arabic sources and some Arabic in the images but I did my best not to mention what I think or what things mean to me. You can't just risk it. I'm doing this for my grade.

As different stakes are involved in more serious, prestige forms of writing in which SE reigns as the only linguistic medium and preferred norm, Diva admits to playing it safe and making an alternative rhetorical choice through withholding her translingual writing practices. As Suresh Canagarajah reminds ưs,

[t]his ability to assess the situation and frame one's language accordingly is part of a multilingual's rhetorical awareness and communicative proficiency. (404)

Throughout the response essay, Diva's writing strategies demonstrate a resistance to English Only hegemony not only in her choice of languages in which to compose but also in how she chose to use those languages in her writing, where exactly, and toward what specific ends. Though Diva owes her sense of empowerment over her language use in an academic writing setting to Luc Sante's own translingual practices, in her response to Sante's text, Diva challenges Sante's assertions about the separateness of languages and identities that deny the vibrancy of the constant traffic in and out of English:

Luc Sante has two tongues: "One is all quivering, unmediated, primal sensation, and the other is detached, deliberate, artificial". To give a full accounting, he would have to split himself in two (Sante, 1997). But you see, I don't have that. I do not even think of my "tongues" in a certain way... Three languages, one meaning - what they mean to me.... And as for that creating the dilemma of identity, I am not like one of those "famous optical illusions, in which the silhouettes of two facing profiles form the outline of a vase." I don't have two images at once; I have only one, the one that shows the three. 
Attesting to the magnitude of the challenge Sante's position and experience with language difference holds for her, Diva describes the oneness of her own way of recontextualizing English in time and place:

I do not have to translate in order for me to write about my childhood, nor do I have to translate now to speak about my present. What goes in my mind is a mixture of words, kalimet - words that make me think in a certain way so that I'm able to express myself les kai - as if it is all some universal language.

In the above excerpt, though Diva seems to be merely mixing English with Arabic and Greek, her translingual writing operates as one unified whole. What intrigued me most was Diva's consecutive use of the Lebanese Arabic kalimet along with its literal translation of "words" and the Greek les kai and its English translation "as if" in ways that a stickler for correctness in writing would normally mark out as instances of redundancy or unnecessary repetition. This alleged repetition strategy, according to Diva, does not make the term 'words' and its Arabic equivalent redundant as each represents a different meaning:

It [this repetition strategy] brings out my English world and the Arabic world of mine

As Diva explains, Kalimet, as the transliterated version of the formal Arabic term 'كلمات' or kalimat, is not in fact interchangeable with its literal English equivalent 'words'. In the vicinity of the English 'words,' the Lebanese Arabic kalimet generates new meanings. "The English 'words' is just so plain; it's just words," argues Diva. Following the lead of the renowned Lebanese soprano Majida El Roumi in her widely celebrated pan-Arab hit song 
'Words that aren't like words' written by Syrian poet Nizar Qabbani, Diva's Lebanese Arabic kalimet inspired by Majida's Modern Standard Arabic kalimat stands for words that aren't like English words.

The Arabic term kalimet, according to Diva, calls up a train of associations that are discredited and unrepresented in the English "words." The simplest and humblest of expressions triggers a variety of sensory associations to the auditory, the kinesthetic, the tactile, the visual, the olfactory, and the gustatory. "When I think of the Arabic kalimet, I think of the authentic Lebanese jaw 'atmosphere' with its defiantly frivolous ambiánce even during the worst of times," she adds. "The Lebanese are like this. We like to live." In keeping with the Lebanese spirit, the Arabic kalimet, as Diva puts it, "is so m'ajja' $a$ [crowded with meanings], you can feel the life inside of it." "When I think of the Arabic kalimet, I immediately think of the Lebanese Qahwwi 'coffee' and all the jaw and passion that comes with it." The finesse of roasting while mixing the blond and dark type highquality Arabica bean together, blending, and brewing is what gives this coffee its specialty: prepared in a narrow, long-handled traditionally brass pot, called a rakweh, and served in small, colorful demitasse cups; generally served in three different ways: very sweet (helwi), moderately sweet (wasat), or bitter (murrrah) mostly at funerals and flavored with cardamom seeds or powder, hot water is brought to a boil several times, extracting deeper flavors each time the water is reheated until the cardamom, water, and coffee are fully infused together, just like all of Diva's language practices that might belong to varying language worlds. As a coffee admirer herself, this nuanced difference in gentle coffee preparation, according to Diva, makes all the difference between the 
"mediocre" English 'words' and the more "lively" kalimet; and as one of my teaching participants argued, "it's the little difference that makes all the difference."

While Diva chose to provide her readers with a translation of les key as "as if" or her own definition and view of kalimet as "words that make me think in a certain way so that I'm able to express myself les kai - as if it is all some universal language," she resorts to a different strategy in the following section:

What goes on in my head when thinking, or when I'm speaking to someone is just a list of words. Three languages, one meaning - what they mean to me. I could feel detached, ma ile jledit hadan, kai den thelo na kano tipota. For I don't want to do anything.

Grappling with the problematic of untranslatability, Diva decides not to negotiate a footing with her readers and offer an English translation for her translingual writing practices. Explaining her resistance to the monolingual nature of the language of the academy and the motivations behind her unconventional rhetorical and linguistic choices that do not accommodate all her readers, Diva argues:

Just like I sometimes had to guess with the French used in the text we were reading, the teacher has to guess when reading the Greek in mine.

When I asked her whether or not this rhetorical choice raised any concerns about miscommunication and one-sided interpretation, she further foregrounded her strategy for dealing with untranslatability by invoking her own view of her translingual writing practices that resemble her "lingua francas" or her own "universal language," a position which she also projected in her opening paragraph and is reflected in the essay's title, as her explanation below suggests:

This is so me. I don't translate them. I have one language, which is my universal language. 
Diva's strategy of using untranslated Arabic and Greek challenges the very notion that language can be the lucid and transparent tool of objective writing. Diva explains her decision to change her footing with her readers and leave things untranslated by providing me with a list of examples from daily language use. The shade of blue that the ghalajio color of the beaches of Greece represents in Diva's imagination and reality has not similar English equivalent; "it's not the turquoise color," it's not sky blue, neither navy blue, nor azure, nor Celeste. Another typical exemplar is the impossibility of translating into English the local language practice of giving someone a special compliment by saying yu'burnee "May you bury me." According to Diva, this declaration of one's hope that they'll die before another dear person due to the difficulty of imagining life without them has no English equivalent. There is also another common complimentary expression of نعيما and its more classical variant حمامالهنا used after a person has taken a shower or got a haircut, words and phrases that have no substitute in English. This great appreciation of hair whether it got cleaned or styled does not render any English interpretation, according to Diva, hence her decision to preserve the locality of meaning through leaving her translingual writing practices untranslated.

Another case study that I closely examine is that of Nathalie, who approached me by the end of our first interview asking for my advice on language-related issues as she presented a bunch of graded writing assignments from current and previous English courses and from various courses in other disciplines:

Everyone keeps saying "read, read, read." I know I should read more in English but it's not fast enough for my language to improve and I honestly don't have that much time. I want a fast solution. As a math minor, business minor, and a fulltime Engineering student, all this is so demanding. I also live in Zouk and have to 
commute for two hours everyday. I felt frustrated when I read [a teacher's comment] "Visit the writing center at AUB. It will help you a lot," or "Avoid language mistakes," or "Revise language use." It was very hurtful of her. I feel trapped because I don't know what to do. In my head, they sound okay. I want to know how I can improve. I want to be a better writer. I am desperate I want to do anything. That's why I came to you. I thought you might be able to help me with my writing and my language.

Nathalie's voluntary decision to get a closer look at her writings and discuss her writing practices was obviously influenced by my own image as a researcher addressing the negotiation strategies of multilingual amid language difference, which was quite apparent to many student participants in the way I introduced the study and in the type of interview questions I posed. But her choice was obviously also affected by the recurrent dilemma, at least in the way she perceived it, that the way she negotiates language difference always "sound[s] okay" only in her "head," but not in writing following SWE rules and conventional forms. It is these propagated images of the central role of the writing center in "fixing" students' messed-up language and of referrals to the writing center for language errors as a source of shame and embarrassment that have led to an increased level of linguistic uncertainty and self-consciousness about language difference in writing in Nathalie's case. Unlike Diva, who experiments more boldly with language and confidently claims ownership over her own "lingua franca," Nathalie is more concerned about using correct English in her academic writing and is desperate for more efficient solutions to what her university professors regard as problems in the way she uses English. As Nathalie described the specificity of her lived realities, she expressed feelings of frustration and anger that her teachers do not understand, attend to, or effectively respond to her immediate concerns and worries as she constantly operates under various individual pressures and conditions at the academic, intellectual, financial, 
emotional, and physical levels. Nathalie mainly voiced her frustration with the way instructors from various disciplines across the university have responded and commented on her own writing:

All they [teachers] do is underline things that don't sound English to them and they do not even appreciate my efforts. Maybe if they guided me on how to address these problems and fix them.... As a French-educated student, I saw them [teachers' comments] coming. I know an English instructor is supposed to point out where I went wrong. My first reaction is always when I get my essays back is: "Tell me something new."

One of the puzzling moments to Nathalie was why her instructor suggested that she use the phrase "partial to" instead of the term penchant, as is depicted in the following response essay:

According to Clifford Landers' second commandment of literary translation, a translator should not "improve upon the original text". In other words;fhe should not add any new ideas or information. This opposes fo Susan Bassnett thoughts that impliy that translators should feel completely free and consider their work as a new piece of writing where they should include their own touch and spirit. Personally, I find myself penchant for Landers' side. As a fart.e. translator, I certainly believe that all cultural features that characterize a certain text should remain unaltered; while it's being translated.

As I started reading this section from an assignment for a translation course, Nathalie immediately explained her rhetorical choice in the following unsolicited comment, 
mostly as an attempt to exclude any dominant assumptions I might have about the source of French-educated students' writing errors, which local writing instructors commonly link with literal translation strategies:

I started writing the English structure and then thought of the French word; it's not that I structured it in French in my mind and then translated it into English.

Nathalie justified her rhetorical choice in the sentence "Personally, I find myself penchant for Landers's side." Nathalie demonstrated how she did a quick Google search, the search engine she frequently uses, to see how the verb penchant is used following correct English sentence structure: "I focused on the meaning of the word and what comes after it in an English sentence." The results of a basic internet search indicated to Nathalie that in most English sentences, the verb penchant is "most frequently followed by the preposition for," as in "their penchant for wandering and their experience in it," and she modeled her own writing after such structures. When I asked Nathalie about how she would rewrite this sentence based on her teacher's suggestions if she had the opportunity to revise her writing, she responded:

I don't want to change penchant. My use of penchant reflects that I'm a good writer. I want to make sure that this is the meaning that I want. I don't see it used that much so I want to have something interesting in my writing. It also preserves the Frenchness in me in my English writing.

In addition to the kind of impact on her audience and the linguistic alignments that this term enables her to preserve and project in her writing, Nathalie was able to tease out some nuances in meaning that explain her rhetorical decision to use the term penchant in her writing and keep it unchanged in her revision. The term penchant, according to Nathalie, is "when you're leaning towards an intellectual direction and taking a strong 
side in an argument." An online Merriam-Webster dictionary that Nathalie normally uses in her academic work defines penchant as "a strong and continued inclination"

(http://www.merriam-webster.com/dictionary/penchant). Also checking the etymology of the term provided by the Merriam-Webster dictionary, Nathalie pointed out that the origin of the term penchant is "French, from present participle of pencher "to incline' and from Latin pendere 'to weigh'." She explained that while the term "penchant" refers to a propensity resulting from an intellectual act of careful weighing, evaluation, and consideration, the notion of partiality that her teacher recommended induces a degree of bias and prejudice resulting from "a personal and sometimes unreasoned judgment." While Nathalie indicated that she "love[s] to give a good impression" on her readers through using "correct" English ("I care about my correctness and I want to impress my readers"), her use of the term penchant is also strongly tied to her identity as a prospective engineer desiring to reflect an image of an intellectual and a professional who can take a stand based on sound reasoning and not mere partiality. The example of "penchant" in terms of the unique meanings it opens up to its writer, meanings that are discredited by standardized language forms, is reminiscent of the nonidiomatic use of the structure of "can able to" produced by a Malaysian student in MinZhan Lu's "Professing Multiculturalism." Though the nonmainstream structure of "can able to" deviates from the official codes of academic discourse, it helps its creative author enact a different approach to "ability" than the hegemonic attitude toward "ability," and it is more true to her conviction that resistance against dominant social relations can empower the less powerful to advance towards their goals and aspirations. In anticipation of conventional readers' expectations, the question here remains whether or 
not the writer of "penchant" should somehow rhetorically cue her readers that she has deliberately chosen to go against idiomatic usage in order to counter a notion of bias that is suggested by her teachers' recommended term "partial."

Even as multilingual students like Diva, Nathalie, Kappa, and many others continue to gradually grow more worldly with English, they still carry around a translingual internal that is meaningful to their specific social, historical location, and idiosyncratic micro/macro contexts, which embodies and exercises many of the prerequisites of ideal translingual work in both language perceptions and practices. As their literacy education is almost entirely in English, and only one variety of English, the writing program and classroom by the dominant longstanding monolingual ideologies remain at best confined spaces for provisional and circumstantial translingualism and at worst for developing an illusion of a mighty system that has immunity against the sweeping waves of difference. What seems to be of paramount importance is an ideological and pedagogical move towards working with students from where they already are in both sociolinguistic and educational landscapes with their strategic language use and creative language design rather than where those in power in both educational and business landscapes think they should be. Literacy laborers in the U.S. and elsewhere can start by building on their students' rich repertoire of translingual and transcultural competence through promoting the work of translation in which multilingual student writers and readers are already engaging in across writing genres and disciplines. If we accept that translingual and transcultural literacy education is the goal of English academic writing instruction, then it is most advantageous to start by looking at English with its own sets of particularities "as a language always in translation" rather than as a 
seemingly transparent universal medium (Pennycook, passim). Based on the few individual cases in this study of multilingual students who are constantly composing, thinking, and living their daily lives along translingual lines, one realizes that a translingual language ideology in all its forms (be it the use of academic sources in foreign languages, composing in modern languages other than English, reshaping SWE rules and conventions, etc.) occupies a dominant position in multilingual students' language learning experiences. With a critical eye towards the nature and operation of language relations in curriculum design and writing pedagogy, both textual and interview data in this study point towards the pressing need for translingualism in educational sites. Translingual work in writing instruction should be closely bound to questions about the language relations, affiliations, and attachments of multilingual writers regardless of their demonstrated level of language expertise and proficiency in that language or language practice (see Lu, "Living English). The translingual approach to writing that I advance in this work takes an orientation sensitive towards the actual translingual practices of language learners and writers with attention to the politics of meaning making.

\section{Translingual Meaning Making and Translation}

"Translation is not a transfer...but a creation of meaning." Amal, foreign language instructor

In this section, based on an analysis of course syllabi, individual course materials, and student work, I bring to light models of translation and the trafficking of meaning that I see as most productive in promoting cross-language relations along translingual 
lines and that I argue can be tapped into in writing and mainstream literacy pedagogy. In contrast to conventional views of translation as a mechanical, unidirectional transposition of texts from the source language into a target language, I align my work with critical approaches in translation studies (put forward by Lefevere; Bassnett and Trivedi; Venuti; Dingwaney and Maier, among many others), which think of translation as a rhetorical act of "re-writing" that challenges traditional notions of "transparency," "neutrality," and correctness in any translation process. Asking what a translingual model built around translation work might look like, I draw attention to differences in the commitment level to translingualism in various approaches to translation in ways that also caution us that the residual forces of monolingual ideologies can still seep even into work that is based on translingual models.

Approved as Humanities general education courses, undergraduate translation courses at AUB are designed to familiarize students with basic translation theories and offer hands-on opportunities to practice the development of basic translation skills. Initially taking the course to fulfill a General Ed. requirement, $77 \%$ of the students I've interviewed who were enrolled in translation courses spoke in favor of translation skills and described how an introductory course in the theory and practice of translation has helped them become better readers and writers in that it has changed the way they approached written texts. The following responses are examples of students' solicited feedback:

When I read translated books or texts, I now pay attention to language usage. My reading is more focused and analytical.

I never thought translation was this in-depth. I never knew there were so many different translation approaches. 
I thought translation is only literal. Now, I know it can have many levels.

I never knew translation was this complex and we had to think of approaches, theories, analyses, and writing styles. I thought it was easy just like Google translations.

I have learned that translation is a complex process of reading, rereading, analyzing, interpreting and rendering the right meaning in the right context. It is not only translating literal words, as I thought it should be, but it is much more than that.

Towards that end, one student, who prefers to be known as Ethan, argues that "instead of working with English separately and with Arabic separately," extensive work in the theory and practice of translation enabled him to "think about the relation between the two languages in this course." This orientation toward language relations enacted in translation courses enables students to break from monolingualist representations of English as operating in isolation and having discrete boundaries. As some of the instructors' responses illustrate:

You think about and work with English and Arabic simultaneously. You think about the content, structure, spirit, phrasing in both languages, usage, etc. This way you learn how not to lose in translation but how to gain.

You become like literary detectives with a profound critical eye towards language. You think of time, place, characters, culture, the psychology of the characters, etc. throughout your interpretation.

One of the sections of the translation courses that I examine involves technicalbased translation and covers topics such as comparative and contrastive linguistics between Arabic and English, computerized translating machines, semiotics, registers, culture, rhetoric, and pragmatics. This section exposes translation students to a plethora 
of non-literary genres represented by legal texts and documents, and excerpts from various sources in finance, business, and economics. Most in-class translation activities invite students to think about rhetorical and stylistic differences and similarities between both languages of Arabic and English with a focus on various linguistic and stylistic features, such as verb tenses, modals, definite and indefinite articles, adjectives and adverbs, proverbs and idioms, sentence structure, etc. As they work with highly technical discourse, students are engaged in a close textual analysis to "identify the basic linguistic, stylistic, idiomatic, and terminological differences between English and Arabic," while "produc[ing] translations that are close to the original, and at the same time in tune with the linguistic and stylistic features of the language the translation is done into" (course syllabus, English 233: Introduction to Translation, Spring 2012). For instance, while the original Arabic newspaper articles leave things vague and the writing style is characterized by a lot of repetitions and redundancies, an unacceptable approach to a native English-speaking audience, their English translations of that article were characterized by a larger degree of brevity, conciseness, and specificity.

Another section is more literary-based and exposes students to a wide range of literary writers and translators working with French, Italian, Latin, German, Turkish, and even different dialects of Arabic (Iraqi Arabic, Egyptian Arabic, and Lebanese Arabic). This translation course helps develop in students a heightened sensitivity to the nuances of meanings through encouraging, as the instructor of this course puts it in the one-onone interview, "deliberate negotiation over register, language usage, sentence structure, word choice, punctuation, etc." A critical analysis of a variety of translated literature and one's own translations in this course "refines the students' analytical abilities and 
empowers their craft as writers by rendering them capable of expressing specific ideas on literary appreciation within the framework of tenets derived from experts in the field" (course syllabus, English 233: Introduction to Translation: (A Writer's Analysis of Translated Literary Texts), Spring \& Summer 2012).

I start my analysis by examining some implicit and explicit language policies and the way they position work with English in relation to other languages. Various examples of policies in course syllabi portray English as the language that translation work is predominantly done into:

Analysis is practiced on the sentence and text levels, allowing the students to refine their writing in English, since the emphasis is on translation into English (course syllabus, English 108: Beginning Translation, Spring 2010; emphasis added)

The purpose of this course is to give students practice in reading and analyzing a variety of translated literary texts from Arabic and other languages into English, and evaluating the linguistic and stylistic content therein. (course syllabus, English 233: Introduction to Translation: (A Writer's Analysis of Translated Literary Texts), Spring \& Summer 2012; emphasis added)

The purpose of this course is to give students practice in translating a variety of texts from Arabic to English and vice versa... The course pays close attention to textual analysis, which would help students learn a lot of English and a fair amount of Arabic. The emphasis is on translation into English, because it is assumed that higher quality translation is achieved in that direction than in translating from English to Arabic. (course syllabus, English 233: Introduction to Translation, Spring 2007, 2012; emphasis added)

Translation work in these English courses predominantly involves a unidirectional process from source texts (ST) written in Arabic into translated texts (TT) in English. Put differently, the target language in translation generally matches the language of instruction in the corresponding department, i.e. the English Department. Echoing dominant ideologies of monolingualism, such policies propagate the "myth of English- 
language superiority" (Spack 766-767) and reinforce cross-language work that seems to always turn texts, writers, and languages back toward the center. Additionally, it is evident that a particular discourse or ideology is at play as the value of translation "into English" (syllabus, Spring 2010, Spring 2012, Spring \& Summer 2012) lies in its ostensible power to "help students learn a lot of English" (syllabus, Spring 2007, 2012) or "to refine their writing in English" (syllabus, Spring 2010). Only one of the statements quoted above actually acknowledged that alongside working with English, translation students would also be learning "a fair amount of Arabic" (syllabus, Spring 2007, 2012). Compared with similar translation courses offered by the Department of Arabic and Near Eastern Languages (Arabic 225: Translation), these courses seem to be driven by and reinforcing monolingual English Only ideologies. The following is excerpted from the syllabus of a bilingual translation course offered by the Arabic department:

I- Naturally, this is a bilingual course. Students are expected to be proficient in both Arabic and English; and the class shall be conducted in both languages. While an adequate level of proficiency in both languages would be conducive to better attainment, the course itself is a unique opportunity for leaming the intricacies of both languages together, or the fundamentals of one through a better understanding of the intricacies of the other. The comparative approach inherent in this course is conducive to a better understanding of both languages, and of the ways they interact, in the translation context.

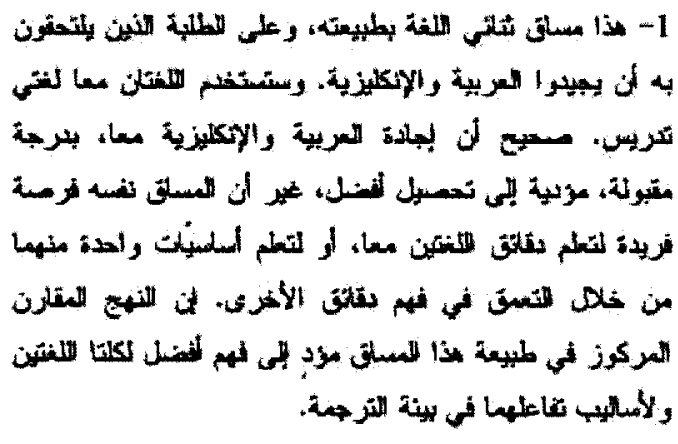


Clearly, the course syllabus is composed in both languages, and translation is approached as a bidirectional process into and out of both English and Arabic. As stated in the syllabus, work in this course is conducive to "a better understanding of both languages, and of the ways they interact, in the translation context" and to a critical engagement with the "intricacies of both languages together, or the fundamentals of one through the understanding of the intricacies of the other" (course syllabus, Arabic 225: Translation, Spring 2011; emphasis added).

Such cross-language work in translation courses offered by the Arabic Department, however, remains hindered by dominant expectations for a finished, monolingual product and insistence on standardized translated versions, as the following section from the syllabus illustrates:

We, the citizens of universities, are the guards of proper understanding and correct communication. We cannot trade in incomprehensible texts that corrupt language, talent, and taste. We shall therefore approach translation as an academic enterprise governed by criteria of correctness and precision, not as an occupational activity, governed by criteria of prompt execution. Occupational fitness can be achieved only through a mastery of the fundamentals first, followed by extended practice. (course syllabus, Arabic 225: Translation, Spring 2011; emphasis added)

(available at http://www.aub.edu.lb/fas/fas home/faculty_resources/Documents/arab225.pdf).

With emphasis on the significance of the "mastery of the fundamentals" and translated products that are "governed by criteria of correctness and precision," the course syllabus portrays appeals to traditional aesthetic value when preserving language standards through warning against translated products that "corrupt language, talent, and taste." 
In relation to their counterparts in the Arabic Department, despite the dominance of translations into English rather than in the other direction in courses offered in the English Department, ${ }^{40}$ student in those courses are encouraged to engage in a critical evaluation of how, when, where, and why translators, including themselves, choose to adhere to or tinker with standard translation criteria and conventions of accuracy and faithfulness to the source text, language, and culture while thoughtfully explaining their investigations and interpretations about selected linguistic and stylistic features. At every turn, students are faced with a wide variety of possible renderings of seemingly straightforward words or phrases and have to critically analyze the perceptible or subtle shading of each. Putting forth the effort and enduring the challenges and difficulties that characterize the work of experienced translators, students have to negotiate a succession of various linguistic and rhetorical choices that might emerge. Sometimes they have to make a choice among a wide range of semantically interchangeable choices that might seem to be conveying the same information and meanings but that differ significantly not only in aesthetic effect but also in subtler layerings of meaning. Going beyond the equivalent terms or phrases offered by a translation dictionary or thesaurus, students are heavily engaged in teasing out the nuances of meanings, or what one of my teaching participants defines as "the little differences that make all the difference," as they weigh and rework their options "from a macro and micro perspective," as one of the student participants puts it, when a plurality of other options are available. For example, in a group translation project on Lebanese poet Elia Abu Madi’s Watana el Noujoum "My Home Land of Stars," students undertook

\footnotetext{
${ }^{40}$ It is worth pointing out that the division into separate departments itself manifests and encourages a monolingual approach to language and literacy learning.
} 
second rounds of translation and revision before they realized their need to exclude the literal translation for the term aghna into "got richer" that can mark material wealth and values and worldly connections that misrepresent the author's spiritual existence and relationship with his homeland as a grownup. As the following section from a collaborative reflection paper illustrates, the group describes their decision for the term "soar" which symbolizes an action of ascension to a level markedly higher than the usual:

By editing this word we had to change most of the sentence making the words fit in context together. For that reason, we meticulously chose the appropriate words that eloquently represented and preserved our understanding of the meaning of the poem. As a result, the edited sentence turned out to be the following "I am the nightingale who soared over the clouds through your glory". Here the translation became more figurative since we replaced "got richer" by "soared over the clouds," since we had interpreted the richness not as a monetary entity but a spiritual one.

In another final translation project, another student conducted a comparative analysis of her English translation of her own French poem "Vos yeux disent tant!" in relation to various translated versions by literate individuals with varying experience levels with translation and familiarity with French and English: a French-educated student-poet; a high-school French teacher; a high-school English teacher who is knowledgeable in French; a French professor; and a French-educated student pursuing a degree in English translation. This student uncovered the sources of her struggles in translating the phrase Je planerai dans le ciel. An advanced Larousse French-English translation dictionary offers multiple options for translating the verb planer from "to soar," "to glide," "to float," "to sail in the air," "to fly," and "to hover over," (McNeillie et Corréard, Larousse 774). Comparing these options to the definitions provided by Collins English Dictionary, 
the author and translator of the poem opts for the verb "glide" that marks a continuous, silent, effortless, and furtive movement:

Here, a question arises: should the translators use glide or soar? According to Collins English dictionary, "to soar" means to fly upwards or high in the sky, whereas "to glide" means to move smoothly, effortlessly, and imperceptibly. This explains why the university professor as well as the author herself preferred using the word "glide" when describing the action taking place, for to both, the smile is enough to leave the lover on and going. Furthermore, the French professor, fancied the use of "heaven" rather than "sky," in an attempt to bring the utmost feeling of happiness to light.

As students grapple in each translation activity with difficult decisions regarding complex terms, local cultural associations, sentence structure, metaphors, register, usage, punctuation, and idiomatic expressions, they are constantly encouraged to consider questions about difference along the lines of culture, language, ideologies, polities, identities, social relations, locations, and time periods. Such investigations, however, remain guided by dominant translation theories under which translation constitutes a faithful representation in the target language of another pre-existing text written in another language. In keeping with Clifford E. Landers' second commandment for sound translations "thou shalt not 'improve' upon the original," students' translations are expected not to compromise equivalence between source and target text ("The Twelve Commandments of Literary Translation," course packet). The notion of "equivalence" is maintained as a guiding principle in any translation process as "the translated text must preserve the accuracy of the original content while flaunting its specific style and spirit" (course syllabus, English 233: Introduction to Translation: (A Writer's Analysis of Translated Literary Texts), Spring \& Summer 2012), an approach that arguably sustains emerging critical orientations in translation studies that problematize givens and map 
micro and macro relations of power and inequality in any work of translation. A model of measuring equivalence between a source and a target text or language is problematized on the occasion of assigning Fateena Al-Naib's radical translation of William Shakespeare's Sonnet 18 tilted Shall I Compare thee to a Summer's Day? Dealing with differences in social, linguistic, and cultural reality in seamless, effective ways, Al Naib unsettles cultural hegemonies thematically, stylistically, and lexically and refrains from giving the exact or equivalent translations of various sections of the English sonnet. In her Arabic translation of the English playwright and poet's work, Al Naib chooses to drop any reference to the month of May or its "temperate" climate as comparing the beloved to the moderate and pleasant English summer season through the long, hot, dry and intolerable summers in a desert area like Iraq does not capture the intended meaning of admiration of divine beauty. Al Naib's rewriting manifests itself on two levels: first, through relocalizing $17^{\text {th }}$ century English poetry in the vast desert territories of contemporary Iraq; and secondly, through appropriating dominant cultural and linguistic forms in British English as an anti-hegemonic stance. It is quite evident that Al Naib reworks the Shakespearean discourse in form and meaning against the backdrop of the ideological, geographical, cultural, linguistic, and religious specificities of her Iraqi culture. As representations of death, even figuratively, with bragging characteristics of the possession of ultimate power to take away a life are unacceptable and forbidden (moharram) in an Islamic culture like Iraq, Al Naib is faced with the dilemma of translating the personification of death in 'Nor shall death brag thou wonder'st in his shade'). The Qur'an makes it clear that only God possesses knowledge of when and where each person will be taken by death, thereby making it clear that the Angel of Death 
has no power of its own. The Angel of Death is generally described in Islamic sources, even literary ones, as subordinate to the unchallengeable will of God "with the most profound reverence." While the literary trope of the personification of death is recurrent in many Shakespearean plays and sonnets, Al Naib adopts a complex process of selective appropriation of Shakespeare's best known sonnets in ways that best reflect the shifting sociocultural, ideological, and religious environments of writing and translating. Rather than representing death as a sentient entity, Al Naib strategically and "deliberately changed the meaning in a way that the shade no longer belonged to death as was in the English version but now belonged to the lover" (student essay, Hanēn Keskes, 19 July 2012). One student's critical textual analysis of other rhetorical features across the two texts further reveals the ideological underpinnings of the Arabic translation:

It is evident from Al-Naib's translation that she has attempted to overcome the discrepancies between English and Arab culture through her slight modifications in the poem.... One example... is her description of the English summer; whereas summertime is celebrated in cold and wet places like England, in the Arab world, it is almost dreaded because of the intense heat and dryness. Despite differences in culture among the English and Arab, Fateena Al-Naib is able to recreate the romantic, sensual aspect of nature, and continue the extended metaphor of summer day as the poet's object of adulation. In line five, she uses the word 'tatalahhab' [to describe "the eye of heaven" instead of the verb "shines"], a unique word best described as a sudden and intense wave of heat coming over something. The word 'tajni' in the third line connotes an unwarranted, rough assault on the innocent buds, and considerably differs in level of intensity from the term "shake" in Shakespeare's version..... Linguistic equivalence takes a backseat to emotional equivalence in Al-Naib's free approach to translation.

Fateena Al-Naib employs a noticeably free method in translating Sonnet 18 , which may be cause for concern for those who emphasise strict adherence to the semantics of an original text. However, to understand the purpose and real meaning of the poem, Fateena Al-Naib needed to translate not only semantics, but the culture, and the mood, which required that she make appropriate modifications to communicate the beauty of the summer's day, and Sonnet 18. 
Posing a challenge for students' acquired sense of "good" translations, their learned translation strategies and the more conventional perspectives of translation theorists like Landers, Vladimir Nabokov, and Eugene Nida, some students' apparent anxiety and rejection of oppositional approaches to translation stirred alternative views from others, as is evident in the following unsolicited heated classroom exchanges that address issues of authorship, culture, and ideology in the translation act:

Nathalie: That is not translation. Fatahit $3 a$ hseba (local idiomatic expression for acting freely and breaking from all restraints).

Hala: Even with those changes, the spirit and flow was preserved. In the Arab world as opposed to the western way of living, we approach love, beauty, and death differently. She Arabized the poem but kept the Modern Iraqi Arabic register.

Rasha: She captures the Shakespearean spirit but adapts it to an Arab Iraqi atmosphere.

Hanën: As an Arab reader who might not know English, I would like to get an exact idea of what Shakespeare's sonnet is about. As a translator, you have to convey the original text's message and meaning as it is.

Hala: Then read another translation. A more literal translation is Hussein Dabbagh's, but it was boring and flat. It had no impact on me. Interpretation in itself is a big part of translation.

Such challenges to the notions of equivalence, accuracy, and faithfulness in any translation act posed by similar translations are exactly the points of friction that writing pedagogy across translingual lines should be about, tensions around the "politics of translation across spaces, times, ideologies, and cultures, and the implications of these not just for writing/texts...but for...collective knowledge construction at large" (Ramanathan 224). Translation is located in particular local milieus both spatially and temporally (Ramanathan; Pennycook). A translingual approach to writing "indelibly tied to 
translation and the diversity of meaning" (34) further foregrounds the intricate relationship between specific instances of languaging, writing, thinking, and living (Lu and Horner, Writing Conventions). This vision of translation is in keeping with the socalled oppositional school in Translation Studies, and particularly the "rewriting" theory put forward by André Lefevre, or what Pennycook describes as "critical approaches to translation" ("Critical" 14) that complicate translation in its more traditional sense as an act of unidirectional, mechanical transfer from one language into another and renders translation a "highly mediated social act" (Zhao 39; also see Asimakoulas and Rogers). Critical approaches to translation contest conventional unrealistic notions of “equivalency," “transparency," "neutrality" (see Dingwaney and Maier 315; Venuti 25; Cronin 35; Bassnett and Trivedi 2), "fidelity" and "faithful[ness]" (see Dingwaney and Maier 313), and "accuracy" (see Dingwaney and Maier 82, 103) in any translation process. Under a view of translation as meaning-creation, critical translation work involves a "dialectic" process always embedded in cultural and political systems, in history, contexts, and ideologies across boundaries of time and space (physical, cultural, or linguistic) (Asimakoulas and Rogers 9). Building on Andre Lefevre's framework and challenging traditional views of translation as neutral and apolitical, Susan Bassnett and Harish Trivedi in Postcolonial Translation: Theory and Practice remind us that translation should be envisioned as "rewriting" or as " "new writing"" (8) that is "not an innocent, transparent activity but...involves a relationship of equality between texts, authors, or systems" (2) and is always "embedded in cultural and political systems, and in history" (6). As the "preferred future" (Pennycook, "Critical" 8) of writing pedagogy, translingualism reimagines "critical" translation" as a potential pedagogical tool for the

\footnotetext{
${ }^{41}$ Also dissociated from reductive notions of translation that: (1) may counterintuitively be seen as part of
} 
diversification of not only languages in the writing classroom but meanings, and most importantly the nuánces of meanings, or what one of my teaching participants defines as "the little differences that make all the difference." Repositioning English in the writing classroom "as a language always in translation" (Pennycook, "English"), always "rewritten by its rewriters" (Lefevre 4), this pedagogy acknowledges and deepens the translingual-translatorial agency of rewriters in ways that prompt their rewritings to go beyond restricting questions of whether or not particular words or phrases have literal or close equivalents in English.

the broader activity of reporting and reproducing previously existent texts, which also covers acts such as quotations, paraphrases, summaries, and reviews; and (2) have come down to us throughout the history of the English language teaching enterprise. For a more detailed survey of the history of translation in ELT methodologies, particularly that associated with the Grammar Translation Method advanced in Europe around 1900 and the later Audio-Lingual Method, see Howard and Widdowson, A History of ELT. 


\section{CHAPTER FIVE}

\section{CONCLUSION: REWORKING ENGLISH AS A LANGUAGE OF "TRANSLINGUAL" PRACTICE}

In this study, I use the multilingual location of Lebanon, and particularly the institutional setting of the American University of Beirut or AUB, as a limit case for investigating the mismatch between multilingualism in official language-in-education policies and sociolinguistic landscapes on one hand and dominating monolingualist ideologies in the teaching and learning of writing on another. What can be of particular interest to U.S. compositionists pursuing translingual directions in their own writing programs and classrooms is the room for combating monolingualism opened up by two significant aspects of language practice in Lebanon: First, the vitality and viability of language resources on the ground where, unlike in the U.S., multilingualism is both a statistical and cultural norm; and secondly, actively multilingual official language and language-in-education policies that enable and promote foreign language learning and translation, thereby significantly contrasting with a tacit policy of English-Only as a historical and continuing norm in the U.S. Despite satisfying these two favorable conditions for translingualism, under the dominance of monolingualist ideologies in the academic knowledge market in Lebanon as well as internationally, the engagement with other languages and cross-language practices sanctioned by official policies and vibrant language practices on the ground remains hindered by the monolingualism governing 
writing pedagogy and curriculum design. The main point I wish to make here is that the academy's difficulty in fully utilizing these two crucial aspects of language practice in Lebanon can shed insight on what U.S. compositionists might expect to face in their growing concern to combat monolingualism and in considering possible shifts into more translingual approaches and policies. A close look in this study at intersections and divergences of linguistic landscapes between Lebanon and the U.S. in degrees of commitment to translingualism points towards the insufficiency of fighting for actively multilingual language policies if not coupled with aggressive changes in the design of writing curricula that would more forcefully invite translingual work. U.S. composition scholars and teachers might, therefore, proceed in their effort to challenge monolingualism in terms of not only language policy but also language dispositions in curriculum design and pedagogical practices.

\section{Implications for Rethinking Language Dispositions}

With the rise of the knowledge economy in a world defined by global capitalism, more language users across the world are, as Catherine Prendergast puts it, "buying into English" both materially and psychologically, "much like buying the "right" stock" (8), which is increasingly manipulated and controlled by "powerful players in powerful countries" (3). Based on her critical ethnographic study of English language politics in Slovakia, Prendergast argues that "English [is] no longer a perk" as "it [has] become an imperative" (11). It has been increasingly likened to "a form of currency" (6) or an "unavoidable" (8) commodity within "systems of exchange ... and storehouses of values"

in the linguistic market. According to Prendergast, "linguistic fixity [in the academic and 
business market] is the promise the global economy makes but never fulfills" (22) and that perpetuates the validity of a longstanding monolingual paradigm. Pertaining to my investigation of the politics of language in the teaching and learning of writing at AUB, multilingual students in this study like Naser, Nathalie and her sister, Christophe, and Maria, who are investing their time, energy, and money into mastering English, seem to buy into the legitimacy of claims about the primacy and promise of Standardized English, and this in turn prevents them from seeing much value in English other than a way to get by academically and professionally. The problem here can be identified as lying in the commodification of English in the academy and the understanding and view of English as a discrete, fixed, and non-living language. English in educational landscapes is represented as a "saleable commodity" in the professional domain and "an investment in cultural capital" that retains high exchange value in the academic and business labor market (Tan and Rubdy 3). In contrast, Diva and Kappa's relationship with English seems to illustrate alternative translingual dispositions towards English as a "living" language inevitably and indelibly interpenetrating and interpenetrated by other languages like Greek, Arabic, French, or Italian. Applied linguist Alastair Pennycook has argued that English needs to always be seen in flux with other languages and language practices, always a language "in translation" and transformation. In contrast to monolingualist assumptions that propagate the one-ness of English, Suresh Canagarajah in his recent book Translingual Practice: Global Englishes and Cosmopolitan Relations states that a translingual orientation adds complexity to English as "a contact language" (68) that is "highly fluid and variable" (71) and "always in a state of becoming, open to reconstitution through ongoing socially situated practices" (70). 
The implied pedagogy for taking a translingual approach in language and literacy instruction is that of reaffirming and engaging the agency of student writers in the constant and active production, revision, and sedimentation of language while utilizing the full multiplicity of their linguistic resources. Under a translingual approach to the teaching of writing, rather than being a "rock" to Nathalie or a "narrow space" to students like Naser, English can become another "resource" for meaning making that students are encouraged to work on and with. We can take multilingual students like Diva and KAPPA as examples of how and why writing teachers might prompt students like Nathalie and Naser to exercise agency and mobilize their multilingual resources when using English. Our writing pedagogies and curriculum designs need to provide opportunities for these students to tap into their language expertise and relations in ways that contest the rigidity of the kind of writing in English they feel is expected of them in the academy or their chosen profession. As Suresh Canagarajah in Reclaiming the Local in Language Policy and Practice reminds us,

the classroom is an important site of policymaking at the microsocial level. The values and practices inculcated in the classroom have the power to reconfigure language relations (xxii).

We can begin by involving our students in the kinds of crucial questions that Min-Zhan Lu puts forward in "Living English Work," questions of not only what English Only writing instruction can do for them but also, what it cannot do for them, that is "address their needs to use English to articulate experiences and circumstances of life consistently discredited by standardized English usages" (46). The responses of multilingual students in this study have highlighted differences in personal, linguistic, social, cultural, regional, and historical experiences and have brought our attention to all the particularities and 
idiosyncrasies of significance to language users that often go unnoticed under unidirectional English-Only monolingual projections. Putting English to work as a "living" language, Lu argues that

[1]iving-English users of English situate their relations to diverse languages and diverse uses of English in the context of a reading of history and of the world that treats intra- and inter-national transactions on all levels (...geopolitical, economic, cultural, technological, linguistic) and in all areas (school, home, paid work, civic, life worlds, etc.) as co-constitutive (46; emphasis added)

Following a translingual approach, let me suggest a set of possible writing assignments for writing courses that bring in personal narrative into their designs and that engage students in close readings of diverse stylistic choices in written texts. Students can compose literacy narratives of their reading and writing practices in diverse languages and other ways of using English, while addressing questions of how, why, where, when, and with whom. In a follow-up assignment, they can be asked to reread and revise existing academic pieces they are writing or have already written in light of their literacy narratives. More specifically, students can be invited to identify moments in their writing where they felt confined or unsatisfied with their meaning production. They can be asked to reflect on these instances and consider alternative ways to rewrite them in light of the meaningful language relations emerging in their literacy narratives. This assignment can also encourage students to assess and negotiate rhetorical cues in their own writing in anticipation of conventional readers' expectations. Such open deliberations over the rhetorical effectiveness of their own writing practices can give students sustained experience with strategies of accommodation, negotiation, revision, and translation of meaning in collaboration with their readers in each rhetorical situation. 
As the personal literacy narrative has become a popular and compelling genre in first-year writing classrooms that serves as an opportunity towards an in-depth investigation of a writer's relationship with literacy and language, the following sequence of assignments for a multilingual section of first year writing that I am currently designing is one possible way for exploring the complexity and heterogeneity of writing students' literacy and language landscapes:

Assignment 1: Compose a 3-5 page narrative that vividly describes your personal experiences of literacy learning and development (reading and/or writing textual and/or multimodal productions) and of language use (both written and spoken) during significant periods in your life. Pay particular attention to giving specific accounts of those experiences and practices with literacy and language in terms of: Who is/are involved? Which language(s)/language varieties? Which media? Where? When? How? and Why?

Here's a list of possible questions you might decide to consider in your narrative: - What ways of using English and/or other language(s) that are important to you and that you utilize frequently (in physical, digital, and/or virtual spaces) do you feel have no room in the college English writing classroom?

- How are these critical to your work with English and/or other languages (be it in textual and/or multimodal formats) personally? Culturally? Emotionally? and intellectually?

- What kinds of social relations, emotions, actions, and future aspirations (personally, academically, or professionally?) do these allow you to maintain?

- What effects do these have on your reading and writing?

- Which of these ways of (re)using English and/or other language(s) make you feel that you are a strong reader and writer and good with language? In what ways? and Why?

Assignment 2: Use this literacy narrative assignment as a chance for you to think through and continue the work you've already begun on a piece of your own choice that involves writing (for this or any other course). Reread the essay you've chosen and locate significant instances in which you feel that the "kind of English" that you're expected to use in the writing classroom is hindering and standing in the way of your intended meaning(s) and/or moments in your writing in which you feel that you don't sound like "yourself." These moments might be single terms used, phrases, sentences, or entire sections in your written work. As you read and reread your previous work, take notes on what you find to be 
difficult, unsatisfactory, and unnatural in what you've read. Be prepared to submit a copy of your work that clearly shows your personal annotations along with a brief description (1-2 pages) of why you chose those moments in particular and how they make you feel about your work with English in the writing classroom.

Assignment 3: After you've read and taken notes on the essay of your choice, consider how you would revise and "rewrite" (modify? substitute? add to? reword? rearrange?) the term(s), phrase(s), sentence(s), or entire section(s) you've selected in Assignment \#2 using the language(s) or dialect(s) you've identified as important to you in your literacy narrative in Assignment \#1.

For the purpose of this assignment, imagine that your current work is not intended for an academic audience. What possible alternatives to these existing term(s), phrase(s), sentence(s), or paragraph(s) can you offer? To help you in considering alternatives, you can consult your literacy narrative that you've composed for Assignment \# 1. What difference do these new ways of saying/writing/representing make to the "original" meaning and understanding, and how?

Assignment 4: One challenge you may face after working on Assignment \#3 is how your "unconventional" writing style will be received or even comprehended by your reader(s). Because our focus in this course is on the relationship between reader, writer, and language use, the difficulties and complexity that Assignment \#3 may present can, in fact, provide a great opportunity for exploring this intricate relationship between readers and writers as a process of establishing mutual collaboration for the co-construction of meaning. Like most of the scholarly readings we have done in this class, your writing is aimed toward an academic audience (in this case, your peers and your instructor) who might not share the same languages and language varieties in your own repertoire. In light of your conventional academic audiences' expectations for successful communication, explain how you would work (or consider not to?) on the "readability" and "intelligibility" of your prose and what kind of rhetorical cues in your writing you would provide (or not?) for your traditional reader(s) and why.

Assignment 5: Draft an essay in which you reflect back on the kind of "rewriting" and "translation" that you engaged in in Assignments \# 3 \& 4. Refer to concrete examples from your work in Assignments \# 3 \& 4 to draw conclusions about what meanings and interpretations get lost and/or are gained in this process of translation.

Special attention in the design of writing curricula to the politics of meaning making and the problematic of translation that lie at the heart of translingualism is a 
necessary start for any translingual writing classroom. As depicted in the sequenced writing assignments listed above, we can weave in work of translation across languages and language practices into existing academic writing curricula as a rhetorical act of negotiating and re-writing English. Based on some students' recommendations ${ }^{42}$, crosslanguage work can become an integral part of argument-based writing and the traditional research paper assignment that is very popular in first year writing courses. In keeping with the learning outcomes of a wide range of first year writing courses that have the overarching goal of developing students' grasp of the analytical, organizational, and synthetic process of research writing and working with academic research sources, we can engage students in locating, evaluating, effectively incorporating, and properly citing substantive non-English academic scholarship into their own research.

With all multilingual students in this study, we witness the importance of preserving the complexity of language relations and expertise to their own personal, professional, social, academic, and intellectual development. Clearly, Kappa's use of Italian academic sources advances his, and his readers', intellectual grasp of research. To preclude cross-language work in the acts of reading and writing for many multilingual students like KAPPA is to hinder important knowledge-making opportunities. Writing teachers wishing to labor along translingual lines can show informed awareness in their language policies and writing pedagogies towards the diversity and complexity of students' lived relations with English and other languages. English needs to be seen as always and for all students in the writing classroom, both multilingual and monolingual, a language in translation, a language of translingual practice. From a translingual

\footnotetext{
${ }^{42}$ For instance, Christophe's comment: "We're living this relationship between languages everyday so why not talk about it, discuss it, take advantage of it, incorporate it...."
} 
perspective, we can begin by recognizing along with our students the potential value to intellectual and academic involvement of translingual work that engages the vibrancy of the constant traffic in and out of English and the necessity of reworking English as a "living" language through that traffic.

Toward a Translingual Norm: Translingual Dispositions in Light of "Conditions of (Im)possibility" in Writing Programs and Courses

In a culturally and statistically sustained translingual space like Lebanon, we can see tangible evidence that despite the dominance of multilingualism in sociolinguistic and sociocultural realities and in language policies, literacy education forcefully sponsors longstanding monolingualist predispositions about language and language relations. The findings in this study confirm that a few writing teachers in multilingual settings still labor under various monolingualist assumptions about language(s) and language difference. One of the driving forces behind such monolingualist orientations is the common misperception that exposure to other languages and discourses in the writing classroom can be very harmful to the attainment of Standard English and can thereby erode language standards. Another dominant perception propagating among some writing teachers is that composing in non-dominant language practices is not fit for academic contexts as there is a common tendency in language pedagogy to use only the "target" language in the classroom, thereby forbidding the use of all other languages and language practices at all times. As monolingualist ideologies towards language and cultural diversity still have strong advocates, it is worth pointing out that literacy laborers are operating under a wide range of socio-economic, political, and ideological conditions 
that are not of their own making and largely beyond their control. These conditions might generate classroom language policies that reinforce English-Only instruction and drastically influence the pedagogical treatment of languages and language relations by most writing teachers.

Such conditioned practices raise questions about institutional power, discourse, and epistemology. The Foucauldian panoptic modality of power serves as a useful metaphor for defining power relations and for identifying the distribution and operation of power in educational landscapes. Following Althusser's framework that characterizes schooling as being one of the key ideological apparatuses ${ }^{43}$ for reproducing power, culture, knowledge, and discourse, university-wide literacy education heavily supports and reproduces dominant ideological practices and long held assumptions about language and language relations. These deeply held and entrenched beliefs and dispositions toward language(s) and language use in writing that are embedded in institutional and programmatic practices and are perpetuated in "continuous, systematic" academic discourse (Foucault 549) contribute heavily to preventing literacy laborers from exercising "sociolinguistically and politically legitimate" (Tupas 170) and realistic ways of treating and working with English.

Going against the grain and dispelling dominant monolingual approaches to language difference, which have eschewed the complexity and depth of understanding the fluidity and dynamism of language use and the permeability of language boundaries, can raise a lot of concerns among writing teachers who have typically been trained to be English-only professionals. It seems that though most writing teachers are critically aware of the interactional and sociolinguistic legitimacy and vibrancy of translingual

\footnotetext{
${ }^{43}$ What Louis Althusser labels as "Ideological State Apparatuses" (ISA) (699).
} 
practices, they also feel that such alternative practices cannot be extended beyond actual discourse into the academic realm in which the rigidity and uniformity of language practices are taken for granted. Most, if not all, teaching participants in this study showed critical awareness of the sociolinguistics and politics of language in their own academic writing classroom; however, their pedagogical and assessment practices remained largely conditioned by the "expressed and real power" of Standard English, which is heavily invested with domineering "power and ideology which cannot be ignored" (Tupas 179). Positioned amid such tensions between political forces on one hand and their own ideological considerations on another, these writing teachers, are sometimes conditioned to go against their belief system and accept the symbolic power of Standard English in the academy over its ordinary users and their subsequent capital (Bourdieu 58). After all, as Luke explains citing Bourdieu, "capital is only capital if it is recognized as such; that is, if it is granted legitimacy, symbolic capital, within a larger social and cultural field" (329). Writing teachers are constantly operating under what Ruanni Tupas describes as "conditions of (im)possibility," since they must inevitably contend with conflicting dominant and emerging language ideologies in their daily work with language (170 and passim). Based on a study on how Phillipino teachers of English deal with the politics of Standard English and World Englishes, Tupas argues that [t]eachers work and live in conditions of (im) possibility, historically positioned to generate both status quo and change in education and, more generally, in society (173).

As the undeniable symbolic power of Standard Written English governs policies and practices in educational landscapes, writing teachers in the U.S. and elsewhere wishing to labor along translingual lines might feel that they are forced to negotiate the growing tensions between the felt need to teach Standard Written English conventions on 
one hand and emerging recommendations for pursuing cross-language relations on another. It is often assumed that invitations towards translingual work in the writing classroom clash with literacy laborers' existing responsibility of providing excellent access to English. On the contrary, a translingual approach calls for changes in predispositions and practices from those of monolingualism that are within the reach of the existing powers of writing teachers. Taking a translingual approach does not entail sidestepping the teaching of language standards but rather involves doing "more, not less" with these (Horner et. al, "Language" 304; emphasis in original). A translingual approach involves recognizing that standards and conventions of written English are actually "heterogeneous, fluid, ...negotiable" (Horner et. al, "Language" 305), and changeable across purposes, audiences, genres, media, languages, cultures, and disciplines (311). Rather than indoctrinating a fixed, uniform set of standardized written rules, enacting a translingual approach would instead involve repositioning written language standards from the center of teaching into gateways for more critical engagements along with students about the working of language and the construction of meaning amid differences in rhetorical traditions across discourses, languages, disciplines, genres, and modalities (see Lu, "Professing"). Under a translingual approach, writing students are challenged to question sedimented structures and meanings commonly recommended by the dominant discourse and culture, and to rewrite these while critically considering a wide range of alternatives. As they reflect on, revise, and even recompose knowledge, writing students under a translingual approach are enabled to exercise agency over language and literacy practices and enact valued habits of the mind and increased metalinguistic awareness. A translingual approach, therefore, shifts 
attention from fluent mastery of SWE conventions and correctness in writing into matters of "writerly agency"- "the ways in which individual language users fashion and refashion standardized conventions, subjectivity, the world, and their relations to others and the world" (Lu and Horner, "Translingual Literacy").

Since dominant practices and politics operate in conjunction with the global economy and global geopolitical trends, a push towards translingualism that is also occurring globally can complicate dominant, uncritical allegiances towards Standard English in the academy. The exponential centrality of language in the new globalized economy now places a premium on alternative modes of linguistic communication and translingual meaning making strategies (see Heller 539). In increasingly multilingual and multicultural realities, not only multilingual but also monolingual language users have to now draw on discursive resources from a wide variety of sources and be proficient in "negotiating multiple dialects, registers, discourses, [and when needed, even] languages" in order to function effectively in translingual and transnational contact situations (Canagarajah, Reclaiming xxv). Movements aligned with a translingual approach to language difference in composition and applied linguistics ${ }^{44}$ have already started to emerge, proliferate, and enjoy wider currency, as represented by the work of Bruce Horner et al.; Suresh Canagarajah; Juan Guerra; Alastair Pennycook; Claire Kramsch; Jan Blommaert, and many others and even in Europe through the work of

\footnotetext{
${ }^{44}$ This is also in concert with the development of work aiming to contest monolingualism and positing alternative neologisms, namely code-meshing (Canagarajah, "The Place of World Englishes"; Young; Young and Martinez); plurilingualism (Council of Europe/Conseil de l'Europe; Daniel Coste, Danièle Moore, et Geneviève Zarate, "Competence Plurilingue"; Philippe Blanchet et Pierre Martinez, Pratiques Innovantes du Plurilinguisme); creolitél Diversalité (Jean Bernabé, Patrick Chamoiseau, and Raphaël Confiant, Éloge de la Créolité); translanguaging (Ofelia Garcia, Bilingual Education; Canagarajah, "Translanguaging" ); transcultural literacy (Min-Zhan Lu, "Metaphors Matter"); post-monolingualism (Yasmin Yildiz, "Beyond the Mother Tongue"); individuals/languages -in-motion (Guerra, "CodeSegregation").
} 
Philippe Blanchet; Jean Bernabé et al., Zarate et al., etc. Given the vibrant interaction and intermingling among World Englishes and other languages in their classrooms, programs, and communities, literacy laborers cannot not pay attention anymore to emerging calls for contesting monolingual ideologies and enacting more translingual dispositions towards language and language difference. As they struggle with their translingual-oriented pedagogies for recognition and legitimacy in the academy and its programs, and as they grapple with the complexity and diversity of language relations in their own writing classrooms, literacy laborers can be in a position to take a broad array of local decisions that are still aligned with broader social, cultural, political, ideological, and economic conditions. The findings with student and teaching participants in this study have clearly shown that not only should we but that it is also possible, excitingly challenging, and an accomplishment to pursue cross-language relations in the college writing classroom. Our practices and policies need to account for the arising and exponential linguistic and discursive changes. In addition to increased attention to learning outcomes in order to identify and assess students' writing development and learning in first writing courses, we can start practicing translingual dispositions by paying special attention to "incomes" (Bawarshi 197; Guerra 5) - to the full multiplicity of "linguistic and discursive resources students bring with them... and, more important, to how they can use these resources within academic writing contexts" (Bawarshi 197). A translingual approach positions the full range of linguistic repertoires already flowing into the writing classroom as valuable resources to be tapped into and utilized for more critical deliberation about the working of language and the constant mediation of language in actual practice rather than as a problem to be eradicated or a linguistic right 
to be merely tolerated. The writing assignments that I've already mentioned in the previous section are some examples of translingual work that is in keeping with the learning outcomes of first year writing courses while also inviting students for more intellectual engagement and depth. As Michael Joseph and Esther Ramani put it, in increasingly translingual and transcultural contact situations, it is not hard to imagine that we may look back one day and "begin to wonder how we ever believed that an EnglishOnly education was the best imaginable" (195). As writing scholars and teachers, we need to engage along with our students in discussions about what the process of reworking and rewriting English in the writing classroom actually involves and how to best negotiate the acceptability of these alternative ways of working through language difference with conventional audiences for the sake of collaboration, successful communication, and the co-construction of meaning.

As we come to terms with linguistic heterogeneity that is increasing in number and intensity in our own classrooms, programs, and even in our communities under the complex communicative networks of the twenty-first century, we need to move forward toward more contextual, responsive, and meaningful policies and practices. While a translingual approach opens up new possibilities and complex ways of thinking about language and language users' agency, Canagarajah cautions that monolingual ideologies and discourses remain to be highly "powerful, and have the possibility of being reproduced in social relationships, educational settings, and language interactions." (Translingual Practice 201). In this sense, "thinking big while acting small” (Tupas 196) can be the theory of practice behind emerging translingual efforts. Translingual dispositions towards language and language difference can be best achieved in small- 
scale, local efforts. This local orientation calls for a close examination of the way language relations are understood and enacted locally- in one's own writing program, writing courses, and writing center- and of the nature of local language policies and pedagogical practices and the ideologies that grant them their power and legitimacy. As we are operating with a view of language that contests monolingualist assumptions, a localized perspective enables a more critical examination of common perceptions about literacy, language use, and language learning (see Tardy). Instead of putting off much needed and timely translingual work, we can start by accommodating the actual translingual practices of incoming students into the design of professional and academic writing courses and by prompting them to draw on all their linguistic and discursive resources for the sake of both monolingual and multilingual students' academic, professional, and intellectual advancement and humanistic understanding. To best enact a translingual ideological stance towards language and language use in writing, our literacy labor along with our students' needs to capture the actual fluid nature of English and its constant trafficking and mutually shaping relation with other languages and language practices.

This study has captured writing students' and teachers' views of language, language relations, and the conflicting language ideologies they are forced to come to terms with in the writing classroom, and has provided insights into the challenges and decisions they confront when working through language difference. By highlighting the exigence for a translingual approach that is directly relevant for the abilities, needs, and desires of writing students, this study also put forward strategies of change aligned with translingual approaches to writing pedagogies. The immediate implications and specific 
logistics of critical interventions along translingual lines have yet to be worked out and translated into actual practices. Based upon the confessions of its advocates, an emerging project of translingualism in U.S. writing programs is still "at the beginning stages of [its] learning efforts..., which by definition will require the ideas and energy of many including literacy workers using diverse languages, from outside as well as within the Anglo-American sphere" (Horner et al., "Language" 306). Future projects still need to address the implications of such growing efforts to contest monolingualism and move towards translingualism for testing and assessment, designing WAC/WID courses, planning increased collaborations with foreign language departments and literacy workers laboring with diverse languages, writing center work, teacher preparation programs, and faculty development initiatives. 


\section{REFERENCES}

Althusser, Louis. "Ideology and Ideological State Apparatuses." Literary Theory, an Anthology. Ed. Julie Rivkin and Michael Ryan. Malden, Mass: Blackwell, 1998. 693-702. Print.

Apple, Michael W., Jane Kenway, and Michael Singh, eds. Globalizing Education: Policies, Pedagogies, and Politics. New York: Peter Lang, 2007. Print.

Arsenian-Ekmekji, Arda. Revisiting Artin in Beirut: How Armenians are Viewed in Lebanon. Web 28 Feb. 2011.

$<\underline{\text { http://static.scribd.com/docs/c614o7k6p07gj.swf?INITIAL VIEW=width }}>$.

Asimakoulas, Dimitris, and Margaret Rogers. Translation and Opposition. Bristol: Multilingual Matters, 2011. Print.

AUB Undergraduate Catalogue 2011-2012. Web 1 Oct. 2012. <http://www.aub.edu.lb/registrar/Pages/catalogue 11-12.aspx $>$.

Auer, Peter. "Monolingual Bias in Bilingualism Research, or: Why Bilingual Talk Is (Still) a Challenge for Linguistics." Bilingualism: A Social Approach. Monica Heller. Basingstoke: Macmillan, 2007. 319-39. Print.

Auer, Peter, and Li Wei. Handbook of Multilingualism and Multilingual Communication. Berlin: Mouton de Gruyter, 2007. Print.

Baalbaki, Rula. Course Packet. English 233. American University of Beirut, English Department. Spring 2012. 
Ball, Arnetha, and Ted Lardner. "Dispositions toward Language: Teacher Constructs of Knowledge and the Ann Arbor Black English Case.” CCC 48 (1997): 469-85. Print.

Bassnett, Susan, and Harish Trivedi, eds. Postcolonial Translation: Theory and Practice. London and New York: Routledge, 1999. Print.

Bawarshi, Anis. "The Genre Function.” College English 62.3 (2000): 335-60. Print.

—. "The Challenges and Possibilities of Taking up Multiple Discursive Resources in U.S. College Composition." Horner, Lu, and Matsuda 196-203. Print.

Bean, Janet, et al. "Should We Invite Students to Write in Home Languages? Complicating the Yes/No Debate." Composition Studies 31.1 (2003): 25-42. Print. Bernabé, Jean, Patrick Chamoiseau, and Raphaël Confiant. Éloge De La Créolité. 1 ed. Paris: Gallimard, 1989. Print.

Bex, Tony, and Richard J. Watts, eds. Standard English: The Widening Debate. London: Routledge, 1999. Print.

Bhatt, Rakesh. "Expert Discourses, Local Practices, and Hybridity: The Case of Indian Englishes. Reclaiming the Local in Language Policy and Practice. Ed. Suresh Canagarajah. Mahwah, N.J: Lawrence Erlbaum, 2005. 25-54. Print.

Blanchet, Phillippe. et Pierre Martinez (Dir.). Pratiques innovantes du plurilinguisme, émergence et prise en compte en situations francophones, Paris, Editions des Archives Contemporaines \& AUF, 2010.

Blommaert, Jan. Grassroots Literacy: Writing, Identity and Voice in Central Africa. London: Routledge, 2008. Print. 
Bou Ayash, Nancy. “Hi-ein, Hi يين Hi? Translingual Practices from Lebanon and Mainstream Literacy Education.” Literacy as Translingual Practice: Between Communities and Classrooms. Ed. Suresh Canagarajah. New York: Routledge, 2013. 96-103. Print.

—. "U.S. Translingualism through a Cross-National and Cross-Linguistic Lens." Working Englishes in Rhetoric and Composition: Global-local Contexts, Commitments, Consequences. Ed. Bruce Horner and Karen Kopelson. forthcoming. Southern Illinois University Press.

BouJaoude, Souama and Ghazi Ghaith. "Educational Reform at a Time of Change: The Case of Lebanon." Education Reform in Societies in Transition: International Perspectives. Ed. Jaya Earnest and David Treagust. Rotterdam: Sense Publishers, 2006. 193-212. Print.

Bourdieu, Pierre. Language and Symbolic Power. Ed. John B. Thompson. Trans. Gino Raymond and Matthew Adamson. Cambridge, MA: Harvard UP, 1991. Print. Broad, Bob. "Strategies and Passions in Empirical Qualitative Research." Writing Studies Research in Practice: Methods and Methodologies. Lee Nickoson and Mary P. Sheridan. Carbondale: Southern Illinois U P, 2012. 197-209. Print.

Burbules, Nicholas C., and Carlos Alberto Torres, eds. Globalization and Education: Critical Perspectives. London: Routledge, 2000. Print.

Burns, Norman. Annual Reports: Board of Managers, Syrian Protestant College, $1866-$ 67-1901-02. Print.

Calvet, L. Jean. La Guerre des Langues et les Politiques Linguistiques. Paris: Payot, 1987. Print. 
Canagarajah, Suresh. "Codemeshing in Academic Writing: Identifying Teachable Strategies of Translanguaging." Modern Language Journal 95.3 (2011): 401-417. Print.

—. "Lingua Franca English, Multilingual Communities, and Language Acquisition." Modern Language Journal 91.1 (2007): 923-39. Print.

—. "Multilingual Strategies of Negotiating English: From Conversation to Writing." $J A C$ 29.1-2 (2009): 17-48. Print.

—. "Negotiating the Local in English as a Lingua Franca." Annual Review of Applied Linguistics 26 (2006): 197-218. Print.

-, ed. Reclaiming the Local in Language Policy and Practice. Mahwah, N.J: Lawrence Erlbaum, 2005. Print.

—. "The Place of World Englishes in Composition: Pluralization Continued." $C C C$ 57.4 (2006): 586-619. Print.

—. "Toward a Writing Pedagogy of Shuttling between Languages: Learning from Multilingual Writers." College English 68.6 (2006): 589-604. Print.

—. "Translanguaging in the Classroom: Emerging Issues for Research and Pedagogy." Applied Linguistics Review 2 (2011): 1-28. Print.

—. Translingual Practice: Global Englishes and Cosmopolitan Relations. Milton Park, Abingdon, Oxon: Routledge, 2013. Print. ed. Literacy as Translingual Practice: Between Communities and Classrooms. New York: Routledge, 2013. Print.

CCCC. "Guideline on the National Language Policy". 1992. Web.

CCCC. "Students' Right to their own Language". 1974. Web. 
Chomsky, Noam. Knowledge of Language: Its Nature, Origin, and Use. New York: Praeger, 1986. Print.

—. Rules and Representations. Oxford: Blackwell, 1980. Print.

Cope, Bill, and Mary Kalantzis, eds. Multiliteracies: Literacy Learning and the Design of Social Futures. London: Routledge, 2000. Print.

Council of Europe/Conseil de l'Europe. Common European Framework of Reference for Languages: Learning, Teaching, Assessment. Cambridge: Cambridge UP, 2001. Print.

Cronin, Michael. Translation and Globalization. London: Routledge, 2003. Print.

Delpit, Lisa. Other People's Children: Cultural Conflict in the Classroom. New York: New Press, 2006. Print.

—. "The Politics of Teaching Literate Discourse." Freedom's Plow: Teaching in the Multicultural Classroom. Ed. Theresa Perry and James W. Fraser. New York: Routledge, 1993. 285-95. Print.

—. "The Silenced Dialogue: Dialogue: Power and Pedagogy in Educating Other People's Children." Harvard Educational Review 58 (1988): 280-98. Print.

—. "What Should Teachers Do Ebonics and Culturally Responsive Instruction." The Real Ebonics Debate: Power, Language, and the Education of African-American Children. Theresa Perry and Lisa Delpit. Boston: Beacon, 1998. Print.

De Saussure, Ferdinand. "Course in General Linguistics." Literary Theory: An Anthology. Julie Rivkin and Michael Ryan. UK: Blackwell, 2004. 59-71. Print. 
Diab, Rula. "Political and Socio-Cultural Factors in Foreign Language Education: The Case of Lebanon." Texas Papers in Foreign Language Education 5.1 (2000): 177-187. Print.

_. "University Students' Beliefs about Learning English and French in Lebanon." System 34.1 (2006): 80-96. Print.

Dingwaney, Anuradha, and Carol Maier, eds. Between Language and Cultures:

Translation and Cross-Cultural Texts. Pittsburgh: U of Pittsburgh P, 1995. Print.

Donahue, Christiane. "Cautionary Tales: Ideals and Realities in Twenty-first Century Higher Education.” Pedagogy 8.3 (2008): 537-53. Print.

—. "Internationalization and Composition Studies: Reorienting the Discourse." $C C C$ 61.2 (2009): 212-43. Print.

Dor, Daniel. "From Englishization to Imposed Multilingualism: Globalization, the Internet, and the Political Economy of the Linguistic Code." Public Culture 16.1 (2004): 97-118. Print.

Elbow, Peter. "Inviting the Mother Tongue: Beyond 'Mistakes', 'Bad English', and 'Wrong Language'." JAC 19.2 (1999): 358-88. Print.

"English is Cool in Trendy Beirut." http://www.thestar.com/news/article/264544-english-is-cool-in-trendy-beirut. (8 October 2007).

Firth, Allen, and Johannes Wagner. "On Discourse, Communication, and (Some) Fundamental Concepts in SLA Research.” Modern Language Journal 91.5(1997): 757-772. Print. 
. "Second/Foreign Language Learning as a Social Accomplishment: Elaborations on a Reconceptualized SLA.” Modern Language Journal 91.5 (2007): 800-819. Print.

Forman, Janis. "Rethinking Reading and Writing from the Perspective of Translation." College English 52. 6 (1990): 676-682. Print.

_. "Translation, Reading, and Writing: An Argument against Don Quixote." Translation Review 30-31(1989): 10-14. Print.

Foucault, Michel. "Discipline and Punish." Literary Theory, an Anthology. Ed. Julie Rivkin and Michael Ryan. Malden, Mass: Blackwell, 1998. 549-565. Print.

Foster, David, and David Russell. Writing and Learning in Cross-national Perspective: Transitions from Secondary to Higher Education. Urbana, IL: NCTE, 2002. Print.

Gal, Susan, and Judith T. Irvine. "The Boundaries of Languages and Disciplines: How Ideologies Construct Difference." Social Research 62.4 (1995): 967-1001. Print. Garcia, Ofelia. Bilingual Education in the $21^{\text {st }}$ Century: A Global Perspective. Oxford: Wiley-Blackwell, 2009. Print.

Grossman, Edith. Why Translation Matters. New Haven, CT: Yale UP, 2010. Print. Guerra, Juan C. "The Place of Intercultural Literacy in the Writing Classroom." Writing in Multicultural Settings. Ed. Carol Severino, Juan C. Guerra, and Johnnella E. Butler. New York: MLA, 1997. 248-260. Print.

_ _ "From Code-Segregation to Code-Switching to Code-Meshing: Finding Deliverance from Deficit Thinking through Language Awareness and Performance.” Literacy Research Association Yearbook, forthcoming. Print. 
Hall, Jonathan. "WAC/WID in the Next America: Re-thinking Professional Identity in the Age of the Multilingual Majority." The WAC Journal 20 (2009): 33-47. Print.

Harris, Joseph. "The Idea of Community in the Study of Writing." CCC 40.1 (1989): 11 22. Print.

Heller, Monica. "Multilingualism and Transnationalism." Handbook of Multilingualism and Multilingual Communication. Ed. Peter Auer and Li Wei. Berlin: Mouton de Gruyter, 2007. 539-554. Print.

Heller, Monica, and Marilyn Martin-Jones. Voices of Authority: Education and Linguistic Difference. Westport: Ablex, 2001. Print.

Hesford, Wendy, Edgar Singleton, and Ivonne M. García. "Laboring to Globalize a Firstyear Writing Program." The Writing Program Interrupted: Making Space for Critical Discourse. Donald Strickland, and Jeanne Gunner. Portsmouth, NH: Boynton/Cook Heinemann, 2009. 113-125. Print.

Horner, Bruce. ““'Students' Right,” English Only, and Re-Imagining the Politics of Language." College English 63.6 (2001): 741-758. Print.

Horner, Bruce, and Min-Zhan Lu. "Working Rhetoric and Composition." College English. 72.5 (2010): 470-494. Print.

_. "Resisting Monolingualism in 'English': Reading and Writing the Politics of Language." Rethinking English in Schools: A New and Constructive Stage. Ed. Viv Ellis, Carol Fox, and Brian Street. London: Continuum, 2007. 141-57. Print.

_ “Translingual Literacy, Language Difference, and Matters of Agency." College English. (forthcoming) 
Horner, Bruce and Trimbur, John. "English Only and U.S. College Composition." CCC 53(2002): 594-630. Print.

Horner, Bruce, Min-Zhan Lu, and Paul Kei Matsuda, eds. Cross-Language Relations in Composition. Carbondale: Southern Illinois UP, 2010. Print.

Horner, Bruce, Min-Zhan Lu, John Trimbur, and Jacqueline Royster. “Opinion: Language Difference: Toward a Translingual Approach." College English 73. 3 (2011): 299-317. Print.

Horner, Bruce, Christiane Donahue, and Samantha NeCamp. "Toward a Multilingual Composition Scholarship: From English Only to a Translingual Norm.” $C C C$ 63.2 (2011): 269-300. Print.

House, Juliane. "English as a Lingua Franca: A Threat to Multilingualism?" Journal of Sociolinguistics 7.4 (2003): 556-78. Print.

Howatt, Anthony P. R, and H G. Widdowson. A History of English Language Teaching. Oxford: Oxford UP, 2004. Print.

Irvine, Judith T. "When Talk Isn't Cheap: Language and Political Economy." American Ethnologist: The Journal of the American Ethnological Society 16 (1989): 248267. Print.

Irvine, Judith and Susan Gal. "Language Ideology and Linguistic Differentiation." Regimes of Language: Ideologies, Polities, and Identities. Ed. Paul V. Kroskrity. Santa Fe, NM: School of American Research P, 2000. 35-83. Print.

Jeha, Shafik. "English as the Teaching Language." Darwin and the Crisis of 1882 in the Medical Department: And the First Student Protest in the Arab World in the 
Syrian Protestant College (now the American University of Beirut). Beirut, Lebanon: American University of Beirut Press, 2004. Print.

Joseph, Michael, and Esther Ramani. "English in the World does not Mean English Everywhere: The Case for Multilingualism in the ELT/ESL Profession." English in the World: Global Rules, Global Roles. Ed. Rani Rubdy and Mario Saraceni. London: Continuum, 2006. 186-199. Print.

Kawtharani, Farah and Lokman Meho. "The Kurdish Community in Lebanon." The International Journal of Kurdish Studies, pp. 137-160, Vol. 19, no: 1-2, 2005.

Kells, Michelle Hall, Valerie Balester, and Victor Villanueva, eds. Latino/a Discourses: On Language, Identity and Literacy Education. Portsmouth, NH: Boynton/Cook, 2004. Print.

King, Nigel, and Christine Horrocks. Interviews in Qualitative Research. Los Angeles: SAGE, 2010. Print.

Kirsch, Gesa E, and Joy S. Ritchie. "Beyond the Personal: Theorizing a Politics of Location in Composition Research." CCC 46.1 (1995): 7-29. Print.

Kramsch, Claire. "The Privilege of the Intercultural Speaker." Language Learning in Intercultural Perspective: Approaches through Drama and Ethnography. Ed. Michael Byran and Michael Fleming. Cambridge: Cambridge UP, 1998. 16-31. Print.

_ _ "The Traffic in Meaning." Asia Pacific Journal of Education 26.1 (2006): 99-104. Print.

Lefevere, André. Translation, Rewriting, and the Manipulation of Literary Fame. London: Routledge, 1992. Print. 
Leung, Constant, Roxy Harris, and Ben Rampton. “The Idealised Native Speaker, Reified Ethnicities, and Classroom Realities.” TESOL Quarterly 31 (1997): 54375. Print.

Lillis, Theresa. "Bringing Writers' Voices to Writing Research: Talk around Texts." Why Writing Matters: Issues of Access and Identity in Writing Research and Pedagogy. Ed. Awena Carter, Theresa M. Lillis, and Sue Parkin. Amsterdam: John Benjamins. 2009. 169-189. Print.

Lillis, Theresa M, and Mary J. Curry. Academic Writing in a Global Context: The Politics and Practices of Publishing in English. Milton Park, Abingdon: Routledge, 2010. Print.

Lippi-Green, Rosina. English with an Accent. Routledge, 1997. Print.

Lisle, Bonnie, and Sandra Mano. "Embracing a Multicultural Rhetoric." Severino et al. 12-26. Print.

Lu, Min-Zhan. "An Essay on the Work of Composition: Composing English against the Order of Fast Capitalism." College Composition and Communication 56.1 (2004): 16-50. Print.

—."Living-English Work." College English. 68.6 (2006): 605-618. Print.

—_. "Metaphors Matter: Transcultural Literacy." JAC 29.1-2 (2009): 285-94. Print.

—. "Professing Multiculturalism: Teaching the Politics of Style." Representing the 'Other': Basic Writers and the Teaching of Basic Writing. Bruce Horner and Min-Zhan Lu. Urbana, IL: National Council of Teachers of English, 1999. 16690. Print.

Luke, Allan. "Genres of Power? Literacy Education and the Production of Capital." 
Literacy in Society. Ed. Ruqaiya Hasan and Geoff Williams. New York: Longman, 1998. 308-338. Print.

Makihara, Miki, and Bambi B. Schieffelin. Consequences of Contact: Language Ideologies and Sociocultural Transformations in Pacific Societies. Oxford: Oxford UP, 2007. Print.

Makoni, Sinfree, and Alastair Pennycook, eds. Disinventing and Reconstituting Languages. Clevedon: Buffalo UP?, 2007. Print.

Matsuda, Paul Kei. "Composition Studies and ESL Writing: a Disciplinary Division of Labor." College Composition and Communication 50.4 (1999): 699-721. Print.

—. "The Myth of Linguistic Homogeneity in U.S. College Composition." College English 68.6 (2006): 637- 51. Print.

McNeillie, Janice, and Marie-Hélène Corréard. Larousse French-English, EnglishFrench Dictionary. Paris: Larousse, 2007. Print.

MLA Ad Hoc Committee on Foreign Language. "Foreign Languages and Higher Education: New Structures for a Changed World." Profession (2007): 1-11. Print. Muchiri, Mary, Nshindi Mulamba, Greg Myers, and Deoscorous Ndoloi "Importing Composition: Teaching and Researching Academic Writing beyond North America." CCC 46 (1995): 175-98. Print.

Newkirk, Thomas. "Seduction and Betrayal in Qualitative Research." Ethics and Representation in Qualitative Research Studies. Ed. Peter Mortensen and Gesa E. Kirsch. Urbana: NCTE, 1996. 3-16. Print. 
Ninnes, Peter, and Meeri Hellstén. Internationalizing Higher Education: Critical Explorations of Pedagogy and Policy. Hong Kong: University of Hong Kong, 2005. Print.

Ofelia Garcia "Spanish Language Loss...: Implications for Language Policy in Schools." Power and Inequality in Language Education. Ed. James W. Tollefson. Cambridge, Cambridge UP, 1995. Print.

Paikeday, Thomas M. The Native Speaker Is Dead!: An Informal Discussion of a Linguistic Myth with Noam Chomsky and Other Linguists, Philosophers, Psychologists, and Lexicographers. Toronto: Paikeday Pub, 1985. Print.

Parakrama, Arjuna. De-hegemonizing Language Standards: Learning from (post)colonial Englishes About "English." Basingstoke, Hampshire: Macmillan Press, 1995. Print.

Pedersen, Anne-Marie. "Negotiating Cultural Identities through Language: Academic English in Jordan." College Composition and Communication 62.2 (2010): 283310. Print.

Pennycook, Alastair. Critical Applied Linguistics: A Critical Introduction. Mahwah, NJ: Erlbaum, 2001. Print.

—. "English as a Language Always in Translation." European Journal of English Studies 12.1 (2008): 33 - 47. Print.

—. Language as a Local Practice. London: Routledge, 2010. Print.

— . "Language, Ideology, and Hindsight: Lessons from Colonial Language Policy." Ideology, Politics, and Language Policies: Focus on English. Ed. Thomas Ricento. Amsterdam: John Benjamins, 2000. 49-65. Print. 
Pinker, Steven. The Language Instinct. New York: William Morrow, 1994. Print.

Pratt, Mary Louise. "Linguistic Utopias." The Linguistics of Writing: Arguments between Language and Literature. Ed. Nigel Fabb et al. New York: Methuen, 1987. 48-66. Print.

Prendergast, Catherine. Buying into English: Language and Investment in the New Capitalist World. Pittsburgh: U of Pittsburgh P, 2008. Print.

Ramanathan, Vaidehi. “Of Texts AND Translations AND Rhizomes: Postcolonial Anxieties AND Deracinations AND Knowledge Constructions." Critical Inquiry in Language Studies: An International Journal 3.4 (2006): 223-44. Print.

Rothenberg, Jerome. Writing Through: Translations and Variations. Middletown, CT: Wesleyan UP, 2004. Print.

Rubdy, Rani and Mario Saraceni, eds. English in the World: Global Rules, Global Roles. London: Continuum, 2006. Print.

Rubdy, Rani, and Peter K. W. Tan. Language as Commodity: Global Structures, Local Marketplaces. London: Continuum, 2008. Print.

Sante, Luc. "Lingua Franca.” Granata 59: 1997. 1-6. Print.

Schaub, Mark. "Beyond These Shores: An Argument for Internationalizing Composition." Pedagogy 3.1 (2003): 85-98. Print.

Shaaban, Kassim. Al-Lugga wa al-Taaleem/ Language and Education [in Arabic]. Beirut: Lebanese Association for Educational Studies, 2000. Print.

. "English Language Teaching in Lebanon: Challenges for the Future." Teaching English to the World: History, Curriculum, and Practice. George Braine. Mahwah, NJ: Erlbaum, 2005. 103-113. Print. 
Shabaan, Kassim and Ghazi Ghaith. Language-in-Education Policy and Planning: The Case of Lebanon. Mediterranean Journal of Educational Studies 1.2 (1996): 95105. Print.

_. Lebanon's Language-in-Education Policies: From Bilingualism to Trilingualism. Language Problems and Language Planning 23.1 (1999): 1-16. Print.

Shaery-Eisenlohr, Roschanack. Shi 'ite Lebanon: Transnational Religion and the Making of National Identities. New York: Columbia UP, 2008. Print.

Schieffelin, Bambi B, Kathryn A. Woolard, and Paul V. Kroskrity, eds. Language Ideologies: Practice and Theory. New York: Oxford UP, 1998. Print.

Schor, Sandra. "Composition Strategy as Translation." College English 48.2 (1986): 187-94. Print.

Schroeder, Christopher, Helen Fox, and Patricia Bizzell, eds. ALT/DIS: Alternative Discourses and the Academy. Portsmouth, NH: Boynton/Cook, 2002. Print. Seth, Vikram. A Suitable Boy. New York: HarperCollins, 1993. Print.

Shuck, Gail. “Combating Monolingualism: A Novice Administrator's Challenge.” WPA 30.1-2 (2006): 59-82. Print.

Silva, Tony, Ilona Leki, and Joan Carson. "Broadening the Perspective of Mainstream Composition Studies: Some Thoughts from the Disciplinary Margins." Written Communication 14.3 (1997): 398-428. Print.

Simon, Sherry. "Translating and Interlingual Creation in the Contact Zone: Border Writing in Quebec." Postcolonial Translation: Theory and Practice. Ed. Susan Bassnett and Harish Trivedi. London: Routledge, 1999. 58-74. Print. 
Smitherman, Geneva. "CCCC's Role in the Struggle for Language Rights." College Composition and Communication 50.3 (1999): 349-76. Print.

Smitherman, Geneva, and Victor Villanueva, eds. Language Diversity in the Classroom: From Intention to Practice. Carbondale: Southern Illinois UP, 2003. Print.

Spack, Ruth. "The Rhetorical Construction of Multilingual Students." TESOL Quarterly 31 (1997): 765-74. Print.

Strauss, Anselm C. and Juliet Corbin. Basics of Qualitative Research: Techniques and Procedures for Developing Grounded Theory. Thousand Oaks, CA: Sage Publications, 1998. Print.

Sullivan, Patricia. "Ethnography and the Problem of the "Other."' Ethics and Representation in Qualitative Studies of Literacy. Ed. Peter Mortensen and Gesa Kirsch. Urbana, Ill: National Council of Teachers of English, 1996. 97-119. Print. Sun, Lulu C. H. "Presenting and Mispresenting Students: Constructing an Ethic of Representation in Composition Studies." Writing on the Edge 13.2 (2003): 45-55. Print.

Syllabus for Arabic 225: Translation. Faculty of Arts and Sciences, American University of Beirut. Web 28 Feb. 2011. $<$ http://www.aub.edu.lb/fas/fas home/faculty resources/Documents/arab225.pdf. Syllabus for English 108: Beginning Translation, Spring 2010.

Syllabus for English 233: Introduction to Translation: (A Writer's Analysis of Translated Literary Texts), Summer 2012.

Syllabus for English 233: Introduction to Translation, Spring 2012. 
Tardy, Christine M. "Enacting and Transforming Local Language Policies." College Composition and Communication 62.4 (2011): 634-661. Print.

Trimbur, John. "Linguistic Memory and the Politics of U.S. English." College English. 68.6 (2006): 575-588. Print.

Tupas, T. Ruanni F. "Standard Englishes, Pedagogical Paradigms, and their Conditions of (Im)possibility." Rubdy and Saraceni 169-185. Print.

Venuti, Lawrence. The Scandals of Translation: Towards an Ethics of Difference. London: Routledge, 1998. Print.

Villa, Daniel. "No Nos Dejaremos: Writing in Spanish as an Act of Resistance". Latino/a Discourses: On Language, Identity and Literacy Education. Kells et al. 85-95. Print.

Wible, Scott. "Composing Alternatives to a National Security Language Policy." College English 71.5 (2009): 460-485. Print.

Williams, Bronwyn T. "Seeking New Worlds: The Study of Writing beyond our Classrooms." College Composition and Communication 62.1 (2010): 127-46. Print.

Williams, Joseph M. “The Phenomenology of Error." College Composition and Communication 32 (1981): 152-68. Print.

Williams, Raymond. "Dominant, Residual, and Emergent." Marxism and Literature. New York: Oxford, 1977. 121-127. Print.

Woolard, Kathryn. "Introduction: Language Ideology as a Field of Inquiry”. Language Ideologies: Practice and Theory. Schieffelin et al. 3-47. Print. 
—. "Is the Past a Foreign Country?: Time, Language Origins, and the Nation in Early Modern Spain." Journal of Linguistic Anthropology 14.1 (2004): 57-80. Print. Yildiz, Yasemin. Beyond the Mother Tongue: The Postmonolingual Condition. New York: Fordham UP, 2012. Print.

Young, Vershawn Ashanti. ""Nah, We Straight': An Argument against Code Switching." $J A C$ 29.1-2 (2009): 49-76. Print.

Young, Vershawn, and Aja Y. Martinez, eds. Code-Meshing as World English: Pedagogy, Policy, Performance. Urbana, IL: NCTE, 2011. Print.

Zamel, Vivian. "Toward a Model of Transculturation." TESOL Quarterly 31 (1997): 341-52. Print.

Zarate, Geneviève, Danielle Lévy, and Claire Kramsch, eds. Précis du Plurilinguisme et du Pluriculturalisme. Paris: Editions des archives contemporaines, 2008. Print. Zhao, Wenjing. "How Ibsen Travels from Europe to China: Ibsenism from Archer, Shaw tto Hu Shi.” Ed. Dimitris Asimakoulas and Margaret Rogers. Translation and Opposition. Bristol: Multilingual Matters, 2011. 39- 58. Print. 


\section{APPENDIX A}

\section{Teacher Participant Demographics}

Table 1: Description of Teacher Participants (Total=15)

\begin{tabular}{cclll}
\hline Pseudonym & Gender & \multicolumn{1}{c}{ Training } & $\begin{array}{c}\text { Course } \\
\text { Currently } \\
\text { Teaching }\end{array}$ & Teaching Status \\
\hline Farah & F & M.A., AUB, Lebanon & Engl 203 & Full-time \\
Zenia & F & $\begin{array}{l}\text { M.A., Vancouver, } \\
\text { Canada }\end{array}$ & Engl 203 & Full-time \\
Randa & F & M.A., AUB, Lebanon & Engl 204 & Full-time \\
Hala & F & M.A., AUB, Lebanon & Engl 204 & Full-time \\
Hiam & F & M.A., U.S.A & Engl 204 & Full-time \\
Leyla & F & M.A., London, UK & Engl 204 & Full-time \\
Caroline & F & M.A., U.S.A & Engl 203 & Full-time \\
Rula & F & M.A., AUB, Lebanon & Engl 233 & Full-time \\
Sahar & F & M.A., AUB, Lebanon & Engl 203 & Full-time \\
Huda & F & M.A., AUB, Lebanon & Engl 203 & Full-time \\
Maya & F & M.A., AUB, Lebanon & Engl 204 & Part-time \\
Zeina & F & M.A., AUB, Lebanon & Engl 203 & Part-time \\
Rami & M & M.A.; CELTA, & Engl 204 & Part-time \\
Amal & F & M.A., AUB, Lebanon & Fren 201 & Full-time \\
\hline
\end{tabular}




\section{APPENDIX B}

\section{Student Participant Demographics}

Table 2: Description of Student participants $($ Total=41)

\begin{tabular}{|c|c|c|c|c|c|}
\hline Pseudonym & Gender & Discipline & $\begin{array}{c}\text { Language } \\
\text { Background* } \\
:\end{array}$ & $\begin{array}{c}\text { English } \\
\text { Courses } \\
\text { Taken } \\
\end{array}$ & $\begin{array}{c}\text { Secondary } \\
\text { School System } \\
\text { Attended } \\
\end{array}$ \\
\hline Ethan & $\mathrm{M}$ & $\begin{array}{l}\text { Computer } \\
\text { Communications } \\
\text { Engineering (CCE) }\end{array}$ & $\begin{array}{l}\text { English, Arabic } \\
\text { (reading and } \\
\text { writing } \\
\text { knowledge), } \\
\text { French, Armenian } \\
\text { (speaking fluency) }\end{array}$ & $\begin{array}{l}\text { Engl } \\
206,233\end{array}$ & $\begin{array}{l}\text { French System: } \\
\text { Sagesse } \\
\text { Ashrafieh, } \\
\text { Lebanon }\end{array}$ \\
\hline KAPPA & M & $\begin{array}{l}\text { Landscape Design } \\
\text { transferring into } \\
\text { Graphic Design }\end{array}$ & $\begin{array}{l}\text { Italian, French, } \\
\text { English, Latin }\end{array}$ & $\begin{array}{l}\text { Engl } \\
203,204\end{array}$ & $\begin{array}{l}\text { Received high } \\
\text { school } \\
\text { education in } \\
\text { Italy with an } \\
\text { early } \\
\text { specialization in } \\
\text { law studies }\end{array}$ \\
\hline Diva & $\mathrm{F}$ & Business & $\begin{array}{l}\text { English, Greek, } \\
\text { Arabic, French } \\
\text { (reading } \\
\text { knowledge) }\end{array}$ & $\begin{array}{l}\text { Engl } \\
203,204\end{array}$ & $\begin{array}{l}\text { Brummana } \\
\text { High school }\end{array}$ \\
\hline Nathalie & $\mathrm{F}$ & $\begin{array}{l}\text { Computer } \\
\text { Communications } \\
\text { Engineering (CCE) }\end{array}$ & $\begin{array}{l}\text { Arabic, French, } \\
\text { English }\end{array}$ & $\begin{array}{l}\text { Engl } \\
203,233\end{array}$ & $\begin{array}{l}\text { French System: } \\
\text { College Notre } \\
\text { Dame De } \\
\text { Louaize, Zouk, } \\
\text { Lebanon }\end{array}$ \\
\hline Abo ROR & M & Chemistry, Pre-med & $\begin{array}{l}\text { Arabic, French, } \\
\text { English }\end{array}$ & $\begin{array}{l}\text { Engl } \\
102,203\end{array}$ & $\begin{array}{l}\text { Lebanese } \\
\text { School, Doha, } \\
\text { Qatar }\end{array}$ \\
\hline Bashar & M & $\begin{array}{l}\text { Electrical } \\
\text { Engineering }\end{array}$ & $\begin{array}{l}\text { English, Arabic, } \\
\text { French }\end{array}$ & $\begin{array}{l}\text { Engl } \\
203,204\end{array}$ & $\begin{array}{l}\text { Saint Mary's } \\
\text { Orthodox } \\
\text { College, } \\
\text { Lebanon }\end{array}$ \\
\hline Jean & M & $\begin{array}{l}\text { Political Science } \\
\text { and Public } \\
\text { Administration }\end{array}$ & $\begin{array}{l}\text { French, Arabic, } \\
\text { English }\end{array}$ & $\begin{array}{l}\text { Engl } \\
102,203, \\
204\end{array}$ & $\begin{array}{l}\text { Lycée Français } \\
\text { du Caire, Egypt }\end{array}$ \\
\hline Christophe & M & Chemistry, Pre-med & $\begin{array}{l}\text { French, Arabic, } \\
\text { English }\end{array}$ & $\begin{array}{l}\text { Engl } \\
102,203, \\
204\end{array}$ & $\begin{array}{l}\text { Grand Lycée } \\
\text { Franco- } \\
\text { Libanais, } \\
\text { Ashrafieh, } \\
\text { Lebanon }\end{array}$ \\
\hline
\end{tabular}




\begin{tabular}{|c|c|c|c|c|c|}
\hline Nadim & $\mathbf{M}$ & Business & $\begin{array}{l}\text { French, Arabic, } \\
\text { English }\end{array}$ & $\begin{array}{l}\text { Engl } 102 \text {, } \\
203,204\end{array}$ & $\begin{array}{l}\text { Collège de la } \\
\text { Saint Famille } \\
\text { Française, } \\
\text { Fanar, Liban }\end{array}$ \\
\hline Khaled & $\mathrm{M}$ & $\begin{array}{l}\text { Environmental } \\
\text { Health }\end{array}$ & English, Arabic & $\begin{array}{l}\text { Engl 102, } \\
203,204\end{array}$ & $\begin{array}{l}\text { Saint Mary's } \\
\text { Orthodox } \\
\text { College, } \\
\text { Lebanon }\end{array}$ \\
\hline Marie & $F$ & Agriculture & $\begin{array}{l}\text { Arabic, English, } \\
\text { French (speaking } \\
\text { knowledge) }\end{array}$ & $\begin{array}{l}\text { Engl 102, } \\
203,204\end{array}$ & $\begin{array}{l}\text { Antonine } \\
\text { Sisters School, } \\
\text { Mar Elias, } \\
\text { Ghazir, } \\
\text { Lebanon }\end{array}$ \\
\hline Mayya & $\mathrm{F}$ & Nursing & $\begin{array}{l}\text { French, Arabic, } \\
\text { English }\end{array}$ & $\begin{array}{l}\text { Engl 102, } \\
203,204\end{array}$ & $\begin{array}{l}\text { French system: } \\
\text { Collège Saint } \\
\text { François, } \\
\text { Lebanon }\end{array}$ \\
\hline Rana & $\mathrm{F}$ & $\begin{array}{l}\text { Going into Business } \\
\text { or Economics }\end{array}$ & $\begin{array}{c}\text { English, Arabic } \\
:\end{array}$ & $\begin{array}{l}\text { Engl 203, } \\
204\end{array}$ & $\begin{array}{l}\text { International } \\
\text { School of } \\
\text { Choueifat, } \\
\text { Dubai }\end{array}$ \\
\hline Ayla & $\mathrm{F}$ & Biology, Pre-med & $\begin{array}{l}\text { English, Arabic, } \\
\text { French (reading } \\
\text { and writing } \\
\text { knowledge) }\end{array}$ & $\begin{array}{l}\text { Engl 102, } \\
203,204\end{array}$ & $\begin{array}{l}\text { Hariri High } \\
\text { School, Saida, } \\
\text { Lebanon }\end{array}$ \\
\hline \multirow[t]{2}{*}{ Sarah } & $\mathrm{F}$ & Business & $\begin{array}{l}\text { Arabic, French, } \\
\text { English }\end{array}$ & $\begin{array}{l}\text { Engl 102, } \\
203\end{array}$ & $\begin{array}{l}\text { Private French } \\
\text { Systems: } \\
\text { Collège des } \\
\text { Frères Maristes } \\
\text { Champville }\end{array}$ \\
\hline & & & & & $\begin{array}{l}\text { Collège Mont } \\
\text { La Salle, } \\
\text { Lebanon (last } 3 \\
\text { yrs) }\end{array}$ \\
\hline Viola & $\mathrm{F}$ & Biology, Pre-med & $\begin{array}{l}\text { Spanish, English, } \\
\text { Arabic (speaking } \\
\text { fluency) }\end{array}$ & $\begin{array}{l}\text { Engl 203, } \\
204\end{array}$ & $\begin{array}{l}\text { Public High } \\
\text { school in } \\
\text { Venezuela }\end{array}$ \\
\hline Lama & $\mathrm{F}$ & Medical Lab & Arabic, English & $\begin{array}{l}\text { Engl 203, } \\
204\end{array}$ & $\begin{array}{l}\text { UNRWA- } \\
\text { operated } \\
\text { School, } \\
\text { Lebanon }\end{array}$ \\
\hline Carine & $F$ & $\begin{array}{l}\text { Food Science and } \\
\text { Management }\end{array}$ & French, English & $\begin{array}{l}\text { Engl 203, } \\
204\end{array}$ & $\begin{array}{l}\text { Lycée Verdun, } \\
\text { Lebanon }\end{array}$ \\
\hline Leyla & $\mathbf{F}$ & $\begin{array}{l}\text { Environmental } \\
\text { Health }\end{array}$ & English, Arabic & $\begin{array}{l}\text { Engl 203, } \\
204\end{array}$ & $\begin{array}{l}\text { Saint Mary's } \\
\text { Orthodox } \\
\text { College, } \\
\text { Lebanon }\end{array}$ \\
\hline Hanaa & $\mathrm{F}$ & $\begin{array}{l}\text { Environmental } \\
\text { Health }\end{array}$ & $\begin{array}{l}\text { Arabic, English, } \\
\text { French }\end{array}$ & $\begin{array}{l}\text { Engl 203, } \\
204\end{array}$ & $\begin{array}{l}\text { National } \\
\text { Collège } \\
\text { Protestant, } \\
\text { Kfarshima, } \\
\text { Lebanon }\end{array}$ \\
\hline Rani & M & $\begin{array}{l}\text { Transferring into } \\
\text { Mechanical } \\
\text { Engineering }\end{array}$ & English, Arabic & $\begin{array}{l}\text { Engl 102, } \\
203\end{array}$ & $\begin{array}{l}\text { Global } \\
\text { International } \\
\text { School, Jeddah, }\end{array}$ \\
\hline
\end{tabular}




\begin{tabular}{|c|c|c|c|c|c|}
\hline & & & & & Saudi Arabia \\
\hline Naser & $\mathbf{M}$ & Graphic Design & $\begin{array}{l}\text { Arabic, French, } \\
\text { English }\end{array}$ & $\begin{array}{l}\text { Engl 102, } \\
203\end{array}$ & $\begin{array}{l}\text { Al Mustapha } \\
\text { High School, } \\
\text { Haret Hreik, } \\
\text { Lebanon }\end{array}$ \\
\hline Ahmad & M & $\begin{array}{l}\text { Computer Science } \\
\text { transferring to } \\
\text { Business }\end{array}$ & English, Arabic & $\begin{array}{l}\text { Engl 102, } \\
203\end{array}$ & $\begin{array}{l}\text { Hariri High } \\
\text { School; Rawda } \\
\text { High School, } \\
\text { Lebanon }\end{array}$ \\
\hline \multirow[t]{2}{*}{ Mohammed } & $\mathbf{M}$ & $\begin{array}{l}\text { Transferring into } \\
\text { Electrical } \\
\text { Engineering }\end{array}$ & English, Arabic & Engl 203 & $\begin{array}{l}\text { American } \\
\text { School of } \\
\text { Dubai; }\end{array}$ \\
\hline & & & & & $\begin{array}{l}\text { International } \\
\text { School of } \\
\text { Choueifat, } \\
\text { Saudi Arabia }\end{array}$ \\
\hline Bahaa & M & $\begin{array}{l}\text { Transferring to } \\
\text { Psychology, Pre- } \\
\text { med }\end{array}$ & $\begin{array}{l}\text { Arabic, French, } \\
\text { English }\end{array}$ & $\begin{array}{l}\text { Engl 203, } \\
204\end{array}$ & $\begin{array}{l}\text { Lycée Verdun, } \\
\text { Lebanon }\end{array}$ \\
\hline Hassan & $\mathbf{M}$ & Biology, Pre-med & English, Arabic & $\begin{array}{l}\text { Engl 102, } \\
203,204\end{array}$ & $\begin{array}{l}\text { Hariri High } \\
\text { School, } \\
\text { Lebanon }\end{array}$ \\
\hline Amer & $\mathbf{M}$ & Biology, Pre-med & $\begin{array}{l}\text { Arabic, English, } \\
\text { French }\end{array}$ & $\begin{array}{l}\text { Engl 203, } \\
204,233\end{array}$ & $\begin{array}{l}\text { Lebanese } \\
\text { system: } \\
\text { National } \\
\text { Evangelical; } \\
\text { Hariri High } \\
\text { School, Saida, } \\
\text { Lebanon }\end{array}$ \\
\hline Toufic & $\mathbf{M}$ & Sociology & English, Arabic & $\begin{array}{l}\text { Engl 203, } \\
204,233\end{array}$ & $\begin{array}{l}\text { International } \\
\text { School of } \\
\text { Choueifat, } \\
\text { Choueifat, } \\
\text { Lebanon }\end{array}$ \\
\hline Emile & $\mathbf{M}$ & Civil Engineering & English & $\begin{array}{l}\text { Engl 203, } \\
204,233\end{array}$ & $\begin{array}{l}\text { International } \\
\text { School of } \\
\text { Choueifat, Abu } \\
\text { Dhabi }\end{array}$ \\
\hline Nizar & M & Civil Engineering & Arabic, English & $\begin{array}{l}\text { Engl 203, } \\
204,233\end{array}$ & $\begin{array}{l}\text { Hariri High } \\
\text { School, Saida, } \\
\text { Lebanon }\end{array}$ \\
\hline \multirow[t]{2}{*}{ Hala } & $\mathrm{F}$ & English Language & $\begin{array}{l}\text { English, Arabic } \\
\text { (speaking fluency) }\end{array}$ & $\begin{array}{l}\text { Engl 203, } \\
204,233\end{array}$ & $\begin{array}{l}\text { Public High } \\
\text { school in } \\
\text { Canada; }\end{array}$ \\
\hline & & & & & $\begin{array}{l}\text { Canadian } \\
\text { College, Qatar }\end{array}$ \\
\hline Ryan & $\mathbf{M}$ & Civil Engineering & Arabic, English & $\begin{array}{l}\text { Engl 203, } \\
204,233\end{array}$ & $\begin{array}{l}\text { International } \\
\text { School of } \\
\text { Choueifat, Syria }\end{array}$ \\
\hline Rima & $\mathrm{F}$ & English Language & $\begin{array}{l}\text { English, Arabic, } \\
\text { French }\end{array}$ & $\begin{array}{l}\text { Engl 203, } \\
204,233\end{array}$ & $\begin{array}{l}\text { Rawdat Al } \\
\text { Fayhaa } \\
\text { Secondary } \\
\text { School, Tripoli, }\end{array}$ \\
\hline
\end{tabular}




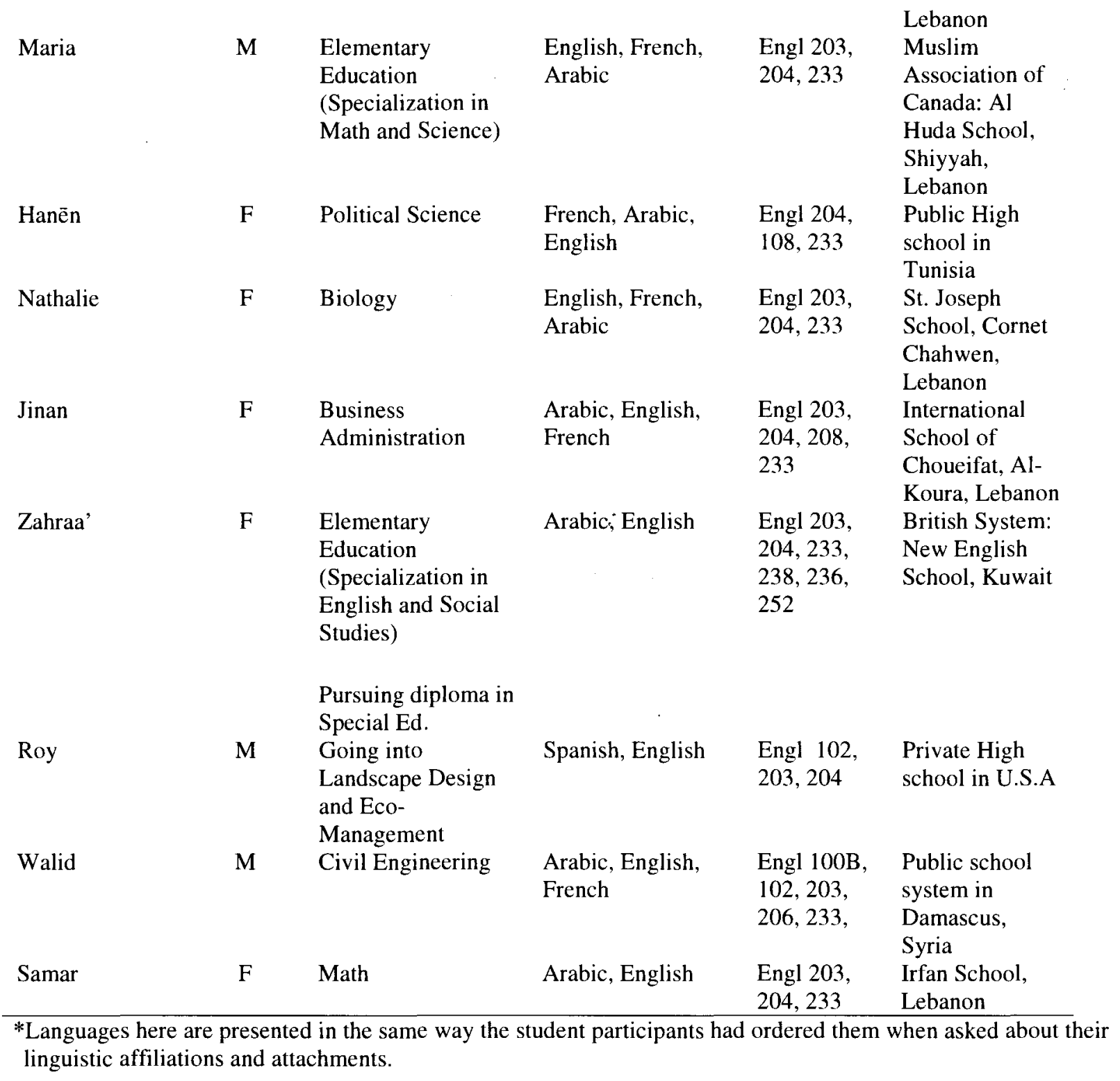


Table 3. Student Participant

Distribution by Academic Discipline

Humanities

2

Natural Sciences

Social Sciences

4

Formal Sciences

1

Professions and Applied Sciences

27

Table 4. Student Participant

Distribution by Specific Major

Engineering

9

Business

6

Biology

5

Agriculture and Food Sciences 3

Environmental Health 3

Education 2

Chemistry 2

Graphic Design 2

Political Studies $\quad 2$

English $\quad 2$

Math 1

Medical Lab Sciences 1

Sociology 1 
Psychology

1

Nursing

1

Table 5. Student Participant

Distribution by Gender

Males 21

Females

$\therefore 20$

Table 6. Student Participant

Distribution by Current Course

Enrollment

ENGL 203

6

ENGL 204

19

ENGL 233

16

Table 7. Student Participant

Distribution by Language Background

Other than English

Arabic

37

French

24 


\begin{tabular}{ll}
\hline Armenian & 1 \\
Italian & 1 \\
Greek & 1 \\
Spanish & 2 \\
Latin & 1 \\
\end{tabular}

Table 8. Student Participant

Distribution by Educational Background

\begin{tabular}{ll}
\hline English-medium Schooling & 19
\end{tabular}

$\begin{array}{ll}\text { French-medium Schooling } & 17\end{array}$

Other 5 


\section{APPENDIX C}

\section{Interview Questions}

\section{Teacher Participants}

Interview questions for the teachers participating in this study included the following:

1. What do you know about your institutions' and/or programs' language policy?

2. What kind of language policy do you as a writing instructor think is most likely to capture the kind of agency you feel your students have in the way they use language in their public, personal, academic, and professional lives?

3. How do you define "good and clear" writing and what forms do you think it should take?

4. How do you present and define standards of language use in your courses? and Why do you approach standards the way you do in your own pedagogy?

5. How would you describe your students' language/ literacy practices and the linguistic resources they bring into the classroom? And what is your sense of their impact on your students' learning, writing, and production of meaning?

6. What do you regard as errors in student writing and English usage?

7. How do you perceive compositions that pose arguments, styles, and language forms alternative to dominant values and practices?

8. How do you handle writing in unconventional ways (e.g. in languages other than English; language practices that deviate from the demands of American Edited English or Standard Written English) in your teaching and assessment practices? and Why? 
9. What do you tell your students to do or not to do when they experience ambivalence as they negotiate (linguistic, cultural, etc,) differences in scenes of reading and writing?

10. What words, images, stories, and activities come to mind when you think of the notion of 'translation'?

11. What role, if any, does translation play in your composition instruction and in the design of your writing assignments and projects?

\section{Student Participants}

Interviews with students were based on the following questions:

1. What do you know about your institutions' or programs' language policy?

2. What kind of language policy do you feel is most likely to reflect the way you use language?

3. How do your writing teachers present and define language standards in their courses?

4. How do your teachers define "good and clear" writing and what forms do they think it should take?

5. What word, image, story, and activity come to mind when you think of the act of 'writing'?

6. What languages, language practices, meanings and interpretations important to you and critical to your sense of self have no room in the writing classroom? How, where, when, with whom, and why are these important to you? 
7. What effects do these have on your literacy practices? What kinds of social relations, emotions, actions, and future prospects do these enable you to enact and maintain (or hinder you from enacting and maintaining)?

8. What ways of using English you utilize frequently do you feel get excluded in the writing classroom? How, where, when, with whom, and why are these important to you at particular instances and places of composing?

\section{Multiple Interview Rounds}

Describe for me something you most recently did or worked on that heavily involves language.

1. Who are involved in that activity? Which languages/language varieties? Which media?

2. Which of these activities do you view as just as important for your identity and well being as the writing you do in class? Which is more important? Which is less important? Why?

3. What exactly do you do with language during each activity that seems to have no room in the writing you do for class? Why?

4. Which of these activities make you feel that you are good with language? Why? 


\title{
CURRICULUM VITAE
}

\author{
Nancy Bou Ayash
}

Department of English

315 Bingham Humanities Bldg

University of Louisville

Louisville, KY, USA 40292

Tel: 502-533-2968

naboua01@louisville.edu

\section{EDUCATION}

2013 Ph.D. in Rhetoric and Composition, University of Louisville, Louisville, KY

Dissertation: "Translingualism in Post-Secondary Writing and Language Instruction: Negotiating Language Ideologies in Policies and Pedagogical Practices"

Committee: Bruce Horner (Chair); Min-Zhan Lu; Bronwyn Williams; Tatjana Soldat-Jaffe; Suresh Canagarajah

2006 M.A. in English Language, American University of Beirut, Beirut, Lebanon Thesis: "The Syntax of Non-native English Negation: A Study of the Acquisition of English Negation by Lebanese Arabic Speakers Committee: Lina Choueiri (Chair); Kassem Shaaban; Rula Diab

2003 B.A. in Education, American University of Beirut, Beirut, Lebanon

\section{PUBLICATIONS}

\section{Book Chapters}

"Hi-ein, Hi يين يين Hi? Translingual Practices from Lebanon and Mainstream Literacy Education." Literacy as Translingual Practice: Between Communities and Classrooms. Ed. Suresh Canagarajah. New York: Routledge, 2013. 96-103. Print. 
"U.S. Translingualism through a Cross-National and Cross-Linguistic Lens." Working Englishes in Rhetoric and Composition: Global-local Contexts, Commitments, Consequences. Ed. Bruce Horner and Karen Kopelson. forthcoming. Southern Illinois University Press.

"(Re) situating U.S. Composition in Cross-National and Cross-Linguistic Perspectives." Transnational Writing Program Administration. Ed. David Martins. forthcoming. Accepted; Full collection under press review.

\section{Bibliographies}

“Global Englishes and Language Difference." With Bruce Horner, Carrie Byars Kilfoil, Samantha NeCamp, Brice Nordquist, and Vanessa Kraemer Sohan. WPACompPile Research Bibliographies, No. 17 (Oct. 2011).

http:/comppile.org/wpa/bibliographies/Bib17/GlobalEnglishes.pdf

\section{Edited Journal Special Issue}

"Economies of Writing." With Bruce Horner, Brice Nordquist, and Carrie Byars Kilfoil. Special issue Journal of Advanced Composition 32.3-4 (2012).

\section{POSITIONS HELD}

2012-2013 Assistant Director of University Writing Center, University of Louisville

2011-2013 Research Assistant for Endowed Chair in Rhetoric and Composition, Professor Bruce Horner, University of Louisville

2009- 2013 Graduate Teaching Assistant, Composition Program, Department of English, University of Louisville

2006-2009 Full-time Instructor, Communication Skills Program, Department of English, American University of Beirut

2003- 2006 Part-time Instructor, Department of English, Translation, and Education, Notre Dame University, Deir El Kamar, Lebanon

2003-2006 Graduate Assistant, Department of English, American University of Beirut

2004-2005 Research Assistant for Dr. Lina Choueiri, Department of English, American University of Beirut

2000-2006 Full-time Instructor, Business \& English Language Center, Baakline, Lebanon 


\section{AWARDS}

2013 Graduate Dean's Citation Award. School of Interdisciplinary and Graduate Studies. University of Louisville, Louisville, KY.

2013 Chairs' Memorial Scholarship, Conference on College Composition and Communication /National Council of Teachers of English (for "Translingualism in Writing Programs: Negotiating Language Difference in Policies and Practices").

2013 Council of Writing Program Administration (CWPA) Graduate Student Writing Award (for "(Re) situating U.S. Composition in Cross-National and Cross-Linguistic Perspectives").

\section{CONFERENCE PAPERS}

"Translingualism in Writing Programs: Negotiating Language Difference in Policies and Practices." Conference on College Composition and Communication. Las Vegas, NV, 14 March 2013.

"Translingualism in Post-Secondary Writing and Language Instruction: Negotiating Language Ideologies in Policies and Pedagogical Practices." 2013 CCCC Workshop on International Research "Diverse Disciplines, 'New' Publics: The Work of International Higher Education Writing Research." Conference on College Composition and Communication. Las Vegas, NV, 13 March 2013.

"Translingualism and Transculturalism in Post-Secondary Writing." Council of Writing Program Administrators (CWPA) Sponsored Session: "Framework for Success in Postsecondary Writing." 2013 MLA Annual Convention. Boston, MA, 4 January 2013.

"Enacting Transnational and Translingual Relations in Language Policy and Writing Pedagogy." Thomas R. Watson Conference in Rhetoric and Composition: "Economies of Writing." Louisville, KY, 18 October 2012.

"Second Language Writing Instruction in Lebanon: Negotiating Language Ideologies in Policies and Pedagogical Practices." Symposium on Second Language Writing. Purdue University, West Lafayette, IN, 6 September 2012.

"Language Relations and Writing Instruction: Learning 'with' Cross-national Contexts." Conference on College Composition and Communication. St. Louis, MO, 23 March 2012. 
"Explorations of the Workings of Language Users: Negotiating Language Difference through New Media in FYC." 22nd Penn State Conference on Rhetoric and Composition: "Rhetoric and Writing across Language Boundaries." State College, PA, 11 July 2011.

"Monolingualism and Multilingualism: Cross-national and Cross-linguistic Perspectives." Conference on College Composition and Communication. Atlanta, GA, 7 April 2011.

"Cross-language Writing: Linguistic Struggle of the Multilingual Majority in the Technical Writing Classroom in Lebanon." $8^{\text {th }}$ Biennial Thomas R. Watson Conference in Rhetoric and Composition: "Working English in Rhetoric and Composition." Louisville, KY, 14 October 2010.

\section{TEACHING EXPERIENCE}

\section{University of Louisville}

ENGL 101: Introduction to College Writing

ENGL 102: Intermediate College Writing

ENGL 306: Business Writing

\section{American University of Beirut}

ENGL 102: Enrichment Course in English

ENGL 203: Academic Writing

ENGL 206: Technical English

\section{Notre Dame University}

ENGL 002: Intensive English II

ENGL 105: College English I

ENGL 110: College English II

ENGL 301: Introduction to the Study of Language

ENGL 413: Advanced English Grammar

ENGL 313: Syntax

\section{WORKSHOPS}

"Succeeding in the American University." University of Louisville, invited by Dean of School of Interdisciplinary and Graduate Studies, Louisville, KY, 8 October 2010.

"Academic Integrity and Plagiarism in Graduate School." University of Louisville, invited by Dean of School of Interdisciplinary and Graduate Studies, Louisville, KY, 19 January 2011. 


\section{GRADUATE COURSEWORK}

\section{University of Louisville}

\section{Rhetoric and Composition}

Special Topics Seminar on Outside Composition (Bruce Horner)

Composition Theory and Practice (Min-Zhan Lu)

Re-vision: Theory and Practice (Min-Zhan Lu)

New Media and Composition Pedagogy (Bronwyn T. Williams)

Teaching College Composition (Joanna Wolfe)

Research Methods in Composition (Debra Journet)

Narrative Theory (Debra Journet)

\section{Literature and Literary Theory/Creative Writing}

Scenes of Reading in $19^{\text {th }}$ Century American Literature (Susan Griffin)

Creative Nonfiction: Practice and Pedagogy (Bronwyn T. Williams)

Contemporary Theories of Interpretation (Karen Hadley)

Special Topics in Literary and Critical Theory: Sexuality and Aesthetics (Matthew Biberman)

Applied Linguistics

Sociolinguistics (Tatjana Soldat-Jaffe)

\section{American University of Beirut}

\section{English Language and Linguistics}

Sociolinguistics (Kassem Shaaban)

Theoretical Linguistics (Lina Choueiri)

Introduction to Bibliography and Research Methods (Rula Diab)

Language Acquisition (Rula Diab)

Graduate Tutorial in Linguistics: The Syntax of Negation (Lina Choueiri)

\section{Education}

Teaching Reading and Literature (Ghazi Ghaith)

Language, Culture, and Curriculum (Ghazi Ghaith)

\section{LANGUAGES}

Arabic (fluency in speaking, reading, and writing)

French (reading knowledge) 


\section{PROFESSIONAL AFFILIATIONS}

National Council of Teachers of English (NCTE)

Conference on College Composition and Communication (CCCC)

Modern Language Association (MLA)

Council of Writing Program Administrators (CWPA)

International Writing Centers Association (IWCA)

Association of Teachers of English in Lebanon (ATEL)

\section{REFERENCES}

Bruce Horner, Professor and Endowed Chair in Rhetoric and Composition University of Louisville, Department of English b.horner@ louisville.edu

Min-Zhan Lu, Professor and University Scholar University of Louisville, Department of English m.lualouisville.edu

Bronwyn Williams, Professor and University Writing Center Director University of Louisville, Department of English bronwyn.williams alouisville.edu

Debra Journet, Professor University of Louisville, Department of English debra.journet alouisville.edu

Tatjana Soldat-Jaffe, Assistant Professor University of Louisville, Division of Humanities tatjana.soldat@louisville.edu 